Louisiana State University

LSU Digital Commons

1997

\title{
The Effects of Augmented Feedback on Students' Perceptions and Performance.
}

Karen Anne buckner Fredenburg

Louisiana State University and Agricultural \& Mechanical College

Follow this and additional works at: https://digitalcommons.Isu.edu/gradschool_disstheses

\section{Recommended Citation}

Fredenburg, Karen Anne buckner, "The Effects of Augmented Feedback on Students' Perceptions and Performance." (1997). LSU Historical Dissertations and Theses. 6419.

https://digitalcommons.Isu.edu/gradschool_disstheses/6419

This Dissertation is brought to you for free and open access by the Graduate School at LSU Digital Commons. It has been accepted for inclusion in LSU Historical Dissertations and Theses by an authorized administrator of LSU Digital Commons. For more information, please contact gradetd@lsu.edu. 


\section{INFORMATION TO USERS}

This manuscript has been reproduced from the microfilm master. UMI films the text directly from the original or copy submitted. Thus, some thesis and dissertation copies are in typewriter face, while others may be from any type of computer printer.

The quality of this reproduction is dependent upon the quality of the copy submitted. Broken or indistinct print, colored or poor quality illustrations and photographs, print bleedthrough, substandard margins, and improper alignment can adversely affect reproduction.

In the unlikely event that the author did not send UMI a complete manuscript and there are missing pages, these will be noted. Also, if unauthorized copyright material had to be removed, a note will indicate the deletion.

Oversize materials (e.g., maps, drawings, charts) are reproduced by sectioning the original, beginning at the upper left-hand corner and continuing from left to right in equal sections with small overlaps. Each original is also photographed in one exposure and is included in reduced form at the back of the book.

Photographs included in the original manuscript have been reproduced xerographically in this copy. Higher quality 6" $\times 9$ " black and white photographic prints are available for any photographs or illustrations appearing in this copy for an additional charge. Contact UMI directly to order.

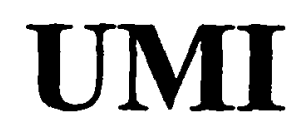

A Bell \& Howell Information Company 300 North Zeeb Road, Ann Arbor MI 48106-1346 USA $313 / 761-4700 \quad 800 / 521-0600$ 


\author{
A Dissertation \\ Submitted to the Graduate Faculty of the \\ Louisiana State University and \\ Agricultural and Mechanical College \\ in partial fulfillment of the \\ requirements for the degree of \\ Doctor of Philosophy \\ in
}

The Department of Kinesiology

\author{
by \\ Karen Anne Buckner Fredenburg
}

B.S., Southwest Texas State University, 1969

M.A., Southwest Texas State University, 1970

May 1997 
UMI Number: 9736014

UMI Microform 9736014

Copyright 1997, by UMI Company. All rights reserved.

This microform edition is protected against unauthorized copying under Title 17, United States Code.

\section{UMI \\ 300 North Zeeb Road \\ Ann Arbor, MI 48103}




\section{ACKNOWLEDGEMENTS}

It is with great pleasure and disbelief that $I$ write this section. To recognize family, friends, acquaintances and even strangers who have helped transform my dream into reality means that the end is actually in sight. Though this journey has challenged and frustrated me at times, it has also most delightfully affirmed my faith in the generosity and goodness of God's people, and I am grateful for the opportunity to acknowledge some of them.

First, I want to thank fellow graduate student, Nancy Cleveland, and one time stranger, Lisa Musgrove, for providing me with free lodging, warm memories and constant encouragement. Without their help, I could not have completed this degree at Louisiana State University.

Special thanks also to Texas elementary physical education teacher, Kim Scott, for sharing her students, organizing the on-site study, and assisting as needed; to Baylor University instructor, Bonnie Luft, for finding qualified teachers and for making the training arrangements; to teachers, Shannon Barrera, Becki Berry, Kristen Cole, and Shelli Ferris, for committing their time, talent and zest to this study; to the wonderful fourth grade participants for their eagemess, their efforts and their honesty; to Texas Women's University assistant professor, Dr. Cindy Gill, for helping code student behavior; to Texas elementary physical education teacher, Jean Garner, for sharing her expertise, her video, and her equipment; to friend, Kate Perot, for taking care of my son; to LSU Administrative Specialist, Sheila Hart, for her assistance and unfailing cheerfulness; and to fellow grad student, Don Belcher, for guiding and stumbling with me through it all.

I also wish to express immense gratitude to Dr. Raja Nassar from Louisiana Tech and Mrs. Gabie Church from Louisiana State University for their expert guidance in the statistical aspects of this study. In a time when university professors 
are often accused of providing students with little personal attention, they found abundant time and patience for a student they had never met. Thank you!

Sincere thanks to the members of my committee (Drs. Carter, Denny, Hebert, Landin, and Magill) for their valuable time and insight throughout this process. These very busy people were always there to answer my questions and encourage my efforts. Thanks also to ex-committee member, Melinda Solmon, who continued to advise and encourage me via long distance from the University of Maryland. Special thanks to my major professor, Dr. Amelia Lee, for her example and her immense patience and dedication. Her excellent grasp of the literature and the process kept me on the right path and inspired me to continue.

And finally, I offer beart felt thanks to my family and friends. Loving kudos to my children Kori, Denver, and Cody who sacrificed while I collected knowledge rather than a paycheck, who ate who knows what while I studied. and who encouraged me even though they doubted my sanity. Words cannot express my gratitude to my husband, Pete, who never let me give up, or to my parents, Jim and Celeste Buckner, who taught me to love learning, to take one day at a time, and to let effort and determination, not IQ scores, drive my dreams. I dedicate this to the memory of my Dad who always believed in me and to the honor of my husband and my Mom who taught me to believe in myself. 


\section{TABLE OF CONTENTS}

Acknowledgements............................................................... ii

List of Tables..................................................................... $\mathrm{v}$

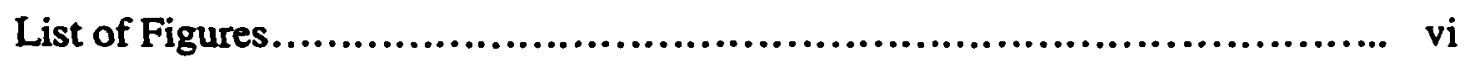

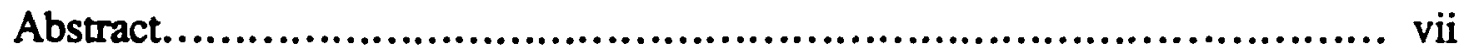

Introduction.........................................................................

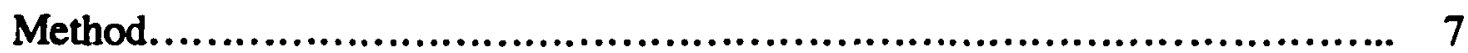

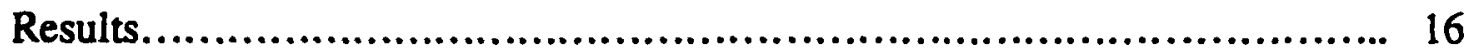

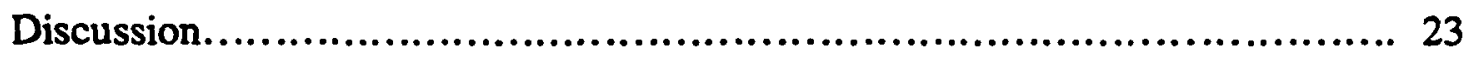

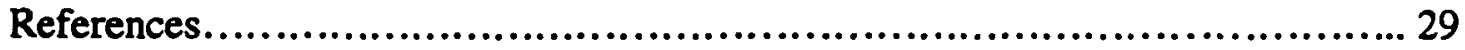

Appendix A: Extended Review of Literature ..................................... 33

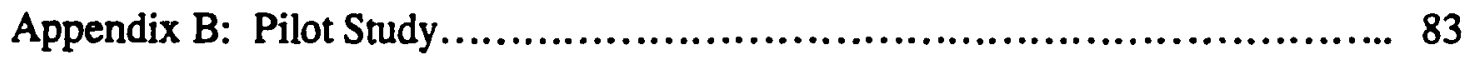

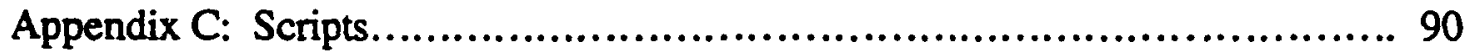

Appendix D: Student Surveys..................................................... 95

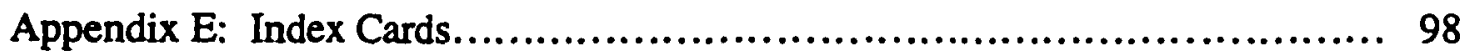

Appendix F: Raw Data.......................................................... 101

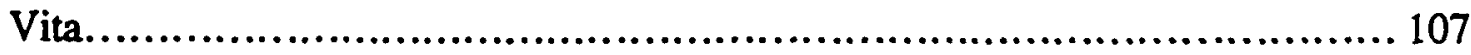




\section{LIST OF TABLES}

1. Latin Square Design........................................ 15

2. Descriptive Statistics........................................ 17

3. Analysis of Variance Summary................................ 18 


\section{LIST OF FIGURES}

1. Diagram of Cup Configuration for the $3 \times 6 \times 3$ and $1 \times 10 \times 1$

Cupstack Skills ........................................................ 8

2. Mean Changes in Self-Perceptions of Ability to Perform the $1 \times 10 \times 1$

Cupstacking Skills

3. Mean Changes in Performance Scores for the $1 \times 10 \times 1$ Cupstacking

Skill ............................................................ 21

4. Mean Time On-Task Scores for Leaming the $3 \times 6 \times 3$ and the $1 \times 10 \times 1$

Cupstacking Skills. 


\begin{abstract}
The focus of this study was to investigate the effects of various augmented feedback conditions on students' self-perceptions of ability (SPA), practice behaviors, and performance during motor skill instruction of a novel task. Fourth grade physical education students $(n=103)$ participating in a one week instructional unit on the skill of cupstacking were randomly assigned to one of four feedback conditions: (a) no feedback, (b) motivational feedback, (c) task or informational feedback, and (d) motivational and task feedback combined. While students practiced simple ( $3 \times 6 \times 3)$ and complex ( $1 \times 10 \times 1)$ cupstacking skills, instruction and feedback were provided by university education majors.

Following an introductory video, students completed surveys indicating their self-perceptions of ability to learn (SPAL) cupstacking and in particular their selfperceptions of ability to perform (SPAP) the $3 \times 6 \times 3$ skill. Pretest performance scores were recorded, and students received 30 minutes of instruction and feedback. Ability perceptions were reassessed and posttest performance scores recorded. Procedures were repeated while students under the same instructor and same feedback condition practiced the $1 \times 10 \times 1$ skill. Classes were videotaped in order to code student practice behavior. Final SPAL cupstacking were assessed by students on a survey.

The results indicate an overall increase in SPA and performance scores and a general decrease in on-task behavior. Specifically, task and combined motivational and task feedback produced greater gains in performance scores on the complex skill. and better on-task behavior patterns with both skills than did no feedback or simple motivational feedback.

The results suggest the importance of task feedback during initial learning phases of a novel skill both in terms of positive student engagement and actual performance improvement, and highlight the need for physical educators capable of providing appropriate, meaningful feedback. Though SPA were not altered
\end{abstract}

vii 
significantly, the combined task and motivational feedback did show a tendency towards interaction with the more specific SPAP measurement. This supports the notion of SPA specificity and correspondence to criterial task (Pajares, 1996).

viii 


\section{INTRODUCTION}

The investigation of how teaching transfers into learning, and the role of the student in the learning process is increasingly dominated by the cognitive paradigm (Lee, 1996; Pintrich, 1988; Prawat, 1992; Roberts, 1992; Winne, 1991). Students are viewed not as passive vessels waiting to be filled with knowledge, but rather as active participants in their own learning. Present and past experiences are filtered through the unique lens of the learner and then translated into some form of action or behavior. Interest in why students are inclined or disinclined to take responsibility for their own learning has stimulated research on motivational cognitions (Solmon, 1991). Many recent investigations in physical education pedagogy are grounded in the belief that achievement strivings are mediated by cognitive, affective and value oriented constructs representing a dynamic interactive learning process (Lee \& Solmon. 1992). This research which is designed to understand the role that students play in their own learning employs a cognitive mediational framework (Doyle, 1977). Consistent with this framework is the social cognitive approach (Feltz, 1988; Roberts, 1992) which has been used in youth sports to explain motivated behavior.

According to Winne (1991), student learning requires two types of knowledge: task and motivational. Task knowledge refers to the skills and knowledge required to complete a task, and regardless of the presence of motivational knowledge, is a prerequisite to achievement. Motivational knowledge refers to students' thoughts about their abilities, ideas about how to approach goals, and attitudes about a subject or class. This knowledge shapes student mediation in a learning experience. While task and motivational knowledge represent different types of information, they are both cognitively processed in a like manner (Winne. 1991). It seems reasonable to believe that at some point task knowledge could become subject to motivational knowledge and influence performance in positive or 
negative ways. For example, augmented (external) feedback for the purpose of providing performance information can be presented in identical fashion to different students and produce quite different results. The understanding and helpfulness of that feedback is subject to the skills, incentives, and ability perceptions of the individual recipient (Lee, Keh, \& Magill, 1993). In physical education settings, research designed to study the effectiveness of augmented feedback containing task knowledge necessary for improved performance is conflicting. In fact, in their review on teacher feedback, Lee, Keh, and Magill (1993) suggest that its effectiveness can best be understood if studied in conjunction with motivational knowledge. This study will examine the effects of different types of augmented feedback on students' motivational knowledge, practice behaviors and performance outcomes.

Perceived ability is one type of motivational knowledge that has received ample support in the literature. In fact, how students understand and interpret their own ability or competence to complete a task has been described as a central mediating influence on overall self-esteem and achievement related behaviors and motivations (Eccles et al., 1983; Feltz, 1988; Nicholls, 1984a; Roberts, 1984, 1992). The investigation of this construct currently represents " the mainstream approach to motivation" (Roberts, 1992, p. 29).

\section{Actual and Perceived Ability}

Ability refers to having the power, the talent, or the skill to do something. Theoretically, students viewed as intentional, goal-oriented individuals who function rationally in an achievement setting are postulated to be energized to demonstrate competence or ability, which in tum sustains motivational efforts and behaviors (Maehr \& Nicholls, 1980; Nicholls, 1984a, 1984b; Roberts, 1992; Xiang, 1995). When there is a perception that ability has been demonstrated, feelings of accomplishment are enhanced (Lee, 1996; Nicholls, 1976). From a cognitive 
mediational perspective it is not as important to understand what ability is as it is to understand what children think ability is. Perceptions of ability involve students' understanding of their own ability or adequacy to confront a particular task or to perform role-appropriate behaviors (Feltz, 1988; Roberts, 1992). The construct does not refer to ability per se, but to the learner's interpretation of that ability in a given situation. Efforts to explain such perceptions have benefited from William James' (1890) research on self, which linked feelings about personal value to concrete achievements (Deci \& Ryan, 1985; Weiss, 1987), and have resulted in a variety of labels. Under various achievement motivational theories, self-perception of ability (SPA) has been identified as: (a) perceived competence (Harter, 1981), (b) selfefficacy (Bandura, 1986), (c) perceived ability (Nicholls, 1976, 1984b), and (d) achievement self-perception (Wigfield et al., 1990).

\section{SPA as a Motivational Mediator}

Regardless of the label used to describe the construct, theories grounded in a social cognitive or a cognitive mediational framework have conceptualized the function of SPA in similar fashion (Bandura, 1986; Harter, 1978; Nicholls, 1984a; Pajares, 1996; Roberts, 1992). Overall the perception of competence or ability is characterized as the most salient predictor of general self-concept (Ebbeck \& Stuart, 1993; Weiss, 1993); the primary mediating construct in a myriad of achievement strivings such as choice, effort, persistence, and resilience (Clifton \& Gill, 1994; Eccles et al., 1983; Feltz, 1988; Nicholls, 1984b; Pajares, 1996: Roberts, 1984. 1992); and a vital determinant of ultimate achievement levels (Pajares, 1996).

At least one study (Solmon \& Lee, 1996) has provided some evidence that students high in perceived competence are more likely to be active participants in physical education class. This research also identified perceived competence, attention during class, and high quality practice as correlates of achievement. While these findings provide substance to the mediational role of SPA in leaming contexts. 
research efforts to alter its level by manipulating how ability is construed have been considered impractical for educational settings. It is argued such efforts would be too costly, time consuming, and unpredictable, and that research for the development of task oriented climates would be more productive (Treasure \& Roberts, 1995).

Present research is investigating how to create task or mastery climates that foster self-referenced assessments of ability and negate the influence mediated by SPA (Ames \& Archer, 1988; Goudas, Biddle, Fox, \& Underwood, 1995; Papaioannou, 1995; Treasure \& Roberts, 1995). While this is appealing, especially with younger students, those in the physical education field cannot ignore the effervescent presence of the competitive spirit. The physical domain is often defined in terms of movement which is observable and solicitous of social comparison. It can be argued that the motivational effects of SPA will continue to mediate achievement to some degree and therefore merit continued examination.

The minimal motivational research that has been conducted in education has focused on classroom instruction (Ames 1992a, 1992b; Maehr \& Midgley, 1991) thus providing teachers with little direct information about SPA in physical education (Veal \& Compagnone, 1995). Much of the current motivational research in sports has been confined to laboratory experiments investigating ways to increase SPA, or directed towards analyzing the relationship between SPA and performance (Feltz, 1992). Initial field based motivational research in physical education (e.g.. Solmon \& Boone, 1993) relied heavily on self-reported questionnaires rather than in-depth quantitative and qualitative studies (Blumenfeld, 1992).

Bandura (1977) and others (Feltz, 1992; Schunk, 1989a) have suggested that participants determine their ability to perform a particular task through their cognitive appraisal of available information. One possible source of information comes from the persuasion of others. Persuasion is described as a situational factor 
represented by techniques such as teacher feedback (Fitzsimmons, Landers, Thomas, \& van der Mars, 1991; Magill, 1993; Schunk, 1991), imagery (Feltz \& Reissinger, 1990), rewards (Lepper, 1983), and self-talk (Wilkes \& Summers, 1984). In educational research, considerable attention has been given to the role of feedback and reinforcement from significant others. The effectiveness of a persuasion technique is enhanced by a credible and trustworthy persuader and a realistic appraisal (Feltz, 1992). Historically, teacher augmented feedback, credited with a variety of effects on learning, has been directed towards the acquisition of skill via performance information or task knowledge rather than encouragement or motivational knowledge (Magill, 1993). While numerous studies have examined the viable role of feedback in the leaming process, the idea of augmented feedback as a tool for the enhancement of student SPA has yet to be adequately explored (Magill, 1993).

Research in academic settings has provided evidence of a linkage between effort and ability feedback, SPA, and subsequent performance (Schunk, 1982, 1983, 1989a). Schunk (1989b) suggests that entry level ability perceptions are affected by personal factors (i.e., information processing and goal setting) and by situational factors (i.e., teacher feedback and rewards). Such factors serve to inform a student about how well he or she is learning and thus mediate the perception of ability that may be used in future learning. Though not yet tested, it is logical to anticipate similar patterns in physical education. The cognitive appraisal of feedback information could serve to extend or redirect SPA and thus provide motivation for continued effort and learning (Horn, 1985; Schunk, 1989b; Weiss, 1987). However, an increase in SPA may be only temporary if students believe their efforts produced failure. On the other hand, failure in the face of strong SPA may not deter beliefs (Treasure \& Roberts, 1995). As a motivational tool, feedback might be used to enhance SPA or to redirect understandings about effort. Conceptually, it follows 
that enhanced SPA could mediate adaptive behavior and ultimately effective performance outcomes.

The focus of this study was the examination of relationships between augmented feedback treatments, SPA, practice behaviors, and performance outcomes. Specifically the following questions were addressed:

1. Can augmented feedback influence SPA?

2. Can augmented feedback influence practice behaviors?

3. Can augmented feedback influence performance scores? 


\section{METHOD}

\section{Setting}

Research was conducted in a public elementary school (grades K-5) in the southern part of the United States. During each 30 minute session, students were taught in all four comers of a large gymnasium.

\section{Participants}

The participants for this study were 56 male and 47 female students from five fourth grade classes. Signed parental permission was obtained for each student.

Classes were taught by four university junior or senior level education majors from a nearby university. Instructors had participated in field based practicums, were recommended by university instructors, and were either all-level physical education majors or elementary specialists with an emphasis in physical education.

\section{Teacher and Tester Training}

In two sessions, instructors were introduced to the skill of cupstacking, the intent of the study, specific treatment scripts, instructional tips, and timing techniques. Sample lessons including class procedures, feedback delivery, and timing procedures were demonstrated by the experimenter and practiced by the instructors. Scripts were provided for individual practice. Goals and procedures were reviewed each day before the students arrived.

Timers included the experimenter and three volunteers. Practice trials were conducted until timers demonstrated $100 \%$ agreement in both testing format and recorded time. During timing sessions, timers rotated from one student to the next in their assigned group and recorded scores on a master sheet. To assure timing reliability, timers were randomly checked by a second timer. Random checks which occurred approximately $35 \%$ of the time (i.e., 18-20 times per tester per session) indicated a $93 \%$ timing reliability. Differences were averaged and recorded. 
Task

Students were introduced to the novel task of cupstacking. Special plastic cups, placed one on top of another, are quickly stacked into various pyramid configurations (upstacking) while moving from left to right. They are then immediately taken down in the same left-to-right direction and replaced in their original position (downstacking). A fumble occurs whenever cups fall or are mishandled during the process of upstacking or downstacking. The most basic cupstack is a three cup pyramid in which two cups are placed face (open end) down side-by-side and a third cup is placed face down on top. A more difficult cupstack is a 10 cup pyramid with 4 cups on bottom, 3 on the second level, 2 on the third level, and 1 on top. Specific skills are delineated by the total number of cups and the required configuration. For example, a $3 \times 3 \times 3$ cup set-up would require 9 cups while a $3 \times 6 \times 3$ or a $1 \times 10 \times 1$ cup set-up would require 12 cups. As can be seen in Figure 1, a $3 \times 6 \times 3$ cupstack refers to having three cups into one pyramid, 6 in another, and 3 in a final pyramid while a $1 \times 10 \times 1$ cupstack means having 1 cup in the first stack, 10 in the middle pyramid, and 1 cup in the last stack. As the overall number of cups and the size of a single pyramid increases so, too, does the difficulty of the task (Cupstack Information and Instruction Brochure, 1988).

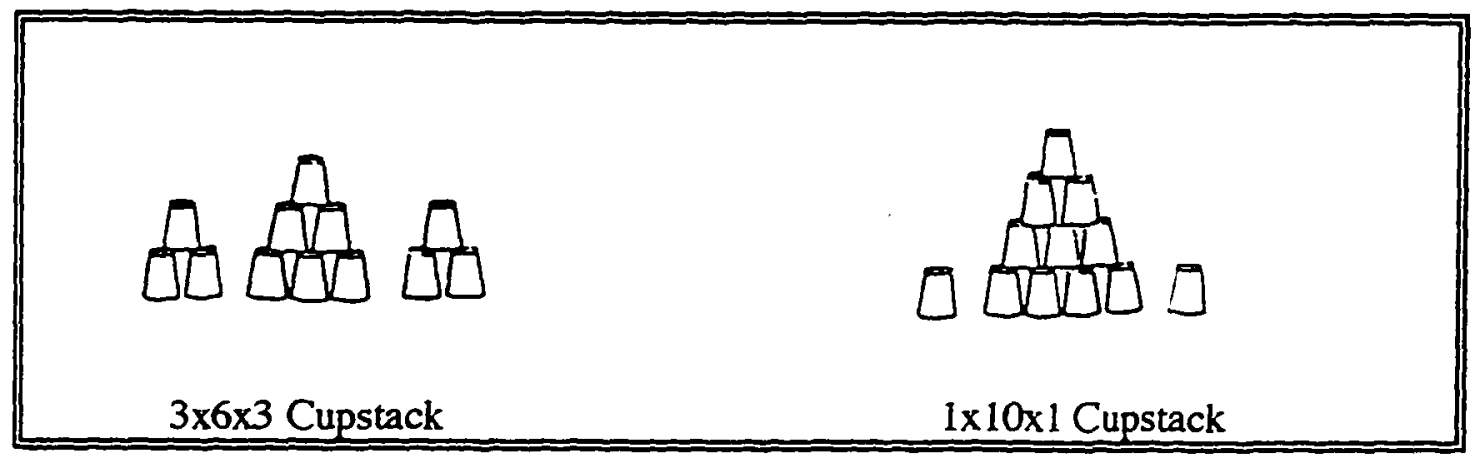

Figure 1. Diagram of cup configuration for the $3 \times 6 \times 3$ and $1 \times 10 \times 1$ cupstack skills. 


\section{Augmented Feedback Treatments}

The four augmented feedback conditions were: (a) no feedback, (b) positive, motivational feedback, (c) task knowledge feedback, and (d) positive, motivational feedback and task knowledge feedback. Students in the control treatment received only instructional information about the goal of the task. They were told to practice and informed if they were not doing the activity according to the initial directions.

Students receiving the second treatment were given positive, motivational feedback about their individual ability and effort. No feedback about technique was provided, but encouraging statements such as: "You are really trying hard", "I can see that you are going to be good at this", "You have quick hands", "You are a fast learner", and "You are really improving" were provided each student as the teacher worked in a continuous cycle within the small group.

Students receiving the third treatment were given only task knowledge feedback related to their performance. No comments were made about students' abilities or efforts. Students were encouraged to concentrate on leaming the skill correctly and were provided with the following progressions: (a) watch cups as you work, (b) always place the cups close together, (c) pick up two cups at a time and use both hands to place them, (d) in the 6 cup pyramid, use both hands to pick up all the cups except the bottom one, place cups on either side of the center one, and then move up, (e) when performing the $1 \times 10 \times 1$, always begin the second row in the center. Progressions and appropriate task knowledge were identified in a pilot study and confirmed by teachers experienced in teaching this skill. Task knowledge feedback statements were given according to the student's skill. If students were already placing the cups close together, then they might be told, "You do a good job of placing the cups close together. You might do even better if you tried picking up two cups at a time." 
Students receiving the fourth treatment were given task knowledge information about how best to perform the skill, and positive, motivational feedback about their efforts and abilities while practicing and performing the skills. The goal was to provide students with combination feedback statements such as, "You are such a hard worker, and you are doing a great job of using both hands at the same time. Next time try to pick up all the cups except the bottom one."

Practice and Achievement Measures

Performance scores. Students were given two pre-treatment time trials and two post-treatment time trials to determine their actual cupstacking ability for each of the cupstacking skills $(3 \times 6 \times 3$ and $1 \times 10 \times 1)$. Trials were timed with stopwatches and recorded to the nearest one hundredth of a second. The student's best time from each testing session was used in the analysis.

Behavior coding system. In order to provide a measure of overt student practice during instruction and practice, time on-task was coded from video tapes using a stop watch. Following opening comments and instructions, students' behaviors were coded for ten minutes during which time they received feedback comments while practicing. Off-task behaviors were timed, recorded, converted to minutes and then subtracted from the 10 minutes. Students who moved out of camera range were not given behavior scores. During feedback. students were coded as on-task if they appeared to be listening to the instructor. They were coded as off-task if they were looking away from the instructor, talking to another student, or engaged in any behavior not related to the instruction. During practice, students were coded as on-task if they were: (a) actively engaged in upstacking or downstacking all or any portion of the skill being taught (For example, students practicing repeat 3 cup stacks during the $3 \times 6 \times 3$ cupstacking lesson were coded as on-task, while students practicing a 12 cup pyramid on that same day were coded as off-task.). or (b) watching their partner perform, and then immediately beginning 
their turn. They were coded as off-task if hej' werc: (a) doing anything with their cups other than the assigned task such as tossing cups in the air, or building towers, castles, or pyramids; (b) engaged in any behavior not related to the skill such as crawling around, reading notices on the wall, talking, or staring; or (c) waiting more than 10 seconds to begin their turn after a partner finished. The inter-rater reliability coefficient for coding student behavior was .93 for the $3 \times 6 \times 3$ cupstacking skill and .90 for the $1 \times 10 \times 1$ cupstacking skill.

\section{Measures of Motivational Beliefs}

Surveys. Prior to instruction, students completed a one page initial survey with open-ended responses in order to obtain information about: (a) skill novelty, (b) interest, and (c) self-perceptions of ability to learn (SPAL) the general skill of cupstacking. Students indicated with a yes or no response if they had ever seen or practiced the cupstacking skill. If they checked yes, they were asked to explain where they had seen this skill and how much they had practiced it. Vague answers were later clarified by the experimenter. Students indicated their initial interest in this activity by checking their response to the question, "How interested are you in learning this skill?". Responses were ranked: 1-not at all interested, 2-sort of interested, 3-interested, 4-very interested, and 5-extremely interested. Students were then asked to write the number of the response they checked and to explain why they chose that answer. Finally students were asked to complete a Likert scale from 1 (not at all ) to 10 (perfect) in order to indicate, "With practice how well do you think you can learn the skill of cupstacking?", and to then explain their choice.

After exposure to the assigned treatment, students completed a final one page survey designed to reveal the following: (a) SPAL the skill of cupstacking, (b) the perceived goal of the unit, (c) suggestions for teacher improvement, and (d) interest in the inclusion of cupstacking in a physical education curriculum. SPAL was indicated by a 1 (not at all) to 10 (perfect) response to the question. "With more 
time to practice how well do you think you can learn these and other cupstacking skills ?", followed by an explanation of why the student selected that response. Students' perceptions about the purpose of the study were determined by how they explained the goal of the unit. Instructor perceptions were determined by answers to the question, "If your teacher had to teach another group of students about cupstacking, how do you think she might improve her teaching?". Student interest was indicated by response to the question, "Do you think this would be a good activity to work on in physical education class? Why or why not?".

SPAP cards. Following a demonstration of the particular cupstacking skill, students were given an index card to record their self-perceptions of ability to perform (SPAP) the identified skill ( $3 \times 6 \times 3$ or $1 \times 10 \times 1)$. SPAP, which could be ranked 1 (the lowest perception of ability) to 10 (the highest perception of ability), were then briefly explained by the student. Before taking final performance time trials, students again recorded their SPAP the practiced skill and their rationale for their rating.

\section{Procedures}

Students participated in an instructional unit on two cupstacking skills: $3 \times 6 \times 3$ and $1 \times 10 \times 1$. On day one, fourth grade students watched a five and a half minute instructional video on a variety of individual and team cupstacking skills performed primarily by male and female elementary students from approximately seven to twelve years of age. The video, which also included regular and special education students, adult community leaders and professional athletes, modeled abilities ranging from beginning to championship levels.

Following the video, the experimenter conducted a brief class discussion about the values and purposes of cupstacking. Students were challenged throughout the study to figure out the most efficient way to perform each cupstacking skill and to become proficient enough so that they could teach this skill to a brother. sister or 
friend. Students individually completed the initial survey. Before having students respond to the question, "With practice how well do you think you can learn the skill of cupstacking?" , ability to learn was defined as being able to demonstrate basic cupstacking skills (as seen in the video) while moving quickly without wasted motion and without fumbles or mistakes. An ideal time was never mentioned. The challenge of learning in order to improve and to be able to teach others was emphasized daily.

Students present for the introduction were divided into four physical education classes with $22,20,31$, or 32 students in a class. The students within each of these small physical education classes were then randomly assigned by gender into four learning groups of 5 to 9 students. Beginning the next day, each group received one treatment. During a given 30 -minute class session, all four of the treatments were administered, each one by a different instructor. Over the course of two hours, each instructor taught a different treatment to four different groups, one from each of the four physical education classes.

Prior to the first session, the $3 \times 6 \times 3$ cupstacking skill was demonstrated. Students then filled out side one of the $3 \times 6 \times 3$ SPAP card and received two pretreatment performance trials by trained timers. No comments were made by timers, and scores were recorded on a master sheet.

In the first feedback sessions, instructors were introduced and terms (e.g., upstacking, downstacking) and procedures (e.g., placement of cups, movement from left to right when upstacking and downstacking) were reviewed. At a given signal, the instructors began to provide the predetermined treatment condition. Toward the end of the class, instructors had the students complete side two of the $3 \times 6 \times 3$ SPAP cards; then the timers recorded two post-treatment performance trials. While students rotated in and out of testing, the instructors continued to provide feedback. 
All classes were videotaped with four cameras filming the concurrent instructional lessons.

Prior to the second sessions, demonstrations of the $1 \times 10 \times 1$ cupstacking skill were provided for each physical education class; side one of the $1 \times 10 \times 1$ SPAP cards was completed individually by each student; and two time trials were recorded by trained timers.

The same procedures used during the first sessions were repeated for the second sessions. Students returned to the same instructor, and received the same augmented feedback treatment while they learned the new $1 \times 10 \times 1$ cupstacking skill.

The final survey was completed by each student during their regularly scheduled class on the last day, and the rest of the class time was spent in cupstacking relay races.

\section{Design and Analysis}

A Latin square design (see Table 1) was used to investigate the effectiveness of the three feedback treatments (motivational feedback, task feedback, and motivational and task feedback) and no feedback while controlling for teacher and class effects. A repeated measures ANOVA was used to determine differences in the following dependent variables within and between treatment groups: (a) SPAL the skill of cupstacking, (b) SPAP for the $3 \times 6 \times 3$ and the $1 \times 10 \times 1$ cupstacking skills, (c) performance scores for the $3 \times 6 \times 3$ and the $1 \times 10 \times 1$ skills, and (d) time on-task behavior scores for each day of practice. A simple main effects analysis was computed to measure the effect of time within each treatment. The unit of analysis for each variable was the mean of student scores within each cell (class) of the Latin square. Since students experienced each of the treatments as a social group, the group mean is the more appropriate unit of analysis than the individual student score. 
Written responses obtained from the initial and final student surveys as well as student comments taken from the video tapes were used to verify certain assumptions and goals of the study such as novelty of task, interest in task, and understanding of purposes. Qualitative responses were not intended to be analyzed but were included to help clarify the quantitative findings.

Table 1.

Latin Square Design

\begin{tabular}{|c|c|c|c|c|}
\hline Instructor & $\begin{array}{l}\text { Class 1 } \\
1: 00\end{array}$ & $\begin{array}{l}\text { Class } 2 \\
1: 30\end{array}$ & $\begin{array}{l}\text { Class } 3 \\
2: 00\end{array}$ & $\begin{array}{l}\text { Class } 4 \\
2: 30\end{array}$ \\
\hline 1. & $\begin{array}{l}F B \cdot A \\
B=2^{\circ} \\
G=3\end{array}$ & $\begin{array}{l}F B \cdot B \\
B=2^{\circ} \\
G=3\end{array}$ & $\begin{array}{l}F B \cdot D \\
B=5^{\circ} \\
G=3\end{array}$ & $\begin{array}{l}\mathrm{FB} \cdot \mathrm{C} \\
\mathrm{B}=5 \\
\mathrm{G}=3^{\circ}\end{array}$ \\
\hline 2. & $\begin{array}{l}F B \cdot B \\
B=4 \\
G=1\end{array}$ & $\begin{array}{l}F B \cdot C \\
B=4 \\
G=2\end{array}$ & $\begin{array}{l}F B \cdot A \\
B=5^{\circ} \\
G=3\end{array}$ & $\begin{array}{l}F B \cdot D \\
B=4 \\
G=4\end{array}$ \\
\hline 3. & $\begin{array}{l}F B \cdot C \\
B=3 \\
G=3\end{array}$ & $\begin{array}{l}F B \cdot D \\
B=3 \\
G=2\end{array}$ & $\begin{array}{l}F B \cdot B \\
B=6 \\
G=3\end{array}$ & $\begin{array}{l}F B \cdot A \\
B=4 \\
G=4\end{array}$ \\
\hline 4. & $\begin{array}{l}F B \cdot D \\
B=3 \\
G=3\end{array}$ & $\begin{array}{l}F B \cdot A \\
B=3 \\
G=2\end{array}$ & $\begin{array}{l}F B \cdot C \\
B=2 \\
G=6\end{array}$ & $\begin{array}{l}F B \cdot B \\
B=5 \\
G=3\end{array}$ \\
\hline
\end{tabular}

Note. ${ }^{\circ}$ One participant from this unit did not complete the study

$\overline{\mathrm{FB}}=$ feedback $\bullet(\hat{\mathrm{A}}=$ no feedback; $\mathrm{B}=$ motivational feedback; $\mathrm{C}=$ task knowledge feedback; $D=$ motivational and task knowledge feedback). $B$ and $G=$ boys and girls. 


\section{RESULTS}

\section{Fidelity of Treatment}

Instructor adherence to the treatment scripts was checked by observers (the experimenter and the regular physical education teachers) and by a review of the audio portions of the filmed lessons. Only two instances of incorrect feedback were noted. Once a teacher in the control feedback treatment gave generic praise ("good") to a pair of students, and likewise a teacher in the task only feedback treatment praised a student for working hard. According to their preference, instructors rotated from one station to the next, or they had the students rotate to them so that, in either case, feedback was freely given as deemed appropriate.

\section{Descriptive Statistics}

Descriptive statistics for SPAL cupstacking in general, for SPAP the specific $3 \times 6 \times 3$ and the $1 \times 10 \times 1$ cupstacking skills, performance scores, and overt student behavior scores are found in Table 2 . The data indicate overall improvement in SPAL, SPAP, performance, and a general decline in on-task behavior across all treatment conditions. Ratings for SPAL which ranged from 1 to 10 points improved 2.15 points from an initial overall mean of 6.04 to a final mean of 8.19 points. Ratings for SPAP the $3 \times 6 \times 3$ skill improved from 6.5 to 8.01 points while ability ratings for the $1 \times 10 \times 1$ skill improved from 6.64 to 7.79 points. Performance scores ranged from 8.17 to 24.79 seconds for the $3 \times 6 \times 3$ skill and from 7.59 to 21.70 seconds for the $1 \times 10 \times 1$ skill. Higher behavior scores reflect better student on-task engagement. During the 10 minute behavior coding time, students were on-task $93 \%$ of the time during the first sessions and $85 \%$ of the time during the second sessions.

\section{Statistical Analysis}

Results of the repeated measures ANOVA can be seen in Table 3. None of the classroom or instructor effects were statistically significant. This was expected 
since students were randomly assigned to learning groups, and teachers were trained to follow prepared scripts.

Table 2.

Descriptive Statistics

\begin{tabular}{|c|c|c|c|c|}
\hline Variable & $\begin{array}{l}\text { Beginning } \\
\text { Mean }\end{array}$ & $\begin{array}{l}\text { Standard } \\
\text { Deviation }\end{array}$ & $\begin{array}{c}\text { Ending } \\
\text { Mean }\end{array}$ & $\begin{array}{l}\text { Standard } \\
\text { Deviation }\end{array}$ \\
\hline $\begin{array}{l}\text { SPAL } \\
\text { No Feedback } \\
\text { Motivational } \\
\text { Task } \\
\text { Motivational/Task }\end{array}$ & $\begin{array}{l}6.93 \\
5.14 \\
5.64 \\
6.45\end{array}$ & $\begin{array}{l}.45 \\
.44 \\
.41 \\
.42\end{array}$ & $\begin{array}{l}8.23 \\
8.05 \\
7.61 \\
8.86\end{array}$ & $\begin{array}{l}.35 \\
34 \\
32 \\
.33\end{array}$ \\
\hline $\begin{array}{l}\text { 3x6x3 PERFORMA } \\
\text { Pretest-Posttest } \\
\text { No Feedback } \\
\text { Motivational } \\
\text { Task } \\
\text { Motivational/Task }\end{array}$ & $\begin{array}{l}\text { NCE SCOR } \\
19.70 \\
18.02 \\
17.75 \\
18.58\end{array}$ & $\begin{array}{l}.89 \\
.87 \\
.81 \\
.83\end{array}$ & $\begin{array}{l}16.80 \\
15.27 \\
14.03 \\
15.31\end{array}$ & $\begin{array}{l}.79 \\
.77 \\
.72 \\
.74\end{array}$ \\
\hline $\begin{array}{l}\text { SPAP } \\
\text { No Feedback } \\
\text { Motivational } \\
\text { Task } \\
\text { Motivational/Task }\end{array}$ & $\begin{array}{l}6.81 \\
6.58 \\
6.71 \\
5.89\end{array}$ & $\begin{array}{l}.19 \\
.18 \\
.17 \\
.17\end{array}$ & $\begin{array}{l}8.09 \\
7.97 \\
7.81 \\
8.17\end{array}$ & $\begin{array}{l}.50 \\
.49 \\
.46 \\
.47\end{array}$ \\
\hline $\begin{array}{l}\text { 1x10x1 PERFORM } \\
\text { Pretest•Posttest } \\
\text { No Feedback } \\
\text { Motivational } \\
\text { Task } \\
\text { Motivational/Task }\end{array}$ & $\begin{array}{l}\text { NCE SCO } \\
18.31 \\
17.42 \\
18.20 \\
18.52\end{array}$ & $\begin{array}{l}.49 \\
.48 \\
.45 \\
.46\end{array}$ & $\begin{array}{l}16.06 \\
15.27 \\
12.57 \\
14.52\end{array}$ & $\begin{array}{l}.56 \\
.55 \\
.51 \\
.53\end{array}$ \\
\hline $\begin{array}{l}\text { SPAP } \\
\text { No Feedback } \\
\text { Motivational } \\
\text { Task } \\
\text { Motivational/Task }\end{array}$ & $\begin{array}{l}6.97 \\
7.08 \\
6.56 \\
5.94\end{array}$ & $\begin{array}{l}.36 \\
.35 \\
.33 \\
.34\end{array}$ & $\begin{array}{l}8.12 \\
8.09 \\
7.57 \\
8.16\end{array}$ & $\begin{array}{l}39 \\
38 \\
.36 \\
.37\end{array}$ \\
\hline $\begin{array}{l}\text { TIME ON-TASK } \\
\text { 3x6x3-1x10x1 } \\
\text { No Feedback } \\
\text { Motivational } \\
\text { Task } \\
\text { Motivational/Task } \\
\end{array}$ & $\begin{array}{l}9.15 \\
8.76 \\
9.62 \\
9.59 \\
\end{array}$ & $\begin{array}{l}.18 \\
.23 \\
.17 \\
.19 \\
\end{array}$ & $\begin{array}{l}7.21 \\
7.72 \\
9.53 \\
9.46 \\
\end{array}$ & $\begin{array}{l}.36 \\
.44 \\
.33 \\
.37\end{array}$ \\
\hline
\end{tabular}

Note. SPAL $=$ self-perceptions of ability to learn $(1-10)$. SPAP $=$ self-perceptions of ability to perform (1-10). Pretest and Posttest performance scores (seconds). Time on-task (0-10 minutes). 
Table 3

Analysis of Variance Summary

\begin{tabular}{|llllll||}
\hline \multicolumn{7}{c|}{ F Values for Analysis of Variance Effects } \\
\cline { 2 - 6 } Dependent Variable & $\begin{array}{l}\text { Treatment } \\
\text { F } 3,6\end{array}$ & $\begin{array}{l}\text { Class } \\
\text { Instructor }\end{array}$ & F 3,6 & Time & Time*Treatment \\
\hline SPAL & $5.77^{*}$ & 1.98 & 3.43 & F 1,6 & F3,6 \\
$3 \times 6 \times 3$ SPAP & 0.32 & 1.24 & 2.14 & $51.61^{* *}$ & 1.23 \\
$1 \times 10 \times 1$ SPAP & 0.77 & 0.13 & 1.47 & $55.75^{* *}$ & 1.73 \\
$3 \times 6 \times 3$ Performance & 1.58 & 3.53 & 0.13 & $87.14^{* *}$ & 4.19 \\
$1 \times 10 \times 1$ Performance & 2.59 & 2.23 & 4.17 & $221.05^{* *}$ & 1.08 \\
Behavior Scores & $10.49 * *$ & 1.13 & 1.78 & $315.44^{* *}$ & $17.94^{* *}$ \\
\hline * significance al the .05 level & $* *$ significance at the .01 levcl & & $21.10^{* *}$ & $7.16^{*}$ \\
\hline
\end{tabular}

Note. SPAL $=$ self-perceptions of ability to learn; SPAP = self-perceptions of ability to perform 
SPAL. The analysis of variance shows a significant difference between treatment groups for SPAL, $\mathrm{F}(3,6)=5.77, \mathrm{p}<.05$, indicating that when collapsed across time, the four feedback group's means were different. This finding is not meaningful or difficult to explain since groups were randomly formed. There was also a significant time effect, $\underline{F}(1,6)=51.61, \mathrm{p}<.01$, indicating that in general students strengthened their perception of their ability to continue to learn the skill of cupstacking regardless of the treatment group they were assigned. The absence of a significant interaction for time by treatment indicates that the increases in overall SPAL did not differ by treatment group.

The open-ended questions designed to gain information regarding the criteria students used to judge their initial ability to learn indicated that a variety of sources were used. Students based their ratings on their perceptions of task difficulty, their beliefs about the power of effort and practice, their uncertainty about a novel task, their reluctance to brag, and their interest in the activity. For example, the 8 students who indicated no interest in learning this skill had an average SPAL rating of 3 while the other 95 students had an average rating of 6.04 . This strongly suggests a tie between initial ability assessment and initial interest in learning.

SPAP. The analysis on perceptions of ability to perform indicates no significant differences between treatment groups for either the $3 \times 6 \times 3$ or the $1 \times 10 \times 1$ skill (see Table 3). Significant time effects were evident for SPAP on the $3 \times 6 \times 3$ skill, $\underline{F}(1,6)=55.75, \underline{\mathrm{p}},<.01$, as well as the $1 \times 10 \times 1$ skill $\underline{\mathrm{F}}(1,6)=87.14, \mathrm{p},<.01$. While the interaction of time and treatment was not significant for either skill at the .05 level, the finding for $1 \times 10 \times 1$ SPAP, $\underline{F}(3,6)=4.19, \mathrm{~g}<.06$, might indicate a possible trend as shown in Figure 2. The mean SPAP scores for Treatment D (task and motivational feedback) show a larger increase from pre to post ( 2.22 points) than the other treatment groups which increased slightly more than one point. 


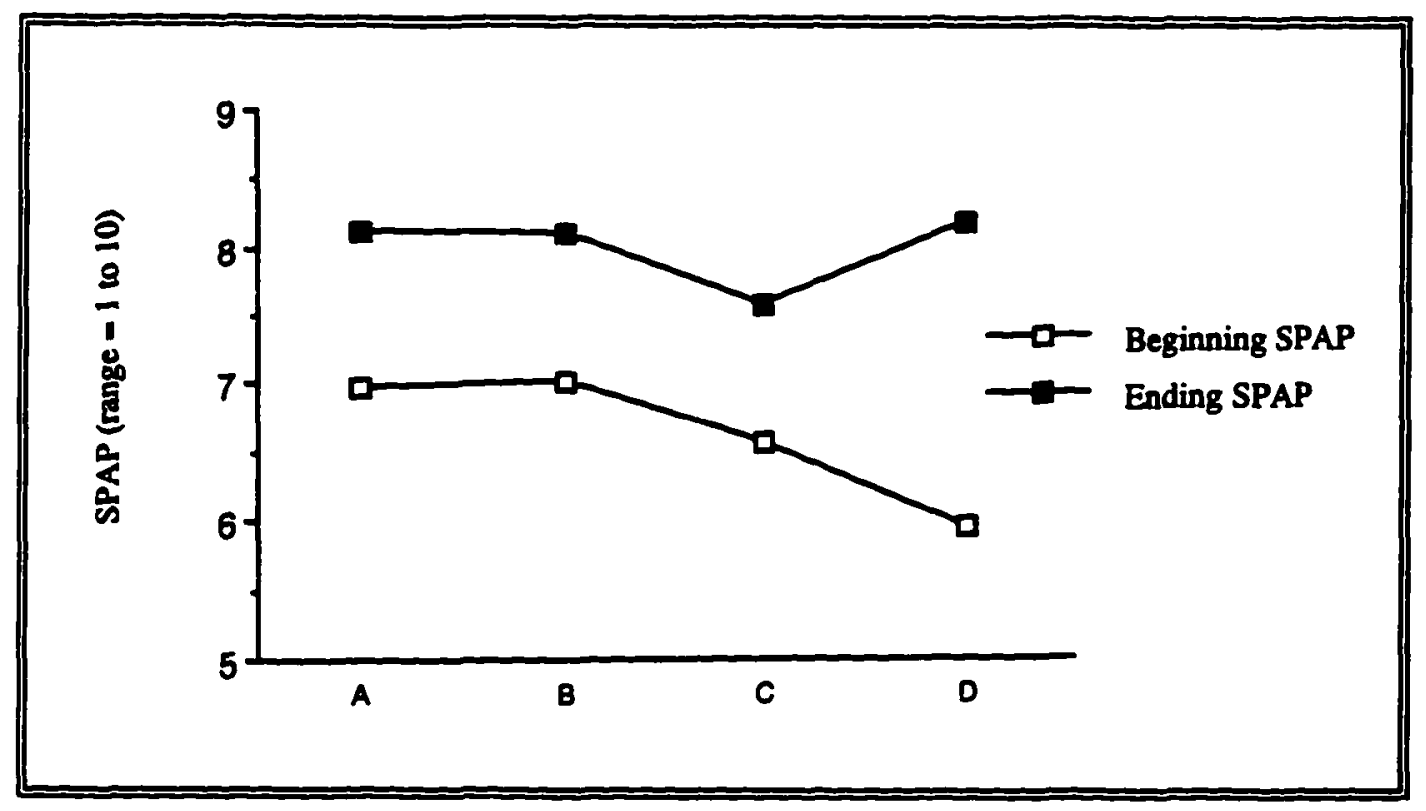

Figure 2. Mean changes in self-perceptions of ability to perform the $1 \times 10 \times 1$ cupstacking skill. $\mathrm{A}=$ no feedback; $\mathrm{B}=$ motivational feedback; $\mathrm{C}=$ task feedback; $D=$ motivational and task feedback.

Performance. When analyzing improvements in performance scores, the time by treatment interaction was significant for the $1 \times 10 \times 1$ skill, $\underline{F}(3,6)=17.94, \mathbb{R}$ $<.01$ (see Table 3), but not for the $3 \times 6 \times 3$ skill, $\mathrm{F}(3,6)=1.08$, $\mathrm{p}>.05$. The mean scores for the $1 \times 10 \times 1$ skill are shown graphically in Figure 3 and numerically in Table 2. The follow up simple main effects analysis within each treatment group indicated a significant, $\mathrm{p}<.01$ increase from pre to post for each treatment. However, as shown, the increase from pre to posttest differed as a function of treatment, with those students receiving task feedback making the greatest gain. Performance scores for the task feedback groups improved by 5.6 seconds. The motivational and task feedback groups improved by 4 seconds. The average improvement for the other two groups was 2.2 seconds, indicating that students practicing without feedback or with motivational feedback were at a disadvantage compared to those receiving task or motivational and task feedback. 


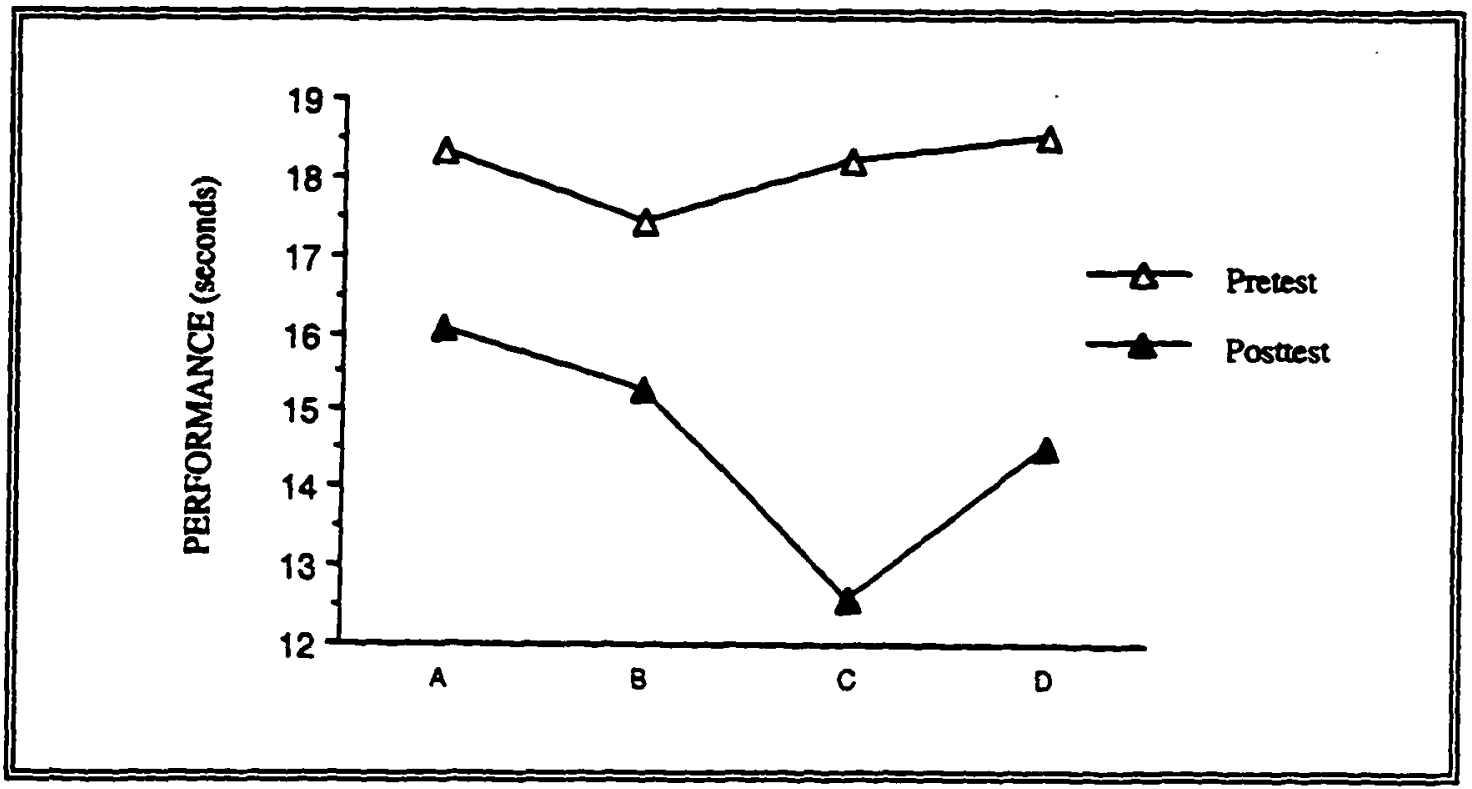

Figure 3. Mean changes in performance scores for the $1 \times 10 \times 1$ cupstacking skill. $\mathrm{A}=$ no feedback; $\mathrm{B}=$ motivational feedback; $\mathrm{C}=$ task feedback; $\mathrm{D}=$ motivational and task feedback.

Engaged behavior. Ten minutes of behavior during practice sessions was coded for each student. Students who moved out of camera range were not given behavior scores $(n-19)$. Those who were off-task for less than 10 seconds received a 10 rating. Those off-task for ten seconds or more received scores indicating their actual on-task minutes out of the possible ten minutes. For example, a student offtask for 30 seconds was on-task for 9 and one half minutes ( 9.5 rating). Overall students received a 9.28 rating during the first day of the study, and an average 8.48 rating on the second day. The coding of on-task behavior revealed a significant time by treatment interaction $\underline{F}(3,6)=7.16, \mathrm{~g}<.05$, and a significant time effect, $\underline{F}(1$, $6)=21.1, \mathrm{p}<.01$. The simple means analysis which is depicted graphically in Figure 4 indicates that no feedback. $\underline{F}(1,3)=13.65 . \mathrm{p}<.05$, and motivational feedback, $\underline{F}(1,3)=25.70, \mathrm{p}<.05$, both resulted in a significant difference in offtask behavior while task feedback. $\underline{F}(1,3)=.88, \mathrm{p}>.05$, and combined motivational and task feedback, $\underline{F}(1,3)=1.91, \mathrm{p}>.05$, showed no significant difference. 


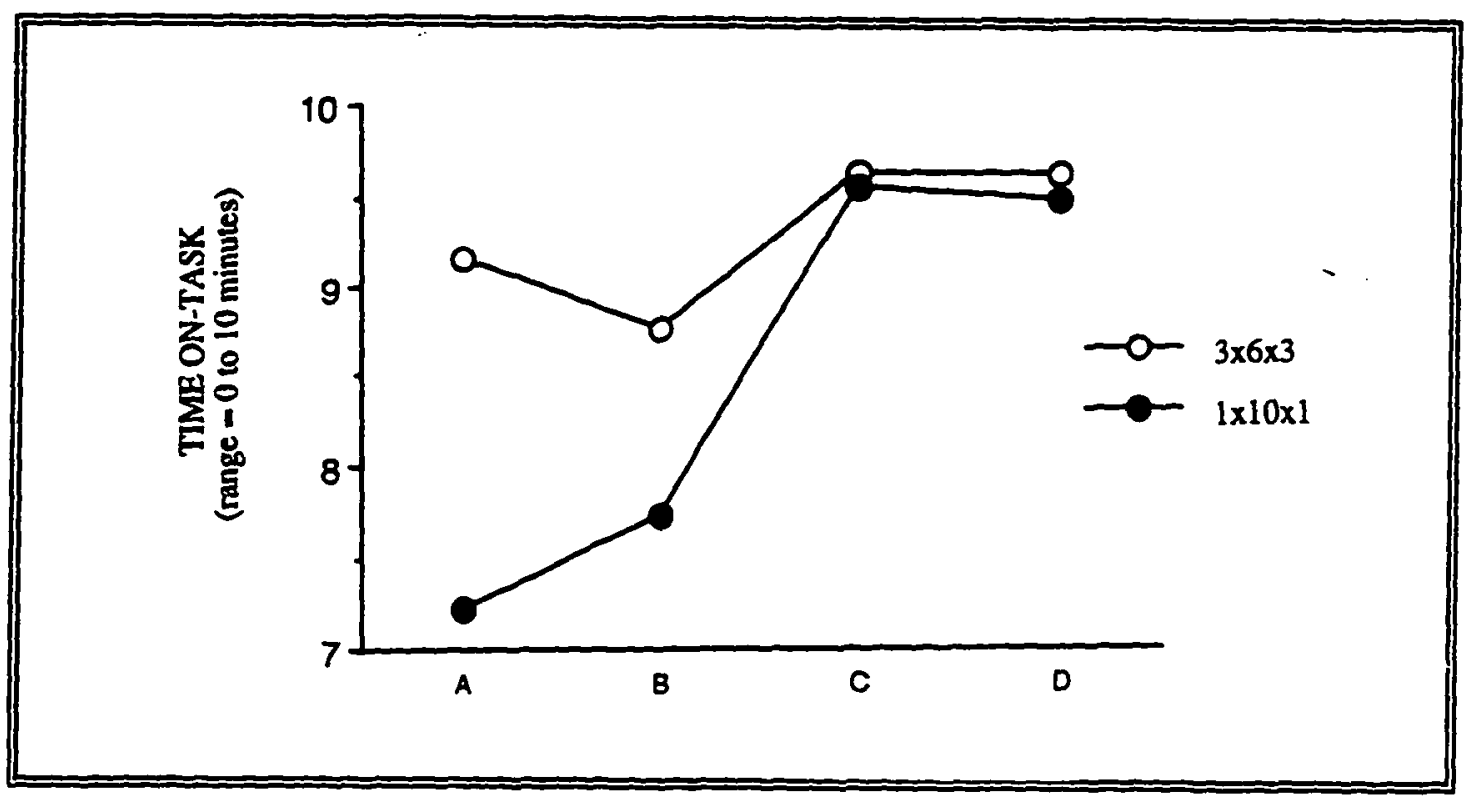

Figure 4. Mean time on-task scores for learning the $3 \times 6 \times 3$ and the $1 \times 10 \times 1$ cupstacking skills. $A=$ no feedback; $B=$ motivational feedback; $C=$ task feedback: $\mathrm{D}=$ motivational and task feedback. 


\section{DISCUSSION}

Traditionally augmented feedback has been postulated to further motor skill learning by either providing the learner performance information or by motivating them to persist in their attempts to learn (Magill, 1993). Feedback has been linked to students' SPA in academic areas (Schunk, 1988), but has yet to be substantiated in physical education classes (Lee, Keh, \& Magill, 1993; Magill, 1993). Difficulties in the investigation of feedback relationships have often been attributed to methodological issues (Lee, Keh, \& Magill, 1993). This study was designed to control for some of these problems. First of all, it was decided to conduct a field based experiment rather than a motor learning laboratory experiment in order to analyze the impact of feedback treatments in the complex and often unpredictable environment of the physical education setting. Secondly, a novel task was selected, and verified as such by the students, to help control for student skill level. Thirdly, a gender neutral task was chosen to control for gender appropriateness. A school was selected in which students have consistently shown a positive attitude towards physical education and a willingness to function in a disciplined environment. This effort was made to minimize disciplinary problems while maximizing attention towards the prescribed feedback treatment. The literature describes SPA as domain and situation specific (Pajares, 1996), so the precise skill of cupstacking rather than a more general skill such as basketball was selected for this study. Finally, classes were kept purposefully small to allow for freely occurring feedback and maximum practice opportunities. Overall the goal was to create a receptive environment with a focus on feedback, performance and perceptions.

The literature review suggests that augmented feedback can influence SPA, in academics (Schunk, 1982) and in youth sports (Horn, 1985). This study failed to substantiate this finding in the physical education classroom. SPA did improve across groups, but changes were not significantly attributable to treatment 
conditions. It does seem reasonable that students with no initial knowledge of an activity and therefore no definitive means by which to base judgments would record higher ability estimations after practice. Thus experience may account for the general increase in SPAL. The lack of interaction between SPAL and treatment groups may simply indicate that more time is needed before various feedback conditions can make a difference.

An inability to determine SPA based on performance accomplishments apparently led over $25 \%$ of the students to infer SPAL for cupstacking from more global perceptions about physical education or education in general. For example, initial ratings of 2 to 7 were attributed to lack of ability, lack of speed, or general feelings that "I'm not good." Global self-concepts are reflected in the following explanations: "I can hardly do anything", "I'm not the best in anything", "I'm not fast at anything", "I can't learn that well." In a similar fashion, students selected ratings from 4 to 10 because they felt they were fast learners. good students, or "good at other sports." A number of students pointed out that they had quick hands, good eye-hand speed. or that they were generally "cortonated." It may be that specific rather than global self-assessments require not a novel task but one that provides some degree of familiarity.

While treatment conditions could not explain ending SPAL for the skill of cupstacking, it is apparent that humility (e.g., "I'm not perfect."), frustration (e.g., "It is harder than I thought."), and effort (e.g., "I practiced alot.") contributed to final assessments. Feelings that "I'm good" produced ratings from 6 to 10. In-depth interviews might have been able to tease out the differences between each of these ratings and reveal why a person who perceived themselves as successful would choose a 6 or 7 rating and rather than an 8,9 , or 10 .

Ratings for SPAP indicate a trend towards a treatment effect during practice of the $1 \times 10 \times 1$ skill. These findings could be attributed to the specificity of this self 
assessment over the more global SPAL the general skill of cuptstacking which supports the contention (Bandura, 1986; Pajares, 1996) that accurate ability assessments require specificity and correspondence to criterial tasks. Response to a specific, definitive question might be more influenced by feedback given about that specific skill. It is also reasonable to suggest that feedback conditions incapable of altering perceptions in one day, can become more persuasive over time. In addition, the complexity of the skill might influence how feedback is appraised. Students learning a simple skill such as the $3 \times 6 \times 3$ may not attend to or need feedback, while those learning a more complex skill such as the $1 \times 10 \times 1$ may attend to and need available feedback. Interestingly, the task and motivation treatment prompted the greatest gain in SPAP though the task treatment produced the greatest gain in other dependent variables. Perhaps some type of affirmation is necessary to improve the perceptions of young children, especially with an unfamiliar task. Without the availability of times, standards of excellence. or past performance knowledge, it is logical to assume that students' cognitive perceptions stemmed in part from the persuasion of others. Perhaps a larger sample size (i.e., larger classes or more classes for each treatment), would produce a significant interaction across treatments. It does appear that these results warrant further investigations.

The literature supports a relationship between augmented feedback and motor-skill acquisition in laboratory settings (Magill, 1993), and physical education teachers have enthusiastically supported the importance of feedback (Keh, 1992). With the exception of the study by Silverman, Tyson, and Krampitz (1992), fieldbased research has yet to consistently establish the feedback-achievement relationship (Keh, 1992; Lee, Keh, \& Magill, 1993; Magill, 1993). In this study feedback treatments did have a significant influence on performance scores in the more complex $1 \times 10 \times 1$ skill, but not on the simpler $3 \times 6 \times 3$ skill. Once again it may be that feedback influences are not discernible in one lesson, or it may be as 
reported by Lee, Keh and Magill (1993) that feedback is not necessary for easy skills. The post analysis on the more complex skill indicates that all four feedback conditions were associated with performance improvements, but that gains were related to the types of information that the students received. Task feedback followed by motivational and task feedback improved students' scores more than either no feedback or motivational feedback. This suggests that information about how to perform a task is important and necessary in at least the initial learning stages of a complex or challenging skill. Such findings support Winne's (1991) assertion that task knowledge is a prerequisite to achievement. Students as a group did not improve when left on their own, nor did simple praise for effort or ability improve their scores. It is interesting that students indicated a belief in the power of practice and effort to produce success (e.g., students' explanations of SPAL rankings), and instructors in the motivational feedback conditions affirmed effortful strivings, but actual scores failed to substantiate such beliefs. It could be argued that motivational feedback in combination with task feedback should be the best opportunity for improved performance. The fact that this did not happen might be because students were given too much information to fully assimilate, or it might be that students discounted some task information in favor of motivational feedback. Though not investigated, it could be that motivational feedback would exert greater influence after initial understanding of how to technically perform the skill when learning tends to plateau and persistence often wanes.

Behavior scores determined by seconds off-task are not very realistic for a regular physical education class where few students could be expected to remain on task the entire class. However, this measure proved appropriate for this study due to the small class sizes, the novelty of the task, the excitement of having new university teachers, and the relatively short scoring period. Overall, on-task behavior was very high. but there were a few typical students who remained 
predominantly off-task. They generally engaged in some form of creative cupstacking but failed to practice the designated skill of the day. Despite some deviations from the normal physical education setting, information about which types of feedback best sustain student on-task behaviors may prove useful even in large classes where feedback would have to be given less to each individual and more to groups of students. Though off-task engaged time did increase across all treatments during practice of the more challenging task (i.e., $1 \times 10 \times 1$ ), there was a difference among treatments. Task knowledge provided a significant difference in performance scores and proved the most significant treatment for sustaining on-task behavior which suggests that when students have the task related information they need to improve performance, they are more willing to remain engaged during practice. Task and motivational feedback was followed by motivational feedback and finally by no feedback. It appears that any type of feedback can help keep students on task, but that informational or needed feedback is more effective. Attempts to characterize teacher effectiveness have often emphasized teacher management techniques as a key to on-task behavior and ultimate learning (Shulman, 1987). This study suggests that appropriate feedback might be a key to positive student engagement.

Similar increases in SPAP, performance achievements and engaged behavior suggest evidence of a linkage among these variables. As on-task behavior improved, so, too, did performance scores and to a lesser degree SPA. This study provides support for the positive influence of task and motivational feedback on performance and behavior in physical education settings. A longer study might reveal whether feedback or successful performance is the stronger mediator of increased SPA. Even with the current emphasis on the establishment of task or mastery environments which attempt to bypass the influence of SPA, understanding the power of feedback in such a climate might serve to help students with low 
ability perceptions and to encourage on-task behavior for all. If, as suggested by Shulman (1987), effective teaching begins with knowledge about what is to be learned and how that information can be transformed to the learner, then university physical education programs must continue efforts to prepare majors with the movement and sports skills knowledge necessary for formulating relative, meaningful feedback. 


\section{REFERENCES}

Ames, C. (1992a). Achievement goals, motivational climate, and motivational processes. In G. C. Roberts (Ed.), Motivation in sport and exercise (pp. 161-176). Champaign, IL: Human Kinetics.

Ames, C. (1992b). Classrooms: Goals, structure, and student motivation. Journal of Educational Psychology, 84. 261-271.

Ames, C., \& Archer, J. (1988). Achievement goals in the classroom: Students' learning strategies and motivation processes, Joumal of Educational Psychology, 80, 260-267.

Bandura, A. (1977). Self-efficacy: Toward a unifying theory of behavioral change. Psychology Review, 84, 191-215.

Bandura, A. (1986). Social foundations of thought and action: A social cognitive theory. Englewood Cliffs, NJ: Prentice-Hall.

Blumenfeld, P. C. (1992). Classroom learning and motivation: Clarifying and expanding goal theory. Journal of Educational Psychology, 84 (3), 272-281.

Clifton, R. T., \& Gill, D. L. (1994). Gender differences in self-confidence on a feminine-typed task. Joumal of Sport \& Exercise, 16, 150-162.

Cupstack Information and Instruction Brochure, (1988). [Brochure]. Oceanside, CA: Karango Enterprizes.

Deci, E. L., \& Ryan, R. M. (1985). Intrinsic motivation and selfdetermination in human behavior. New York: Plenum Press.

Doyle, W. (1977). Paradigms for research on teacher effectiveness. Review of Research in Education, 5. 163-198.

Ebbeck, V., \& Stuart, M. (1993). Who determines what's important? Perceptions of competence and importance as predictors of self-esteem in youth football players. Pediatric Exercise Science, 5, 253-262.

Eccles, J. S. (Parsons), Adler, T. F., Futterman, R., Goff, S. B., Kaczala. C. M., Meece, J. L., \& Midgley, C. (1983). Expectancies, values and academic behaviors. In J. T. Spence (Ed.), Achievement and achievement motives (pp. 75 146). San Francisco: W. H. Freeman.

Feltz, D. L. (1988). Self-confidence and sports performance. In K. B. Randolph (Ed.), Exercise and sport science reviews (Vol. 16, pp. 423-456). New York: Macmillan.

Feltz, D. L. (1992). Understanding motivation in sport: A self-efficacy perspective. In G. C. Roberts (Ed.), Motivation in sport and exercise (pp. 93-127). Champaign, IL: Human Kinetics.

Feltz, D. L., \& Riessinger, C. A. (1990). Effects of in vivo emotive imagery and performance feedback on self-efficacy and muscular endurance. Journal of Sport \& Exercise Psychology, 12. 132-143. 
Fitzsimmons, P. A., Landers, D. M., Thomas, J. R., \& van der Mars, H. (1991). Does self-efficacy predict performance in experienced weightlifters? Research Quarterly for Exercise and Sport, 62, 424431.

Goudas, M., Biddle, S., Fox, K., \& Underwood, M. (1995). It ain't what you do, it's the way that you do it! Teaching style affects children's motivation in track and field lessons. The Sport Psychologist, 9, 254-264.

Harter, S. (1978). Effectance motivation reconsidered: Toward a developmental model. Human Development, 21, 34-64.

Harter, S. (1981). The development of competence motivation in the mastery of cognitive and physical skills: Is there still a place for joy? In G. C. Roberts \& D. M. Landers (Eds.), Psychology of motor behavior and sport-1980 (pp. 3-29). Champaign, IL: Human Kinetics.

Horn, T. S. (1985). Coaches' feedback and changes in children's perceptions of their physical competence. Journal of Educational Psychology. 77.174186. Holt \& Co.

James, W. (1890). The principles of psychology (Vol 1). New York: Henry

Keh, N. C. (1992). Students' use of teacher feedback during badminton instruction. Unpublished doctoral dissertation, Louisiana State University, Baton Rouge.

Lee, A. M. (1996, April). Contributions of Research on Student Thinking in Physical Education. Paper presented at the annual meeting of the American Educational Research Association, New York.

Lee, A. M., Keh, N. C., \& Magill, R. A. (1993). Instructional effects of teacher feedback in physical education. Joumal of Teaching in Physical Education. 12. 228-243.

Lee, A. M., \& Solmon, M. A. (1992). Cognitive conceptions of teaching and learning motor skills. Quest. 44, 57-71.

Lepper, M. R. (1983). Extrinsic reward and intrinsic motivation: Implications for the classroom. In J. M. Levine \& M. C. Wang (Eds.), Teacher and student perceptions: Implications for learning (pp. 281-317). Hillsdale, NJ: Lawrence Erlbaum Associates, Inc.

Maehr, M. L \& Midgley, C. (1991). Enhancing student motivation: A schoolwide approach. Educational Psychologist, 26, 399-427.

Maehr, M. L. \& Nicholls, J. G. (1980). Culture and achievement motivation: A second look. In N. Warren (Ed.), Studies in cross-cultural psychology (pp. 221 267). New York: Academic Press.

Magill, R. (1993). Augmented feedback in skill acquisition. In R. N. Singer, M. Murphey, \& L. K. Tennant (Eds.), Handbook of research on sport psychology (pp. 193-212). New York: Macmillan. 
Nicholls, J. G. (1976). Effort is virtuous, but it's better to have ability: Evaluative reponses to perceptions of effort and ability. Journal of Research in Personality. 10, 306-315.

Nicholls, J. G. (1984a). Achievement motivation: Conceptions of ability, subjective experience, task choice and performance. Psychological Review. 91, 328-346.

Nicholls, J. G. (1984b). Conceptions of ability and achievement motivation. In R. Ames \& C. Ames (Eds.), Research on motivation in education: Student motivation (Vol. 1, pp. 39-73). New York: Academic Press.

Pajares, F. (1996). Self-efficacy beliefs in academic settings. Review of Educational Research. 66, 543-578.

Papaioannou, A. (1995). Motivation and goal perspectives in children's physical education. In S. J. H. Biddle (Ed.), European perspectives on exercise and sport psychology (pp. 245-269). Champaign, IL: Human Kinetics.

Pintrich, P. R. (1988). A process-oriented view of student motivation and cognition. In J. S. Stark \& L. A. Mets (Eds.), Improving teaching and learning through research (pp.65-79). New Directions for Institutional Research, no. 57. San Francisco: Jossey-Bass.

Prawat, R. S. (1992). Teachers' beliefs about teaching and learning: A constructivist perspective. American Journal of Education. 100, 354-395.

Roberts, G. C. (1984). Achievement motivation in children's sport. In J. G. Nicholls (Ed.), Advances in motivation and achievement: Vol. 3. The development of achievement and motivation (pp. 251-281). Greenwich, CT: JAI Press

Roberts, G. C. (1992). Motivation in sport and exercise: Conceptual constraints and convergence. In. G. C. Roberts (Ed.), Motivation in sport and exercise (pp. 3-29). Champaign, IL: Human Kinetics.

Schunk, D. H. (1982). Effects of effort attributional feedback on children's perceived self-efficacy and achievement. Journal of Educational Psychologv. 74 , 548-556.

Schunk, D. H. (1983). Ability versus effort attributional feedback: Differential effects on self-efficacy and achievement. Joumal of Educational Psychology, 75, 848-856.

Schunk, D. H. (1989a). Self-efficacy and achievement behaviors. Educational Psychology Review, 1. 173-208.

Schunk, D. H. (1989b). Self-efficacy and cognitive skill learning. In C. Ames \& R. Ames (Eds.), Research on motivation in education: Vol. 3. Goals and cognitions (pp. 13-44). San Diego: Academic.

Schunk, D. H. (1991). Self-efficacy and academic motivation. Educational Psychologist. 26 (3\& 4), 207-231. 
Shulman, L. S. (1987). Knowledge and teaching: Foundations of the new reform. Harvard Educational Review, 57, 1-22.

Silverman, S., Tyson, L. A., \& Krampitz, J. (1992). Teacher feedback and achievement in physical education: Interaction with student practice. Teaching and Teacher Education. 8. 333-334.

Solmon, M. A. (1991). Student thought processes and quality of practice during motor skill instruction. Unpublished doctoral dissertation, Louisiana State University, Baton Rouge.

Solmon, M. A., \& Boone, J. (1993). The impact of student goal orientation in physical education classes. Research Quarterly for Exercise and Sport, 64, 418 424.

Solmon, M. A., \& Lee, A. M. (1996). Entry characteristics, practice variables, and cognition: Student mediation of instruction. Joumal of Teaching in Physical Education, 15, 136-150.

Treasure, D. C., \& Roberts, G. C. (1995). Applications of achievement goal theory to physical education: Implications for enhancing motivation. Quest. 47. 475-489.

Veal M. L., \& Compagnone, N. (1995). How sixth graders perceive effort and skill. Journal of Teaching in Physical Education. 14, 431-444.

Weiss, M. R. (1987). Self-esteem and achievement in children's sport and physical activity. In D. Gould \& M. R. Weiss (Eds.), Advances in pediatric sport sciences (pp.87-119). Champaign, IL: Human Kinetics.

Weiss, M. R. (1993). Children's participation in physical activity: Are we having fun yet? Pediatric Exercise Science, 6, 205-209.

Wigfield, A., Harold, R., Eccles, J. S., Aberback, A., Freedman-Doan, K, \& Yoon, K. S. (1990, April). Children's ability perceptions and values during the elementary school years. Paper presented at the annual meeting of the American Educational Research Association, Boston, MA.

Wilkes, R. L., \& Summers, J. J. (1984). Cognitions, mediating variables, and strength performance. Joumal of Sport Psychology. 56, 407-415.

Winne. P. H. (1991). Motivation and teaching. In H. Waxman \& H. Walberg (Eds.), Effective teaching: Current research (pp.295-314). Berkeley, CA: McCutchen Publishing.

Xiang, P. (1995). Determinants of students' achievement-related cognitions and behaviors: A goal perspective theory approach. Unpublished manuscript, Louisiana State University at Baton Rouge. 
APPENDIX A

EXTENDED REVIEW OF LITERATURE 


\section{SELF-PERCEPTIONS OF ABILITY: DETERMINATES, EFFECTS, AND INTERVENTION STRATEGIES}

Increased concerns about the state of education in America coupled with a growing acceptance of a constructivist perspective to learning should serve to augment motivational research efforts. If students are no longer viewed as passive vessels to be filled with knowledge, but rather as active participants filtering present and past knowledge through their own unique lenses, then learning contexts must center on students' efforts for understanding. Such a scenario highlights student expectancies, values and the whole range of motivational thoughts and beliefs related to persistence in learning situations. A review of the literature reveals numerous motivational theories which seek to explain achievement behaviors such as effort, persistence, attention, choices, and performance. The insight gained through a better understanding of these theories might provide pathways for the development of effective interventions in motivation and thus ultimately in student learning. While no single motivational theory exists to explain all achievement behaviors, much has been learned about the cognitions which impact and enhance achievement behavior (Pintrich, 1988; Prawat, 1992; Roberts, 1992; Winne, 1991).

In general motivational theories incorporate an explanation of the energization, direction, and regulation of behavior (Deci \& Ryan, 1985; Ford. 1992). Energization refers to either innate needs such as food, shelter, and love or socially constructed needs such as a need to demonstrate ability. Energization behaviors provide the impetus which can fire people up or tum them off. Understanding direction behaviors involves the study of the processes and structures utilized to satisfy needs and as such indicate which way people are headed and what they are trying to accomplish. The third psychological factor, regulation. involves achievement behaviors associated with sustaining or terminating goal directed activities. For example, a need to demonstrate superior ability may illicit behaviors 
such as persistence and intense concentration which often produce successful outcomes. Typically classification as a motivational theory requires at least energization and direction (Deci \& Ryan, 1985) if not all three (Ford, 1992). Thus an achievement behavior such as goal setting which indicates direction, but lacks impetus is not viewed as a theory. Achievement behavior is differentiated from other types of behavior by its focus which is to establish competence while avoiding a lack of competence (Maehr \& Nicholls, 1980). Motivational theories seek to provide answers to why certain behaviors occur, and are typically viewed along a descriptive continuum from mechanistic to organismic (cognitive). Mechanistic theories represent the passive human driven by psychological factors while cognitive theories, on the other end of the spectrum, present the active human capable of initiating actions (Deci \& Ryan, 1985; Ford, 1992; Roberts, 1992). The motivational theories discussed in this paper embody a cognitive framework.

A presentation of motivation in its totality would require writings of novel proportions; therefore, this paper will seek to identify and explain what appears to be a key psychological construct in achievement-related cognitions and behaviors self-perceptions of ability (Nicholls, 1984b; Treasure \& Roberts, 1995). Perceptions of ability will be presented with respect to both the antecedent and consequential aspects. Since future insight into achievement motivation facilitates practical application, this paper will also provide suggestions for interventions in physical education contexts as well as a synopsis of current research needs.

\section{Self-Perceptions of Ability: Definition}

References to self-perception of ability are pervasive in the motivational literature. This construct involves how one perceives his or her own ability or adequacy to confront a particular task or to perform role-appropriate behaviors. To adequately assess an individual's ability, two things must be considered. First, the situation must demand optimal effort. Second, the person's performance must be 
weighted according to an appropriate comparison group. Ability cannot be determined if an individual does not really try and a level of incompetence cannot be evaluated without a comparison of like others. Thus ability is generally viewed as the amount of ability one has in relation to others (Nicholls, 1990; Nicholls \& Miller, 1984; Treasure \& Roberts, 1995).

While efforts to describe this variable have produced a variety of labels, they all have primarily been grounded in William James' (1890) initial work on self which linked feelings about personal value to concrete achievements (Deci \& Ryan. 1985; Marsh, 1994; Weiss, 1987). Global constructs of self-worth, self-concept, and self-esteem have emerged from this original concept of self. Self-worth may be viewed as an umbrella term that incorporates both self-concept and levels of social support (one's relation to a social environment). Self-concept is in part a result of perceived competence or perceptions of ability, while social support may be dependent on either peer or maternal acceptance (Cramer \& Skidd, 1992; Wigfield et al, 1990). The multidimensional construct of self-concept may be discussed from a global perspective or from a more specific perspective such as physical selfconcept. Marsh (1989) and Fox (1990) suggest a hierarchical approach to constructs concerning perceived importance. They place self-esteem or global self-concept at the pinnacle of their model and allocate global physical self-concept and distinct physical self-concept at descending levels. Self-esteem involves individual assessments about one's worthiness as evidenced in verbal or behavioral attitudes (Coopersmith, 1967). The descriptive element of self-esteem ("I feel good about the presentation I made.") naturally involves a specific evaluative and affective dimension of the individual's competency.

Below self-esteem, self-concept or self-worth on the hierarchical ladder is the construct 'self-perceptions of ability' which has been operationalized as perceived competence, perceived ability, movement confidence, sport-confidence, 
self-efficacy, and self-confidence. These variations of the construct can be found in motivational models and theories such as competence motivation theory (Harter, 1981a, 1981b), attributional theory (Weiner, 1985), self-efficacy theory (Bandura, 1986, 1989), expectancy-value model of achievement choices (Eccles et al., 1983; Eccles, Barber, Updegraff, \& O'Brien, 1995), achievement goal theory (Duda, 1987, 1992; Nicholls, 1984b; Roberts \& Treasure, 1992), and cognitive evaluation theory (Deci \& Ryan, 1985). In general these theories view ability perceptions as central to understanding the more global constructs of self-worth, self-concept and self-esteem and as significant causal antecedents to various achievement related thoughts and actions (Eccles et al., 1983; Roberts, 1992; Weiss, 1987). For purposes of this paper, the generalized construct self-perceptions of ability will be used except when referring to a specific theoretical framework.

\section{Self-Perceptions of Ability: Common Characteristics}

Regardless of the theoretical foundation or the label ascribed to this concept, several common characteristics can be identified. Research has determined this construct to be domain specific, situation specific, and amenable to intervention. In sports settings, efforts to understand the development and the resultant effect of individual ability perceptions have primarily utilized a social cognitive theoretical approach which depicts motivational efforts as a dynamic process in which the absence or presence of individual strivings is mediated from an affective, cognitive, and value oriented perspective.

Domain Specific. It is generally agreed that self-perception of ability is a multidimensional concept subject to numerous social and psychological influences. The many facets of each individual's "self" led theorists from a global concept to differentiated domains and finally to specific activities or events (Feltz, 1988b; Harter, 1981b; Lirgg, 1991; Marsh, 1994; Roberts, 1992: Weiss, 1987). The Self Description Questionnaire II (Marsh, Parker, \& Barnes, 1985), a multidimensional 
instrument on self-concept, has identified and measured 11 different facets of selfconcept. A 6-point Likert Scale varying from " $1=$ false $^{n}$ to ${ }^{n} 6=$ true" measures seifconcept overall and within the school context. Scales also assess self-concept of math, verbal, and physical abilities; physical appearance, honesty, and emotional stability; and self-concepts with peers of the same and opposite sex; and finally selfconcepts in relations with parents.

Harter's (1982) competence motivation theory views the development of perceived competence as salient to general individual self-worth but it also delineates such development into specific social, cognitive and physical domains. An individual with overall high self-esteem or self-worth may have differentiated perceptions of ability from a domain perspective. He or she might have a low selfperception of ability in a cognitive domain such as math and a very high selfperception in the physical domain of a physical education class.

Feltz and Brown (1984) determined that perceived soccer competence was a better indicator of actual soccer ability than either general self-worth or perceived physical competence. Thus, despite a high self-perception of ability in the physical domain, an individual might have low self-perceptions in a specific sport like basketball, or they might perceive themselves to be adequate in basketball, but have low perceptions of their ability for a specific skill such as shooting a jump shot. Clearly understanding self-perceptions of ability can be a complex task which must focus on specific activities within a domain rather than the domain in general.

Situation Specific. The multiplicity of self-perceptions of ability can be explained in part by its amenability to different contextual environments. It is not only domain-specific, but research has revealed it to be situation-specific and alterable as well. Many factors such as age, gender, and value system serve to influence an individual's disposition to adopt a certain ability perception, and research has demonstrated that this perception once obtained can be manipulated by 
factors such as task difficulty, teaching style, and goal focus. For example, a strong self-perception of ability in a physical education tennis class may be reduced to a low self-perception of ability in a country club tennis match. Since individual perceptions may vacillate from one situation to the next and since these perceptions are subject to manipulation, an analysis of self-perceptions of ability should consider both dispositional and situational influences (Harter, 1981b; Nicholls, 1990; Treasure \& Roberts, 1995).

\section{Theoretical Framework}

Much of the current motivational research on self-perceptions of ability is drawn from theoretical frameworks utilizing a social cognitive approach. Such an approach relies on the expectancies and values that embody an individual's energization, directive and regulatory behavior patterns. In other words, social cognitive theories focus on students' thoughts about their abilities as well as their perceptions of their environment. The construct of self-perceptions of ability is seen as the "common cognitive mechanism for mediating people's motivation and behavior" (Feltz, 1988b, p. 425).

Efforts to understand motivation in the context of physical or psychomotor skill development have followed several paths. The most prolific research has been conducted by sport psychologists with athletes and youth sport participants. Their investigations of self-esteem and sport performance has relied primarily on Bandura's (1977) self-efficacy theory (Feltz, 1988b, 1992), as well as Harter's competence motivation theory (1978, 1981a, 1981b), and Maehr and Nicholl's goal perspective theory (1980).

Research efforts have been directed towards understanding the antecedents of self-perceptions of ability and the relationships between self-perceptions of ability and sports participation, and self-perceptions of ability and performance (Feltz, 1992; Roberts, 1992; Weiss, 1993). Though self-perceptions of ability are 
viewed as a primary mediator of motivation, thoughts, and behavior patterns, scant research has been conducted to substantiate this theoretical tenet (Feltz, 1992).

Other efforts to examine motivation for learning movement and sports skills have occurred in the much different environment of the physical education class. Students have less latitude in terms of their participation choices, and they generally are not privilege to the small instructor leamer ratios prevalent in most sports contexts. Motivation is consistently identified as a problem in physical education, yet little is known about what motivates students to learn (Solmon \& Lee, 1996). In education efforts to understand the role that students play in their own learning have been grounded in a cognitive mediational framework (Doyle, 1977).

\section{Self-Perceptions of Ability: Determinants}

Self-perceptions of ability are related to a myriad of factors some of which are more malleable than others. The influence of elements such as age, developmental level, gender, race, ethnicity, and culture has shown a remarkable predictability across groups. However, these somewhat preordained characteristics cannot fully explain a person's self-perceptions of ability. In fact, the assessment of one's ability is a complex process involving the collection and cognitive appraisal of information from several sources. This process of analysis does not occur in a vacuum; rather, it is related to stable elements, facilitated by skill knowledge, and tempered by other types of motivational knowledge such as attributions, incentives, outcomes, and utility (Bandura, 1977, 1986; Eccles et al., 1983; Feltz, 1992; Harter, 1974, 1981a; Maehr \& Nicholls, 1980; Wigfield et al., 1990)

Predetermined predictors. The predetermined predictors of self-perceptions of ability refer to those conditions such as age, developmental level, gender, race, ethnicity, and culture which at an initial level may determined by destiny rather than by disposition or direction. A student can do very little about their age or the fact that they are White or Black or male or female or Japanese or American, and as such 
they are inherently influenced by the physiological characteristics as well as the stereotypical depictions of their grouping. At this initial level there is a certain predictability about a specific group as a whole. When studying the individuals within a certain group, predictability is considerably less definitive. From a teaching perspective, it is important to understand the characterizations that define a child's identity within a specific group. It is only from this point, that a teacher can move effectively towards understanding each student as an individual.

Age and developmental level. Several researchers concur that an individual's self-perception of ability is developmental in nature and thus will change over time (Duda, 1987; Harter, 1982; Lee, Carter, \& Xiang, 1995; Nicholls \& Miller, 1984; Weiss, 1987). The development of the concept of ability may be best explained as a process of differentiation. Across developmental levels student understanding of ability can be traced from a general belief concept to one that encompasses many distinct beliefs. Students progress from acceptance of selfperception of ability as a single construct to a differentiated understanding of ability perceptions so that, by age eight, they can delineate general feelings of competence into each of the following four domains: general self-worth, social, cognitive and physical (Harter, 1982).

The notion of a developmentally influenced self-perception of ability is extended by goal perspective theory (Nicholls, 1984b, 1989). It suggests the existence of not one, but two different conceptions of ability. Initially young children are driven to demonstrate learning or improvement. The goal, to demonstrate perceived mastery, is seen as the amount of effort extended. Successful students are assumed to have tried hard and therefore have ability, while unsuccessful students are assumed to not have tried hard enough and therefore lack ability. By age 12 , children realize that ability is relative to the performance of others, and the focus is on self in comparison to others. This normative conception 
of ability establishes ability as capacity and allows students to differentiate luck, task difficulty, effort from ability. Success and failure may be attributed to one or more of these factors (Nicholls \& Miller, 1984). Likewise, expectancy-value theory suggests that elementary students can distinguish between perceptions of ability and task value, but that the understanding of ability remains a fuzzily defined concept incorporating beliefs about ability, success expectations, and task difficulty that cannot be differentiated (Wigfield et al., 1990). Though maturity may provide a differentiated conception of ability, usage will depend on an individual's personal beliefs, values, goals, and goal orientations in a given situation (Nicholls, 1990; Nicholls \& Miller, 1984; Treasure \& Roberts, 1995). Clearly the study and reporting of research relating to self-perceptions of ability must begin with an understanding of the conception of ability that is being utilized by the subject.

Differences in how children understand ability might explain the general decline of ability perceptions through the elementary years until age 12 when they begin to more accurately reflect actual abilities (Eccles \& Wigfield, 1985; Lee, Hall, \& Carter, 1983; Nicholls \& Miller, 1984). In contrast to actual performance and teacher evaluation, young children tend to exhibit an overly optimistic view of their abilities. For example, girls in first and third grade physical education classes were found to have higher perceptions of their ability than did their instructors (Belcher, Fredenburg, \& Lee, 1996). Other studies (Stipek, 1984; Weiss \& Horn, 1990) found little agreement between the self-evaluations of primary school children and their actual performance. By age 12 this gap between actual and perceived ability narrows considerably (Eccles \& Wigfield, 1985; Nicholls \& Miller, 1984).

Developmental changes are also evident in the sources of information that a student uses to determine his or her level of ability. Horn and Hasbrook (1986) found that 8 to 11 year olds rely more on parental feedback as a measure of their ability while 12 to 14 year olds assess ability based on peer feedback. Younger 
children are also more inclined than older ones to assess their ability on the basis of performance outcomes. Thus a young child's ability perceptions are likely to be enhanced when their team wins, while a win for an older child may only enhance their self-perceptions if they feel they personally contributed to the success. This indicates developmental disparity in the way in which children assess qualitative and quantitative performance dimensions (Weiss, 1987).

Competence motivation theory (Harter 1981a) proposes that young children possess an inherent drive to demonstrate mastery. When their activity results in perceived competence or success or mastery then accompanying intrinsic satisfaction serves to facilitate future strivings. In an attempt to determine the catalyst behind children's motivation for classroom learning, Harter (1981b) developed a scale for measuring intrinsic motivation in young students. This selfreport scale seeks to differentiate between motivation internally driven by a desire to learn, to master, to answer a challenge, to exhibit independence, or to satisfy innate curiosity, and motivation externally stimulated by a desire to please a teacher, to get a good grade, to find the easiest path, or to get help. Changes across grades in the challenge, curiosity and mastery areas indicate that third graders began with a viable intrinsic mastery motivation which is somehow stifled by ninth grade. Conversely young students exhibit an extrinsic reliance on the teacher judgments about success and competence which develops into an intrinsic or autonomous judgment by ninth grade. It should be noted that a shift from intrinsic to extrinsic or from extrinsic to intrinsic motivation may also be influenced by environmental determinates such as teaching styles, or transitions to new schools. Obviously self-perceptions of ability are determined in part by the developmental level and/or age of the student.

Gender. Bem (1981) suggests that gender schema, a cognitive structure that drives perception, determines how a child analyzes his or her ability. Socialization or social leaming often produces stereotypical expectations which may be sex-typed 
or gender-typed. A society's propensity to ascribe roles and to describe experiences in light of a person's sex often results in individuals defining their self-concept in terms of their gender. Thus if society or a significant other stereotypes females as less competent than males, and if females accept these gender-role perceptions and intemalize them into their own self-perceptions then they may feel less confident (Bem, 1981; Meece \& Courtney, 1992). Research does indicate variances in gender perceptions of academic abilities even before school matriculation, and in math and science, such perceptions appear to be maintained across the school years (Meece \& Courtney, 1992). In a physical education or sport context, elementary males have higher ability perceptions than females (Clifton \& Gill, 1994: Gill, 1992; Wigfield et al., 1990; Williams \& Gill, 1995), and similar findings have been extended to adults in the 45-65 age range (McAuley, Duncan, Wraith, \& Lettunich, 1991). Not only do girls report lower ability perceptions, but they also reveal lower expectations for success than their male counterparts, even when faced with equitable past performances (Eccles et al., 1983).

Gender differences may not be so readily evident when comparisons are framed in less general terms. Though the research of Wigfield and his colleagues (1990) did substantiate overall higher perceptions of males over females, it also revealed higher ability perceptions for females in the specific area of tumbling. This does suggest that gender-differentiated perceptions are subject to situational variables, and as such, must be explored within a specific domain or in the context of a specific activity (Clifton \& Gill, 1994; Lenney, 1977; Wigfield et al., 1990). In fact, gender differences appear most salient in activities labeled as gender specific or gender appropriate. Various studies have determined that people perceive football. boxing, wrestling. weight lifting, rugby, shot put. pole vault, discus. baseball, javelin, basketball, soccer, mountaineering and ice hockey to be masculine tasks; ballet, jump rope, gymnastics, cheerleading, field hockey, ice skating, dance. 
and yoga to be feminine tasks; and tennis, swimming, jogging, diving, roller skating, volleyball, downhill skiing, and softball as neutral tasks (Csizma, Witting, \& Schurr, 1988; Fredenburg, Belcher, \& Prevost, 1995; Sanguinett, Lee, \& Nelson, 1985). Predictably, females report low success predictions in activities determined to be appropriate for males (Corbin \& Nix, 1979; Lee, Belcher, Fredenburg, \& Cleveland, 1996; Lirgg, 1991; Meece \& Courtney, 1992; Sanguinetti et al., 1985). However, differentiated gender perceptions of ability are less evident when the task in question is classified as gender-neutral, and they are minimal in studies involving gender-appropriate tasks (Clifton \& Gill, 1994; Lee et al., 1996; Sanguinetti et al., 1985). Regardless of the task classification, males characteristically overestimate their abilities more than females (Bombolt, Goodnow, \& Cooney, 1994; Lee, Nelson, \& Nelson, 1988).

When success is achieved, attributional causality differs across gender with giris being more apt to attribute failure to a lack of ability and success to something other than high ability (Frey \& Ruble, 1987; Meece \& Courtney, 1992). Likewise, in the athletic arena, young, inexperienced males use ability and effort to explain their success, while females attribute success to unstable factors such as luck or social support. However attributional causality is not differentiated by gender when athletes are experienced (Hendy \& Boyer, 1993).

Socialization into "appropriate" roles and behaviors provides a direct and indirect influence on what a student values. Thus males and females typically value activities differently. The more persuaded a student is to accept the notion of gender appropriateness, the more inclined they will be to value activities deemed acceptable and appropriate for their gender (Meece \& Courtney, 1992). It is anticipated that an increase in exposure to stereotypes will result in increased gender differentiations (Bornholt et al., 1994). Conversely, such differences may be minimized by teacher's expectations and interaction patterns. In fact, when exposed to a neutral 
environment, changes over time in self-perceptions of ability show no gender differences (Meece \& Courtney, 1992).

While self-perception of ability has been recognized as a valuable determinant in achievement patterns, research concerning competence by gender is not without problems. It has been suggested that sex-typing is influenced by beliefs and practices of significant others (Eccles et al., 1983; Pellet \& Ignico, 1993), the gender who is the most active participant (Cizma et al., 1988), the population, the gender, and the grade level or age of the participant (Fredenburg et al., 1995; Lee et al., 1996). The reporting of gender related research would be incomplete or misleading without reference to the context in which the research was framed or to the description of the sources of information. For example, studies on cheerleading found that college students rate this activity feminine, but actual college cheerleaders, both male and female, rate it as a neutral activity (Clifton \& Gill, 1994). A study (Fredenburg et al., 1995) of 581 first, third and fifth grade girls and boys found jogging to be perceived as a masculine activity by boys, and a gender neutral activity by giris, while rollerskating was perceived as gender neutral by boys and feminine by girls. Interestingly, first graders identified softball and jump rope as more gender neutral than their older counterparts. Apparently as children grow older these two activities become more gender appropriate for females. Many studies have simply used masculine appropriate tasks; others have failed to have participants sex-type activities prior to analyzing ability perceptions; and one study identified levels of ability based on a child's comparison of their ability to the most confident athlete they knew (Clifton, 1992). When analyzing self-perceptions it is belpful to view stereotypes as flexible ideas that vary across subjects and disciplines. A sex-typing bias for males in mathematics and science does not necessarily indicate the same type of bias and resulting achievement perceptions in 
physical education nor will such a bias hold true for all populations (Meece \& Courtney, 1992).

Race, ethnicity, and culture. The extent to which race, ethnicity, and culture effects an individual's self-perception of ability remains evasive. It is evident that the cultural context in which attitudes, values, and self-schemas are shaped impacts eventual opportunities, achievements and choices to an extent that cannot be ignored (Harrison, 1994; Tannehill \& Zakrajsek, 1993; Xiang, 1995). Research in math and reading have revealed cultural variances in attitude, ability perceptions, and causal attributions (Lee, Ichikawa, \& Stevenson, 1987). In contrast to American practices, the Japanese place more emphasis on the role of effort and less on the role of ability as mediators of achievement. Japanese homes and schools promote a task orientation which stresses mastery and learning as an end in itself rather than an ego orientation which stresses the individual rather than the material to be learned (Holloway, 1988).

In a motor skill study of 7, 9, and 11 year olds, Lee, Hall, and Carter (1983) reported higher male success expectations and subsequent higher performances on a neutral task than the same age females. These differences were attributed primarily to American sociocultural expectations rather than anatomical or physiological variances. Gender differences in adults' exercise perceptions have also been attributed to cultural constraints rather than to biological differences. Findings that adult women revealed lower expectancies for success and less belief in their own physical abilities than adult males was explained by the lack of exercise encouragement for females in their youth (Godin \& Shephard, 1985). Cross-cultural studies in physical activity vary in their explanations of cultural differences. The African American males in Duda's study (1986) found sport success through skill mastery while the African American males in Tannehill and Zakrajsek's study (1993) related losing or a poor performance is their dislike for physical education 
and winning to their enjoyment of physical education. An adequate understanding of self-perceptions of ability dictates an awareness of the cultural differences manifested in students efforts, attitudes, values and behaviors. Informed sensitivity to the cultural experiences of students is a must in effective curriculum planning and teacher interactions with students (Tannehill \& Zakrajsek, 1993).

Cognitive Appraisal. While social cognitive theories all identify events or people that impact self-perceptions of ability or expeciancies for success, Bandura (1989) has perhaps most succinctly identified the general sources of information which influence how students judge their ability or efficacy for a particular task. These four information sources include: (a) prior performance accomplishments. (b) vicarious experiences, (c) forms of persuasion, (d) and physiological indicators (Bandura, 1989; Chase \& Feltz, 1995; Feltz, 1992). Rather than explaining how a variable such as ability influences effort, social cognitive research has focused on understanding how students interpret their ability, their situation, their goals, and their values (Lee, 1996). The linkage between information sources and selfperception of ability is subject to the cognitive appraisal of the participant (Schunk, 1991).

Performance accomplishments. Performance accomplishments have the most direct influence on the development of an individual's self-perception of ability (Ames, 1987; Feltz, 1988b). The success or failure of past performances is a key mediator of self-perceptions of ability. If experiences are perceived as successful, then ability perceptions are enhanced. Conversely perceived failures, especially repeated failures, serve to lower ability perceptions (Feltz, 1992; Walling \& Martinek, 1995). The relationship between past experiences and self-perceptions of ability is tempered by perceptions about the difficulty of the task, the amount of effort expended, the need for guidance or performance aids, and the frequency of early failure experiences. Enhancement of self-perceptions is more likely when 
success is accomplished on an optimally challenging task, with little help from others and with minimal failure experiences during initial learning (Feltz, 1988b, 1992; Harter, 1974).

Perhaps true understanding of this information source of efficacy development requires an answer to the question, "What is success?". For example, in the sport of basketball does success constitute being on a winning team, scoring the most points, scoring a point, achieving a personal best, getting off the bench, not quitting, not embarrassing oneself, pleasing a significant other, not getting a foul. not fouling out, or fouling out? Obviously when a student's evaluation of performance accomplishment is viewed from a constructivist perspective, the possibilities are numerous. Students construct their own feelings of success in reaction to their perceptions of their ability, the climate, the task goal, the opinions of others, and in the context of their own values, beliefs and socialization experiences.

Weiner's attributional theory (1985) describes success in light of causality. He suggests that attributions, perceptions about the reasons or causes for an occurrence. are the critical mediators of motivation. Causal attribution or how an individual explains the causes for their past successes or failures influences future achievement expectations and achievement beliefs and actions. Thus positive selfesteem is derived when one can attribute success to one's own actions and deny blame for failures or both. For example, a student who attributes past successes to high ability may be expected to project higher motivation and higher achievement expectations than a student who attributes past successes to elements beyond their control such as low ability or luck. When success is attributed to effort, and lack of success is attributed to a lack of effort, ability perceptions are maintained or enhanced. While this interaction between effort attributions and positive selfperceptions of ability is supported by both attributional and self-efficacy theories of 
motivation, controversy remains as to which element of the relationship actually drives the resultant behavior. McAuley (1985) found that gymnasts' perceptions about the causes of their performance directly influenced their perceptions about success. Self-efficacy proponents argue that positive perceptions, not attributional causalities, direct effortful behaviors which in turn facilitate skill development, successful experiences, and further enhancement of self-perceptions of ability (Ames, 1987).

The motivational climate established by a teacher, coach or significant other also serves to determine the criterion by which success is measured. Even in a competitive situation improvement or getting better can be stressed as the measure of success, and students willing to exert effort should maintain or enhance their selfperceptions of ability. If students perceive the goal of the class to be competitive in nature and their ability to be high, then appropriate behaviors and eventual success might be expected. If, however, the goal or climate is perceived as competitive while ability is perceived as low, then inappropriate behavior might be expected followed by fewer success experiences and diminished self-perceptions of ability (Roberts, 1992; Theeboom, DeKnop, \& Weiss, 1995).

Persnasion elements. A student's self-perceptions of ability can also be influenced through realistic persuasive elements provided by significant others. individual cognitive strategies, self-perceptions of autonomy, and personal goal theory. Though the influence from this source of information is not perceived to be as strong as the influence achieved from performance accomplishments (Feltz, 1992), it should vary across developmental levels and possibly gender and cultural identities. As previously mentioned, young children might be more inclined to internalize parental feedback than performance outcomes, girls might be less receptive to suggestions that they are capable, and according to a study by Harrison 
(1994), young Black males might be more inclined than other students to believe positive feedback about their basketball abilities.

Students' ability perceptions may be enhanced through the persuasive techniques of significant others such as parents, teachers, coaches, peers. and friends. The impact of these techniques which may include verbal and nonverbal feedback, and performance deception are varied across activities and performance outcomes (Feltz, 1992). Harter (1978) contends that positive reinforcement and the communication of approval of mastery strivings facilitate the development of intrinsic motivation and enhanced perceptions of competence. Furthermore, the absence of such feedback and approval may create a need for extrinsic motivation and a sense of insufficient competence. Evaluations that stress the product rather than the process may lead to self-perceptions commensurate with the performance outcomes.

Parents have a stronger impact on students' ability perceptions than any objective, academic performance measure (Meece \& Courtney, 1992). Reinforcement by a significant adult in a physical environment has also proven salient to students' perceptions of ability and self-worth (Weiss, 1987). It is also possible that the significant other providing the basis for physical competence might also provide the vehicle for judging the importance of physical competence (Ebbeck \& Stuart, 1993). In fact Brustad (1993) found that adult encouragement along with their own enjoyment of sports created a student's attraction to physical activity indirectly through its effects on a child's perceptions of competence.

Even studies in exercise rehabilitation have verified a relationship between spoirsal support and the ability perceptions of cardiac patients (McAuley, 1992). However, the impact of a significant other may only extend as far as their credibility and believability (Feltz, 1992). 
There are several psychological techniques such as goal setting. imagery, and self-talk that can be used to improve individual performance. Both short and long-term goal setting can provide a powerful influence on behavior. Goals become the standard by which success and failure are measured, and they confirm failure or indicate success. It is unclear whether ability levels influence goal setting effectiveness or whether goal setting differentiates ability perceptions. Goal setting may cause undue failure worries for low ability students, and goals set beyond ability limits can negatively influence ability perceptions (Burton, 1993). Newsham (as cited in Duda, 1992) found goal setting that directs students to judge physical competence in light of personal performance goals, rather than performance outcomes, can significantly increase perceptions of ability in physical education settings. Imagery has proven to increase self-perceptions of ability but the effects were short-lived when confounded with performance failure (Feltz \& Riessinger. 1990). Though only limited study has been conducted on the role of cognitive strategies as a persuasion influence on ability perceptions, results so far indicate people typically make ability assessments in light of their personal experiences or in comparison to others (Feltz. 1992).

The construct of perceived control is also a persuasive source of information which impacts students' self-perceptions of ability, understandings of intrinsic motivation, and understandings of their successes or failures. It has been argued that ability perceptions will not be enhanced unless students feel responsible for their performance outcomes (Deci \& Ryan, 1985; Harter, 1981a, 1981b; Walling \& Martinek, 1995). When students perceive little relationship between their actions and the resulting outcome, when they are confused about who is responsible, or when they credit powerful others for their success, there is a resultant negative or diminished sense of competence (Feltz, 1988b). This perception of control will vary across developmental lines. Typically young children are unable to recognize the 
causes for their performance outcomes. In time, they begin to view outcome in relation to their own effort or ability, or to extemal factors such as luck or task difficulty. This understanding of personal control is augmented by the feedback of significant others as well as the student's own goal orientation (Weiss, 1987).

A student's goal orientation or motivation orientation is a source of powerful persuasion which can have direct bearing on his or her self-perceptions of ability. Goal orientation theory has provided a framework for understanding much of the motivational research concerning students' perceptions about their behavior in achievement contexts. This theory, which assimilates several constructs addressed in other motivational approaches, examines achievement behaviors both from a cognitive and an affective perspective. It focuses on student's beliefs about why they are engaging in particular activities and suggests that a student's perceptions and beliefs, which may be reflective of gender, culture, and developmental level. will serve to frame subsequent ability perceptions and performance evaluations. Viewing self-perceptions of ability in light of a goal orientation approach, highlights the importance of knowing how perceptions are constructed. The choice of a specific conception of ability (undifferentiated or differentiated) indicates a personal theory concerning achievement which is driven by either of two perspectives which may be referred to as ego and task (Duda, Olson, \& Templin, 1991) or a mastery and performance (Ames \& Archer, 1988), or performance and learning (Eliott \& Dweck, 1988). Simply stated, individuals can demonstrate their competence via an ego or a task orientation, and such an orientation within a distinct achievement context directs one's focus and subsequent success mediation (Duda. 1992; Nicholls, 1989; Papaioannou, 1995; Treasure \& Roberts, 1995; Weinberg, 1992). Success to the task oriented student involves mastery of a skill, self-improvement, or leaming. The higher effort solicited by this goal orientation is self-referenced and often results in the utilization of a less differentiated concept of ability. In contrast. 
success to the ego oriented student involves social comparisons which result in winning, or being the best. Higher effort which indicates less ability elicits a more differentiated conception of ability. Thus a task orientation is more apt to enhance self-perceptions of ability, while for most, an ego orientation is more likely to negatively impact self-perceptions of ability (Nicholls, 1984b). While students can exhibit both high-task and high-ego orientation at the same time, high-task orientation may the more salient construct in terms of perceptions of ability and perceptions of control. Regardless of high or low ego orientation, high-task oriented students with positive perceptions of ability have reported strong perceptions of effort.

Phrsiological and emotional states. A third source of information influencing ability perceptions involves what Bandura (1977) termed physiological states. Bandura (1989) suggested that physiological arousal as evidenced by increased heart rate, respiration rate, sweating, or nausea leads to cognitive appraisals which influenced ability perceptions and resultant behaviors and performances. Thus physiological indicators in the face of challenges produce emotions such as fear, anger, and excitement which are then interpreted from the individual's frame of reference. Arousal may be interpreted as fear which can lower perceptions of ability. Fear anxiety that is placated by relaxation techniques or verbal persuasion can serve to increase ability perceptions while arousal which creates a "psyched" or "pumped" feelings may be interpreted as an enhancer to ability perceptions. Physiological states may result from, or be confounded by, fitness, fatigue, and pain conditions.

While the relationship between physiological state and self-perception of ability is less clearly established than the first two sources (Feltz, 1988b), there is some empirical evidence of such a relationship (Feltz, 1992; Hackfort \& Schwenkmezger, 1993; Weiss, 1987). In Brustad and Weiss's study (1987) 
concerning competitive trait anxiety (CTA or the perception of competition as threatening) in athletes, boys with high CTA were found to have lower self-esteem levels and greater incidence of worry than their low CTA counterparts. However, correlates between CTA levels and specific baseball competence were hard to establish without a specific skill component analysis. The lack of correlation for girls' CTA and competence or worry levels was attributed to socialization practices. According to Brustad and Weiss (1987), society's devaluing of the importance of female success in physical activity creates greater inconsistencies in female affect responses. Males are socialized to value sport success and so as a group respond in a more predictable manner.

Harter (1981a) has identified a link between competence and the capability to learn skills and to experience emotional enjoyment. Her suggestion to legitimize the construct of joy is echoed by Nicholl's (1990) and Weiss's (1993) call for a renewed focus on value, satisfaction, and meaningfulness. This positive affective element is not as well understood as the element of anxiety, but enjoyment research is becoming more evident (Weiss, 1987). It does appear that perceptions of ability contribute more as a source of enjoyment than the reverse. Students who feel competent appear more capable of experiencing joy in movement itself, in mastery attempts and in competitive engagement (Scanlan \& Simons, 1992). Elite skaters reported enjoyment was in part reflective of perceptions of ability produced from mastery of skating skills. Mastery achieved through persistence, effort, and work ethic increased their ability perceptions and made them enjoy their practice experiences (Scanlan, Stein, \& Ravizza, 1989). This is perhaps logical because while both anxiety and enjoyment demonstrate the role of affect, the former generally occurs before and during performance while the latter occurs during and after performance. The limited empirical research in sport activities focuses primarily on anxiety reduction (Hackfort \& Schwenkmezger, 1993) while the 
limited enjoyment research seeks to explain its significant role in motivation (Scanlan \& Simons, 1992). Obviously each experience has the potential to alter subsequent competence and affective levels.

Vicarions experiences. A fourth source of information, vicarious experiences, involves visualizing or modeling, observing others perform a task, which enhances the belief that the observer can also do the task. While this source is not as influential as performance accomplishments or persuasion elements, it can be made more salient if the model is closely aligned to the observer in age, sex and/or athletic ability (Schunk, 1988; Weiss, 1981), and if a competent model provides a skilled performance (Lirgg \& Feltz, 1991). Peer models may increase ability perceptions more effectively than teacher models, especially with "at risk" students who feel incapable of performing like their teacher (Schunk, 1988).

In general, ability perceptions will remain only as influential and as strong as the cognitions which produce them. The appraisal of information is filtered not only by developmental level, gender and culture, but also by student valuing of a particular activity (Bandura, 1977; Eccles et al., 1983; James, 1890; Nicholls, 1990; Rejeski, 1992). A student with no cognitive or psychomotor knowledge about the game of tennis, and no desire to learn the game, may give minimal attention or concern to teacher feedback, peer appraisal, modeling, past personal experiences, class goal orientation, or feelings of anxiety or enjoyment. Eccles and colleagues (1983) have suggested that a student's composite valuing of an activity can be explained by the student's perception of three components: (a) the importance of the task, (b) the utility of the task, and (c) the interest in a task. Importance includes perceptions about how success in a particular activity might serve to confirm valued personal characteristics such as femininity, competence, intelligence; or to provide a platform for obtaining friends, power, or prestige. Utility of a task involves the perception of future usefulness or need while interest relates to intrinsic needs. 
Each component while related in part to gender role perceptions and socialization influences, is driven primarily by the perception of what is valued by significant others (Eccles \& Harold, 1991). Virtually all motivational theorists suggest that self-perceptions of ability must be weighted by perceptions of value (Bandura, 1977; Eccles et al., 1983; Harter, 1981a, 1981b).

\section{Self-Perceptions of Ability: Effects}

Regardless of the label used to describe the construct, theories grounded in a social cognitive or a cognitive mediational framework explain the function of selfperceptions of ability in similar fashion (Bandura, 1986; Harter, 1978; Nicholls, 1984a; Roberts, 1992). Overall the perception of competence or ability is characterized as the most salient predictor of general self-concept (Ebbeck \& Stuart, 1993; Weiss, 1993), and the primary mediating construct in a myriad of behaviors such as choice, effort, persistence, and performance, or the lack of participation, effort, diligence, or achievement (Clifton \& Gill, 1994; Eccles et al., 1983; Feltz, 1988b; Nicholls, 1984b; Roberts, 1984, 1992).

Performance. Self-perceptions of ability have been identified as a salient factor in performance. A causal relationship between ability perceptions and performance is yet to be established, but there is evidence of a reciprocal relationship (Feltz, 1988a, 1988b). High self-perception of ability fosters adaptive behaviors which influence performance and which in turn alter ability perceptions (Bandura, 1977). A study on the back dive found unequal reciprocity between selfperceptions of ability and performance. On the first of four diving trials, selfperception of ability was the primary predictor of performance, but performance on subsequent dives was predicted by success or failure on previous attempts. Thus initially self-perceptions of ability mediated performance, but over time performance began to mediate self-perceptions of ability (Feltz, 1982). 
Adaptive Behaviors. Adaptive behaviors may include such characteristics as willingness to participate, ability to adjust, demonstration of persistence, selection of challenging tasks, help seeking, and the use of appropriate learning strategies such as self-regulated learning. Typically students demonstrate adaptive behaviors when their personal theory of achievement or goal orientation coincides with the environmental climate. Regardless of their goal disposition, students with high selfperceptions of ability in a competitive classroom, tend to exhibit adaptive behavior patterns. If their mastery disposition is stronger than the ego climate, then perceptions of ability become irrelevant. Likewise, the behavior of mastery oriented individuals in mastery environments is not dependent on ability perceptions. It is assumed that ego oriented individuals in mastery climates will operate in an adaptive manner regardless of their ability perceptions (Ames, 1992a, 1992b).

Participation. Perceptions of ability along with support from significant others, positive affect and effective skill level are seen as the salient influences on children's motivation to engage and persist in physical activities and youth sports (Weiss, 1993) and academic endeavors (Eccles et al., 1983). Klint and Weiss (1987) found a relationship between children's perceptions of ability in the physical domain and their motivation to participate in youth sports for the purpose of learning skills. This study also revealed a relationship between ability perceptions in the social domain and motivation to participate in youth sports for affiliation purposes. In addition, studies (Ames \& Archer, 1988; Elliott \& Dweck, 1988) emphasizing self-referenced perceptions of ability found students more willing to accept challenging tasks.

Effort and Persistence. In addition to being more willing to participate a student with high self-perception of ability is more likely to make full use of their practice time than students with low perceptions (Eccles et al.. 1983; Solmon \& Lee, 1996). Cardiac rehabilitation patients with strong ability beliefs are also more 
willing to participate in exercise activities and to adhere to exact exercise prescriptions than their low or high efficacious counterparts (McAuley, 1992). Students with high ability perceptions demonstrate persistence and high performance expectations (Eccles et al, 1983; Solmon \& Boone, 1993); and when the value of a mastery orientation is highlighted, higher perceived ability, persistent effort, intrinsic motivation, and positive attitude toward the activity are reported (Ames \& Archer, 1988; Elliott \& Dweck, 1988).

High perceptions of ability also appears to have social acceptance implications. Friendship patterns have been closely linked to children's physical competence levels. Thus students, especially boys, competent in physical activities valued by their peers experience greater social acceptance. It has been suggested that physical education classes which improve the skills of children with low ability perceptions might also serve to improve the social acceptance and status of each child (Evans \& Roberts, 1987).

Efiective learning strategies. High ability students in a physical education class were able to explain their motivational processes, and to note and correct their own errors (Solmon \& Lee, 1996). However, in classroom settings, the use of effective learning strategies which focus on self-regulated learning appears to be related to the personal theory of achievement which is adopted. The hypothesis that high ability students will be more cognizant of helpful learning strategies, was found to be related to their assessment of the class goal orientation. A mastery goal orientation has been shown to elicit desirable learning strategies (Ames \& Archer, 1988; Solmon \& Boone, 1993). In addition, understanding and using self-regulated leaming provides a way for students to increase their self-perceptions of ability (Ames, 1987).

Maladaptive Behaviors. Low perceptions of ability in ego oriented situations can result in maladaptive achievement behaviors. Maladaptive behaviors 
have been characterized as failure to participate, demonstration of laziness, reduced effort, inclination to quit, learned helplessness; and use of inappropriate learning strategies.

Task avoidance. Academically, students with low perceptions of their ability set less challenging standards for themselves and lower expectations for success than their positive counterparts (Phillips, 1984), and they tend to not only avoid participation, but to develop negative attitudes as well (Bandura, 1986; Lee et al., 1995). It is possible that failure to find a relationship between self-perceptions of ability and participation in sport is due to the relationship's developmental nature. Young children, whether they participate or not, tend to report high ability perceptions (Ulrich, 1987).

Poor persistence and efiort. There is a correlation between ability perceptions and time use. Low skill students were observed to spend a good portion of their physical education practice time chasing balls, waiting for a practice time, or practicing incorrectly (Solmon \& Lee, 1996). Similarly classroom students demonstrated poor persistence and a tendency to attribute positive performance results to effort rather than ability (Phillips, 1984; Solmon \& Boone, 1993). Loss of optimism occurs when students with low ability perceptions view ability as a stable trait unresponsive to change (Lee et al., 1995). Students with low self-perceptions of ability in an ego oriented environment tend to avoid challenging tasks in favor of simpler ones that facilitate a demonstration of competence. Furthermore, when participation brought negative feedback, these students demonstrated a learned helpless attitude, a willingness to attribute errors to lack of ability, a negative emotional response, and an unwillingness to persist despite their actual ability to leam (Elliott \& Dweck, 1988; Lee et al., 1988; Walling \& Martinek, 1995). In a gender study, girls who underestimated their actual ability revealed a tendency to select less challenging tasks, to report higher anxiety levels and weaker perceptions 
of internal control than girls reporting correct or overestimations of ability. For boys, underestimators had higher scores in unknown perceptions of control. They apparently did not know what forces determined the success or failure outcomes, or they chose not to reveal what they thought (Weiss \& Horn, 1990).

Absence of effective learning strategies. While low ability students may listen well and attempt learning strategies such as visualizing, they seem unable to describe motivational thoughts or to recognize or correct performance errors (Lee, Landin, \& Carter, 1992; Solmon \& Lee, 1996). Low perceptions about the ability to learn a particular task does appear to deter effective utilization of self-regulated learning practices; however, interventions which teach learning strategies can increase competence (Ames, 1987; Schunk, 1988).

\section{Self-Perceptions of Ability: Intervention Strategies}

It has been suggested that a key to establishing students' feelings of selfworth is the establishment of a school environment which maintains high selfperceptions of ability (Covington. 1984). While it might seen logical to think of self-perceptions as a natural consequence of learning, research supports the need for teachers to mediate this ability through various manipulative techniques (Bressan \& Weiss, 1982). Interventions to achieve such an environment have reported success in academic achievement (Eccles et al., 1983) and in physical education settings (Goudas, Biddle, Fox, \& Underwood, 1995). Intervention strategies might begin with an understanding of the components which classify motivational theories: energization, direction and regulation. A teacher intent on enhancing a students' self-perceptions of ability should assess their perceived competence for physical education in general and for the specific activity being taught as well as the students' perceptions of the value and importance of the particular activity. The knowledge that self-perceptions of ability can only be enhanced when students value an activity (Meece \& Courtney, 1992) coupled with specific knowledge about students' 
self-perceptions would allow a teacher some insight into the needs that drive the students in his or her class. Directions or processes that students use to satisfy their needs can be evaluated from inquires and observations about student mediation of instruction. This component might be strengthened by introducing students to effective learning strategies. Regulation which involves sustaining effort should benefit from proven intervention strategies such as challenging tasks, initial learning success, rewards, and task motivational climaie.

In education, intervention research has focused on efforts to manipulate the environment in order to better understand how goal orientations are constructed and to study how the environmental structure can influence a dispositional goal orientation (Ames, 1992a). Adaptive or maladaptive behavior patterns reflect not only students goals of action (ego or task), but also their perceptions of the motivational climate (Roberts, 1992). A synopsis of intervention strategies to further self-perceptions of ability include: (a) the development of task oriented settings, (b) the development of interesting, enjoyable experiences, (c) the development of teacher awareness through training techniques, and (d) enhancing student constructivism.

Development of Task Oriented Settings. The physical education setting is typically viewed as a competitive arena where social comparisons are common and performance outcomes are stressed. Hopefully such a picture is obsolete, but even the most ardent advocates of an individual mastery focus caution about the inherent public, competitive nature of movement activities (Duda, 1992; Solmon \& Boone, 1993; Williams \& Gill, 1995). Social comparison situations for students with low self-perceptions of ability are not conducive to adaptive achievement behaviors. One way to combat the deleterious effects of competition is to create a task involved orientation through manipulation or intervention techniques. Intervention strategies may be more effective when they are focused on the classroom setting and the 
perceived motivational climate rather than on a student's dispositional inclination to evaluate success from a ego or task perspective. The promotion of a learning environment rather than a competitive environment has motivational appeal for students with both high and low perceptions of ability. A successful method for creating a motivational climate in the classroom and in physical education settings, incorporates the acronym TARGET which refers to task, authority, reward. grouping, evaluation and timing structures (Epstein, 1989).

Tasks. Assignments or tasks, a primary element in classroom learning, provide students information that will influence their ability perceptions, their behaviors, and their feelings of satisfaction. The most effective tasks appear to be those that provide varied, individual, meaningful experiences which limit social comparison and increase interest and success (Ames, 1992b; Treasure \& Roberts, 1995). In a track and field unit, students allowed to select their own hurdle heights and to determine the rules for scoring reported higher self-perceptions of ability as well as more intrinsic motivation than students that followed direct group instructions (Goudas et al., 1995). Efforts to keep students actively involved and to eliminate situations in which one student performs in front of the rest of the class, can also serve to minimize social comparison (Walling \& Martinek, 1995).

Authority. Locus of responsibility refers to students' involvement in decision making and ultimately influences behaviors and actions. To facilitate a task climate, students need to be given choices about which tasks they will attempt. and what pace they will follow as well as responsibility for setting up equipment, filling out charts, and recording results (Ames. 1992b). Goudas and colleagues (1995) allowed their track students to select which method of baton exchange they would use as well as which level of difficulty they would attempt. In addition to promoting a task climate, the provision of situations that promote a sense of 
responsibility can help shy or learned helpless students to feel involved and in control of outcomes (Walling \& Martinek, 1995).

Rewands. Recognition in the form of rewards can be detrimental as well as positive to self-perceptions of ability. Published or announced rewards tend to promote social comparisons, while private rewards or those given for individual improvement promote mastery strivings (Treasure \& Roberts, 1995). Walling and Martinek (1995) note that learned helpless students do not accurately perceive their own improvement. A child who improved from 0 sit-ups in September to 25 sit-ups in February saw only that her classmates were doing 40 sit-ups. Teacher feedback and praise about her personal improvement was necessary to enhance her selfperceptions of ability.

Grouping. How a class is organized can foster social comparison or mastery learning. Ability grouping based on competitive scores fosters ego involvement while cooperative groups focused on group efforts can function to create group success or failure rather thar: individual success or failure.

Evalnation. Various types of evaluative methods can serve to promote different perceptions of ability. The intervention of evaluative measures which avoid normative referenced criteria allow students to move from self-perceptions based on social comparisons to self-referenced perceptions of ability (Nicholls, 1989). Self assessment, private evaluations and evaluations based on effort or improvement create task involvement (Ames, 1992b; Treasure \& Roberts, 1995).

Timing. Individualization may allow students to schedule their own activities, select their own pace, and their own alternative activities when required tasks are completed. Timing might also involve the provision of tasks that foster success during initial learning attempts (Feltz, 1988b, 1992)

Development of Enjoyable Experiences. Since enjoyment has been identified as a source influential in the development of self-perceptions of ability 
and eventual activity participation, it is important to determine what stimulates enjoyment and what barriers prevent its growth (Chase \& Feitz 1995; Weiss, 1993). It is felt that parental influence; the perceived achievement goals of student, teacher, and parents: and personal achievement goals can all influence opportunities for enjoyment. Task oriented climates produce students with significantly higher enjoyment levels than ego oriented climates (Theeboom et al., 1995). Ames (1992b) has cautioned that the provision of a task orientation must include challenging tasks, an emphasis on the value of each task, an effort to attract students' interest, and an effort to on instructing students in the setting of short-term, selfreferenced goals. Children with low self-perceptions of ability may benefit from activity experiences outside the school setting. Walling and Martinek (1995) suggest that practice at home and encouragement from parents might be the catalyst that makes a child willing to participate and free to enjoy physical education experiences.

\section{Development of Teacher Awareness Through Training Techniques.}

Teachers need to be made aware of how their beliefs and values influence student learning. Often teachers believe they are unbiased in their treatment of males and females, and are surprised when differential practices are brought to their attention (Solmon \& Carter, 1995; Wigfield \& Harold, 1992). Time set aside for teachers to observe the teaching of others and to discuss practices which reflect gender bias can increase awareness and promote effective changes (Wigfield \& Harold, 1992). Teachers encouraged to question the perceptions that students, parents, and principals have concerning the purpose of their overall program and of each individual unit may be more empowered to help their students (Graham, 1995). Teachers trained to use differential teaching styles should be more equipped to meet the needs of all students and to increase student autonomy which influences selfperceptions of ability (Goudas et al., 1995). 
Enhancing Student Constructivism. Since it is recognized that students are active participants in the learning process, teaching cognitive strategies that help students mediate the instruction they receive can increase their self-perceptions of ability and skills (Schunk, 1988; Solmon \& Lee, 1996). Training students in selfregulated learning strategies involves helping them learn how to learn and while it can be as simple as self-planning or goal setting, such interventions appear related to how students view effort in relation to their performance (Ames, 1987). Teaching students to attribute failure to lack of effort rather than lack of ability or in essence to manipulate students to operate from a mastery orientation which focuses on learning. Such attributional training has not only changed explanations for failure, but has also resulted in greater student persistence (Ames, 1987).

\section{Conclusion and Recommendations}

Self-perceptions are a critical piece in the motivation achievement puzzle, and they are irrevocably tied to students' overall self-esteem (Ebbeck \& Stuart, 1993; Duda, 1987). Ability perceptions are tied to motivation to initiate and sustain activity (Weiss, 1993), and they are precursors to the adoption of adaptive or maladaptive achievement beliefs and actions. They are also related to positive affect (Fox, 1990), and they have been identified as a strong predictor of performance (Feltz, 1988b). In the field of physical education. there is strong concern about students' participation in physical activities in both education settings and lifestyle practices. Changes in behaviors and attitudes must begin with an understanding of what makes some children willing, interested participants, and others reluctant bystanders (Goudas et al., 1995; Weiss, 1993). Clearly an understanding of the forces that generate high self-perceptions of ability, the methods for manipulating such forces, and the strategies for sustaining such perceptions can be significant steps towards developing active individuals. 
While the construct of self-perception of ability is firmly established in the motivational literature, it has been studied predominantly in academic settings and in relation to athletics and youth sports. Results from these areas are certainly important, but they do not necessarily have direct application for physical education classrooms and efforts to increase children's activity habits. Not only is there limited research specific to the physical education setting, but there is also a need to move beyond pen and pencil surveys to field based case studies and intervention strategies (Blumenfeld, 1992) that can help practicing teachers effect change. Knowledge bases should be extended beyond the identification of sources and into the discovery of how students weight and utilize their information sources (Chase \& Feltz, 1995).

Research has shown that self-perceptions of ability differ across developmental levels, but most information has been generated from primary school children, single age group studies, or from cross-sectional correlational studies. The majority of sports research utilized college activity classes, college athletes, or youth sports participants. Physical education research would benefit from developmental, life span studies which could indicate how ability perceptions change across time, and how such differences occur.

Much as been learned about differentiated gender perceptions, but little is known about the nature and magnitude of such differences across ability levels (Meece \& Courtney, 1992). Recent research has revealed that differences are minimal when male and female subjects are skilled athletes, and perhaps gender discrepancies would also be minimal in physical education settings if various social and psychological influences such as sex typing in physical education activities, teacher expectations, and interest and value beliefs were weighted into the equation. The influence of sex role stereotyping is evident in young children, and it has been shown to increase with age, but little is known about how such knowledge affects 
success expectations for children in movement activities. Results might also vary if differences were studied across specific movement experiences. Racial, ethnic and cultural differences are also evident, but physical education research is limited in this area. These differences might be minimized in a task involved physical education setting.

There is a known relationship between anxiety and arousal, but once again the research has been primarily in the academic or athletic arena. Few studies are available concerning anxiety in the physical education setting. At one level this might seem appropriate since an educational setting should be expected to foster a protective or comfortable environment; however, deeper inquiry might reveal high levels of anxiety in certain students as a result of their perceived competence, goal orientation and motivational climate perceptions. Such anxiety, with its reciprocal influence on self-perceptions of ability might better clarify why students report negative physical education experiences (Carlson, 1995).

The illusion of incompetence has been documented in numerous educational disciplines, but there is still a need to determine why students in physical education underestimate their ability. It would be interesting to determine which sources of information underestimators use. Do they vicariously identify with only low ability students, or do they pay attention to the best students and as a result feel less able by comparison (Weiss \& Hom, 1990)? Understanding students with low ability perceptions and poor performances remains sketchy. Just as Piaget focused on what children could not do, physical education researchers might more succinctly address what students with low ability perceptions cannot do and what sources influence their behaviors. Qualitative studies tracking small numbers of students in order to better understand the reasons for their behaviors are minimal. A recent case study (Walling \& Martinek, 1995) of a middle school student did provide insight into the 
learned helplessness syndrome. There is merit in additional in-depth studies to increase understanding about the causes that mediate behavior.

The element of enjoyment needs to be further explored so that children's early love of movement for movement's sake can, in some part, be maintained. As children move from individualized experiences to more socially interactive games their source of enjoyment may change from pure physical movement to more purposeful movements. Phenomenological analysis of fourth grade students in physical education found "feeling good" meant "scoring" (Wessinger, 1994). Wessinger found that while competitive games were played in physical education, scoring or performance outcomes were consciously minimized by instructors. Children, however, found pleasure in their performance outcomes. Explanations for their enjoyment included scoring a point for their team, helping their team to be successful, and personally achieving a goal such as getting to base. Weissinger (1994) suggests that if scoring makes students feel good, then the adaptation of scoring systems to include unconventional actions may promote such feelings of enjoyment. If children "score" when they throw correctly or when they catch a ball then they have many opportunities to feel good. Small teams may also create more chances to score. Additional research into how student mediate experiences might uncover additional intervention strategies.

Goal orientation is a powerful mediator of self-perceptions of ability and a vast amount of literature is available to explain this concept and to define its influence. Task involvement has been linked to perceptions of ability based on effort and to adaptive behaviors and beliefs in the face to challenging tasks. Efforts to structure motivational climates that highlight task involvement have proven effective. However, more research is needed to determine what happens to the ego oriented student when the mastery climate is not able to override his or her disposition. What results when such a student seeks to implement competition into 
the activity? It might be unrealistic to expect all physical education experiences to be void of social comparison. While there is ample justification for a mastery environment, there is also a need to better understand how to teach children to cope with the competitiveness inherent in some individuals and in many physical activities. Perhaps research efforts could better prepare teachers to preserve positive self-perceptions of ability in the face of apparent lack of competitive success. It is clear that task goals can be emphasized even in competitive situations, but students must learn how to sustain adaptive behaviors when effortful strivings fail to produce winning scores, or anticipated self-improvement.

Continuing to focus research on only ego and task achievement goal orientation may limit the complete understanding of motivation and achievement in schools (Urban \& Maehr, 1995). Clearly a social goal orientation mediates the ability perception of many students, but how and to what extent is not fully understood. Social affiliation has been documented as a reason for participation in youth sports (Weiss, 1993), but has not been studied in the physical education context. Social orientation might be a viable source of ability perceptions in physical education, and if this is true, continued efforts to provide cooperative experiences and leadership responsibilities would be valuable. However, placing students in cooperative groups does not make cooperation a salient goal to all students. Likewise providing task involved goals for students does not prevent the saliency of ego goals. Teachers must find ways to make their goals the goals of their students.

The TARGET intervention strategies provide practical application, but lack specificity. If self-perceptions of ability can be enhanced by success on optimally challenging tasks, with little help from others, and with minimal failure experiences during initial learning, then it appears that teachers can be most instrumental in shaping students' perceptions. Research might better explain how to provide 
challenging tasks for students across all levels of ability without boring those with high perceived abilities or frustrating those with low perceived abilities. Obviously the teacher that can construct individualized, multilevel tasks can come close to achieving this, but exact suggestions in physical education are just beginning to be explored. The presence of student autonomy contributes significantly to a student's sense of responsibility and to enhanced ability perceptions, but practical steps for giving students this perception of control are still limited in physical education. Often low ability students with maladaptive behaviors are labeled as discipline problems with limited self-control. How do teachers successfully release control or authority to such students without losing control themselves?

Nicholls (1989) has argued for evaluative techniques that avoid normative referenced criteria. Efforts such as the provision of self-monitored check lists have helped to do this. However, ego oriented students are sometimes prone to cheating and sloppy performance in an effort to complete the assignment. They may view the process as a means to an end rather than a process for developing mastery. Perhaps the key to this dilemma and other efforts for the establishment or enhancement of self-perceptions of ability is to find ways to increase student interest in the activity. Apparently many of the barriers to improved ability perceptions and ultimately to effective achievement behaviors can be overcome when a student values the experience. A girl who values basketball will often ignore stereotypical barriers, overcome negativism from significant others, and attend to information that can increase her skill or knowledge. Research of potential links between perceptions of ability and student values might further explain student actions during class.

Self-perceptions have been shown to be linked to influences from significant others such as teachers. In addition, there is evidence of a relationship between positive self-perceptions of ability and the absence of repeated failures during initial 
leaming (Feltz, 1988b). If early success can enhance ability perceptions, then teachers can influence change by effective structuring of the learning environment. Hebert and Solmon (1996) found a progressive task organization more successful than simplification or whole skill methodologies in three ways: (a) students experienced more practice successes, (b) students reported higher self-perceptions of ability, and (c) students experienced greater skill acquisition. While the connection between success and enhanced ability perceptions has been suggested as an effective instructional strategy (Bressan \& Weiss, 1982), more empirical evidence is needed in physical education.

Teacher feedback is another method for influencing student action. Historically, augmented feedback has been directed towards the acquisition of skill, and while the strength of this relationship is currently under debate, it is apparent that feedback is a viable part of the learning process (Magill, 1993). Feedback has also proven to be a salient source of information about children's self-perceptions of ability, particularly at a young age (Weiss, 1987). Perhaps an overlooked strength of augmented feedback is the potentiality for indirect skill acquisition via the enhancement fo students' ability perceptions. If research about the effective use of feedback was applied to the purposeful enhancement of students' ability perceptions, then the development of appropriate skills should occur over time.

Treasure and Roberts (1995) make a convincing argument for research which seeks to evaluate the variables of disposition and situation in concert rather than as two separate variables. According to Roberts (1992, p.157),"human behavior is best described as a motion picture, yet we use methods analogous to still photography to capture relevant variables for prediction." The suggestion of an integrated effort could more fully explain achievement in physical education, and it could be extended to include the integration of other variables such as 
self-perceptions of ability, goal orientation and success experiences, or ability perceptions, goal orientation and feedback influences.

\section{References}

Ames, C. (1987). The enhancement of student motivation. In M. L. Maehr, \& D. A. Kleiber (Eds.), Advances in motivation and achievement (Vol. 5, pp. 123148). Greenwich, $C N$ : Jai Press Inc.

Ames, C. (1992a). Achievement goals, motivational climate, and motivational processes. In G. C. Roberts (Ed.), Motivation in sport and exercise (pp. 161-176). Champaign, IL: Human Kinetics.

Ames, C. (1992b). Classrooms: Goals, structure, and student motivation. Journal of Educational Psychology, 84, 261-271.

Ames, C., \& Archer, J. (1988). Achievement goals in the classroom: Students' learning strategies and motivation processes, Joumal of Educational Psychology, 80, 260-267.

Bandura, A. (1977). Self-efficacy: Toward a unifying theory of behavioral change. Psychology Review, 84, 191-215.

Bandura, A. (1986). Social foundations of thought and action: A social cognitive theory. Englewood Cliffs, NJ: Prentice-Hall.

Bandura, A. (1989). Human agency in social cognitive theory. American Psychologist, 44, 1175-1184.

Belcher, D., Fredenburg, K. B., \& Lee, A.M. (1996). Comparison of students' and teachers' perceptions of students' abilities. Unpublished manuscript, Louisiana State University at Baton Rouge.

Bem, S. L. (1981). Gender schema theory: A cognitive account of sextyping. Psychological Review, 88 (4), 354-364.

Blumenfeld, P.C. (1992). Classroom learning and motivation: Clarifying and expanding goal theory. Journal of Educational Psychology, 84 (3), 272-281.

Bornholt, L. J., Goodnow, J. J., \& Cooney, G. H. (1994). Influences of gender stereotypes on adolescents' perceptions of their own achievement. American Educational Research Joumal, 31 (3), 675-692.

Bressan, E. S., \& Weiss, M. R. (1982). A theory of instruction for developing competence, self-confidence and persistence in physical education. Joumal of Teaching in Physical Education, 2(1), 38-47.

Brustad, R. (1993). Who will go out and play? Parental and psychological influences on children's attraction to physical activity. Pediatric Exercise Science. 5, 210-223. 
Brustad, R., \& Weiss, M. R. (1987). Competence perceptions and sources of worry in high, medium, and low competitive trait-anxious young athletes. Joumal of Sport Psychology, 97 97-105.

Burton, D. (1993). Goal setting in sport. In R. N. Singer, M. Murphey, \& L. K. Tennant (Eds.), Handbook of research on sport psychology (pp.467-491). New York: MacMillan Publishing Co.

Carlson, T. B. (1995). We hate gym: Student alienation from physical education. Journal of Teaching in Physical Education, 14, 467-477.

Chase, M. A., \& Feltz, D. L. (1995, September). Sources of self-efficacy in sport and physical activities for individuals across the life span. Paper presented at the meeting of the Association for the Advancement of Applied Sports Psychology, New Orleans, LA.

Clifton, R. T. (1992). Gender differences in the relationships among selfconfidence, gender appropriateness, and value. Unpublished master's thesis, University of North Carolina.

Clifton, R. T., \& Gill, D. L. (1994). Gender differences in self-confidence on a feminine-typed task. Journal of Sport \& Exercise, 16, 150-162.

W. H. Freeman.

Coopersmith, S. (1967). The antecedents of self-esteem. San Francisco:

Corbin, C. B., \& Nix, C. (1979). Sex-typing of physical activities and success predictions of children before and after cross-sex competition. Joumal of Sport Psychology, $1,43-52$.

Covington, M. V. (1984). The motive for self-worth. In R. Ames and C. Ames (Eds.), Research on motivation in education (Vol. 1, pp. 77-113). New York: Academic Press.

Cramer, P., \& Skidd, J. E. (1992). Correlates of self-worth in preschoolers: The role of gender-stereotyped styles of behavior. Sex Roles, 26, 369-390.

Csizma, K., Wittig, A. F., \& Schurr, T. (1988). Sport stereotypes and gender. Journal of Sport \& Exercise Psychology 10, 62-74.

Deci, E. L., \& Ryan, R. M. (1985). Intrinsic motivation and selfdetermination in human behavior. New York: Plenum Press.

Doyle, W. (1977). Paradigms for research on teacher effectiveness. Review of Research in Education, 5, 163-198.

Duda, J. L. (1986). Perceptions of sport success and failure among white, black and Hispanic adolescents. In J. Watkins, T. Reilly, \& L. Burwitz (Eds.), Sport Science (pp. 214-222). London: E \& F.N. Spon. 
Duda, J. L. (1987). Toward a developmental theory of children's motivation in sport. Joumal of Sport Psychology, 9, 130-145.

Duda, J. L. (1992). Motivation in sport settings: A goal perspective approach. In G. C. Roberts (Ed.), Motivation in sport and exercise (pp. 57-91). Champaign, IL: Human Kinetics.

Duda, J. L., Olson, L. K., \& Templin, T. J. (1991). The relationship of task and ego orientation to sportsmanship attitudes and the perceived legitimacy of injurious acts. Research Quarterly for Exercise and Sport, 62, 79-87.

Ebbeck, V., \& Stuart, M. (1993). Who determines what's important? Perceptions of competence and importance as predictors of self-esteem in youth football players. Pediatric Exercise Science, 5, 253-262.

Eccles, J. S. (Parsons), Adler, T. F., Futterman, R., Goff, S. B., Kaczala, C. M., Meece, J. L., \& Midgley, C. (1983). Expectancies, values and academic behaviors. In J. T. Spence (Ed.), Achievement and achievement motives (pp. 75146). San Francisco: W. H. Freeman.

Eccles, J. S., Barber, B., Updegraff, K., \& O'Brien, K. M. (1995, April). An expectancy-value model of achievement choices: The role of ability self-concepts, perceived task utility and interest in predicting activity choice and course enrollment. Paper presented at the annual meeting of the American Educational Research Association in San Francisco, CA.

Eccles, J. S., \& Harold, R. D. (1991). Gender differences in sport involvement: Applying the Eccles' expectancy-value model. Joumal of Applied Sport Psychology, 3, 7-35.

Eccles, J. S., \& Wigfield, A. (1985). Teacher expectancies and student motivation. In J. B. Dusek (Ed.), Teacher expectancies (pp. 185-226). Hillsdale, NJ: Erlbaum.

Elliott, E. S., \& Dweck, C. S. (1988). Goals: An approach to motivation and achievement. Joumal of Personality and Social Psychology, 54, 5-12.

Epstein, J. (1989). Family structures and student motivation: A developmental perspective. In C. Ames \& R. Ames (Eds.), Research on motivation in education, (Vol.3, pp. 259-295). New York: Academic Press.

Evans, J., \& Roberts, G. C. (1987). Physical competence and the development of children's peer relationships Quest, 39, 23-35.

Feltz, D. L. (1982). Path analysis of the causal elements in Bandura's theory of self-efficiacy and an anxiety-based model of avoidance behavior. Joumal Personality and Social Psychology. 42, 764-781. 
Feltz, D. L. (1988a). Gender differences in the causal elements of selfefficacy on a high avoidance motor task. Joumal of Sport and Exercise Psychology $10,151-166$.

Feltz, D. L. (1988b). Self-confidence and sports performance. In K. B. Randolph (Ed.), Exercise and sport science reviews (Vol. 16, pp. 423-456). New York: Macmillan.

Feltz, D. L. (1992). Understanding motivation in sport: A self-efficacy perspective. In G. C. Roberts (Ed.), Motivation in sport and exercise (pp. 93-127). Champaign, $\mathbb{L}$ : Human Kinetics.

Feltz, D. L., \& Brown, E. W. (1984). Perceived competence in soccer skills among young soccer players. Journal of Sport Psychology, 6, 385-394.

Feltz, D. L., \& Riessinger, C. A. (1990). Effects of in vivo emotive imagery and performance feedback on self-efficacy and muscular endurance. Joumal of Sport \& Exercise Psychology, 12, 132-143.

Ford, M. E. (1992). Motivating humans. London: Sage Publications.

Fox, K. R. (1990). The physical self-perceptions profile manual. DeKalb, IL: Northem Illinois University, Office for Health Promotion.

Fredenburg, K. B., Belcher, D., \& Prevost, M. (1995). Are physical activities sex-typed? Unpublished manuscript, Louisiana State University at Baton Rouge.

Frey, K. R., \& Ruble, D. N. (1987). What children say about classroom performance: Sex and grade differences in perceived competence. Child Development. 58, 1066-1078.

Gill, D. L. (1992). Gender and sport behavior. In T. S. Horn (Ed.), Advances in sport psychology (pp. 143-160). Champaign, IL: Human Kinetics.

Godin, G., \& Shephard, R. J. (1985). Gender differences in perceived physical self-efficacy among older individuals. Perceptual and Motor Skills, 60, 599-602.

Goudas, M., Biddle, S., Fox, K., \& Underwood, M. (1995). It ain't what you do, it's the way that you do it! Teaching style affects children's motivation in track and field lessons. The Sport Psychologist, 9, 254-264.

Graham, G. (1995). Physical education through students' eyes and in students' voices: Implications for teachers and researchers. Journal of Teaching In Physical Education, 14, 478-482.

Hackfort, D., \& Schwenkmezger, P. (1993). Anxiety. In R. N. Singer, M. Murphey, \& L. K. Tennant (Eds.), Handbook of research on sport psychology (pp.328-364). New York: MacMillan Publishing Co. 
Harrison, L. Jr. (1994). Race as a self-schema affecting physical activity choice. Unpublished manuscript., Louisiana State University at Baton Rouge.

Harter, S. (1974). Pleasure derived from cognitive challenge and mastery. Child Development, 45, 661-669.

Harter, S. (1978). Effectance motivation reconsidered: Toward a developmental model. Human Development, 21, 34-64.

Harter, S. (1981a). The development of competence motivation in the mastery of cognitive and physical skills: Is there still a place for joy? In G. C. Roberts \& D. M. Landers (Eds.), Psychology of motor behavior and sport-1980 (pp. 3-29). Champaign, IL: Human Kinetics.

Harter, S. (1981b). A model of intrinsic mastery motivation in children: Individual differences and developmental change. In W. A. Collins (Ed.), Minnesota symposium on child psychology (Vol. 14, pp. 215-255). Hillsdale, NJ: Erlbaum.

Harter, S. (1982). The perceived competence scale for children. Child Development, 53, 87-97.

Hebert, E. P., \& Solmon, M. A. (1996, April). The impact of content development strategies on student cognition, behavior and achievement in physical education. Paper presented at the annual meeting of the American Educational Research Association, New York.

Hendy, H. M., \& Boyer, B. J. (1993). Gender differences in attributions for triathlon performance. Sex Roles, 29 (7/8), 527-543.

Holloway, S. D. (1988). Concepts of ability and effort in Japan and the United states. Review of Educational Research, 58 (3), 327-345.

Horn, T. S., \& Hasbrook, C. A. (1986). Informational components influencing children's perceptions of their physical competence. In M. R. Weiss \& d. Gould (Eds.), Sport for children and youths (pp. 81-88). Champaign, IL: Human Kinetics. Holt \& Co.

James, W. (1890). The principles of psychology (Vol 1). New York: Henry

Klint, K. A., \& Weiss, M. R. (1987). Perceived competence and motives for participating in youth sports: A test of Harter's competence motivation theory. Joumal of Sport Psychology, 9, 55-65.

Lee, A. M. (1996, April). Contributions of Research on Student Thinking in Physical Education. Paper presented at the annual meeting of the American Educational REsearch Association, New York.

Lee, A. M., Belcher, D., Fredenburg, K. B., \& Cleveland, N. (1996). Gender differences in children's conceptions of competence and motivation in physical education. Unpublished manuscript, Louisiana State University at Baton Rouge. 
Lee, A. M., Carter, J., \& Xiang, P. (1995). Children's conceptions of ability in physical education. Joumal of Teaching in Physical Education, 14 (4), 384-393.

Lee, A. M., Hall, E. G., \& Carter, J. A. (1983). Age and sex differences in expectancy for success among American children. The Journal of Psychology 113, 35-39.

Lee, A. M., Landin, D.,K., \& Carter, J. A. (1992). Student thoughts during tennis instruction: Journal of Teaching in Physical Education,11, 256-267.

Lee, A. M., Nelson, K, \& Nelson, J. (1988). Success estimations and performance in children as influenced by age, gender, and task. Sex Roles, 18 (11/12), 719-726.

Lee, S., Ichikawa, V., \& Stevenson, H. W. (1987). Beliefs and achievement in mathematics and reading: A cross-cultural study of Chinese, Japanese, and American children and their mothers. In M. L. Maehr \& D. A. Kleiber (Eds.), Advances in motivation and achievement (Vol. 5, pp.149-179). Greenwich, CN: Jai Press Inc.

Lenney, E. (1977). Women's self-confidence in achievement situations. Psychoiogical Bulletin, 84 , 1-13.

Lirgg, C. D. (1991). Gender differences in self-confidence in physical activity: A meta-analysis of recent studies. Journal of Sport \& Exercise Psychology 8, 294-310.

Lirgg, C. D., \& Feltz, D. L. (1991). Teacher versus peer models revisited: Effects on motor performance. Research Quarterly for Exercise Sport. 62, 217-224.

Maehr, M. L. \& Nicholls, J. G. (1980). Culture and achievement motivation: A second look. In N. Warren (Ed.), Studies in cross-cultural psychology (pp. 221267). New York: Academic Press.

Magill, R. (1993). Augmented feedback in skill acquisition. In R. N. Singer, M. Murphey, \& L. K. Tennant (Eds.), Handbook of research on sport psychology (pp. 193-212). New York: Macmillan.

Marsh, H. W. (1989). Age and sex effects in multiple dimensions of selfconcept: Presadolescence to early adulthood. Journal of Educational Psychology,

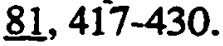

Marsh, H. W. (1994). The importance of being important: Theoretical models of relations between specific and global components of physical selfconcept. Journal of Sport \& Exercise Psychology, 16, 306-325.

Marsh, H. W., Parker, J., \& Barnes, J. (1985). Multidimensional adolescent self-concepts: Their relationship to age, sex, and academic measures. American Educational Research Journal, 22 (3), 422-444. 
McAuley, E. (1985). Success and causality in sport: The influence of perception. Journal of Sport Psychology, 7, 13-22.

McAuley, E. (1992). Understanding exercise behavior: A self-efficacy perspective. In G. C. Roberts (Ed.), Motivation in sport and exercise (pp. 107-127). Champaign, IL: Human Kinetics.

McAuley, E., Duncan, T. E., Wraith, S. C., \& Lettunich, M. (1991). Selfefficacy, perceptions of success, and intrinsic motivation. Journal of Applied Social Psychology, 21, 139-155.

Meece, J. L., \& Courtney, D. P. (1992). Gender differences in students' perceptions: Consequences for achievement-related choices. In D. H. Schunk \& J. L. Meece (Eds.), Student perceptions in the classroom (pp. 209-227). Hillsdale, NJ: Erlbaum.

Nicholls, J. G. (1984a). Achievement motivation: Conceptions of ability, subjective experience, task choice and performance. Psychological Review, 91, 328-346.

Nicholls, J. G. (1984b). Conceptions of ability and achievement motivation. In R. Ames \& C. Ames (Eds.), Research on motivation in education: Student motivation (Vol. 1, pp. 39-73). New York: Academic Press.

Nicholls, J. (1989). The competitive ethos and democratic education. Cambridge, MA: Harvard University Press.

Nicholls, J. G. (1990). What is ability and why are we mindful of it? A developmental perspective. In R. J. Slemberg \& J. Kalligan Jr. (Eds.), Competence considered (pp. 11-40). New Haven, CT: Yale University Press.

Nicholls, J. G., \& Miller, A. T. (1984). Development and its discontents: The differentiation of the concept of ability. Advances in Motivation and Achievement, 3, 185-218.

Papaioannou, A. (1995). Differential perceptual and motivational pattems when different goals are adopted. Joumal of Sport \& Exercise Psychology. 17, 18 34.

Pellett, T. L., \& Ignico, A. A. (1993). Relationship between children's and partents' stereotyping of physical activities. Perceptual and motor skills, 77, 12831289.

Phillips, D. (1984). The illusion of incompetence among academically competent children. Child Development, 55, 2000-2016.

Pintrich, P. R. (1988). A process-oriented view of student motivation and cognition. In J. S. Stark \& L. A. Mets (Eds.), Improving teaching and learning through research (pp.65-79). New Directions for Institutional Research, no. 57. San Francisco: Jossey-Bass.

Prawat, R. S. (1992). Teachers' beliefs about teaching and learning: A constructivist perspective. American Joumal of Education, 100,354395 . 
Rejeski, W. J. (1992). Motivation for exercise behavior. A critique of theoretical directions. In G. C. Roberts (Ed.), Motivation in sport and exercise (pp. 129-157). Champaign, II: Human Kinetics.

Roberts, G. C. (1984). Achievement motivation in children's sport. In J. G. Nicholls (Ed.), Advances in motivation and achievement: Vol. 3. The development of achievement and motivation (pp. 251-281). Greenwich, CT: JAI Press.

Roberts, G. C. (1992). Motivation in sport and exercise: Conceptual constraints and convergence. In G. C. Roberts (Ed.), Motivation in sport and exercise (pp. 3-29). Champaign, IL: Human Kinetics.

Roberts, G. C., \& Treasure, D. C. (1992). Children in sport. Sport Science Review, 1(2), 46-64.

Sanguinetti, C., Lee, A. M., \& Nelson, J. (1985). Reliability estimates and age and gender comparisons of expectations of success in sex-typed activities. Joumal of Sport Psychology, 7 379-388.

Scanlan, T. K., \& Simons, J. P. (1992). The construct of sport enjoyment. In G. C. Roberts (Ed.), Motivation in sport and exercise (pp. 199-215.). Champaign, II: Human Kinetics.

Scanlan, T. K., Stein, G. L., \& Ravizza, K. (1989). An in-depth study of former elite figure skaters: II. Sources of enjoyment. Joumal of Sport \& Exercise Psychology, 11, 65-83.

Schunk, D. H. (1988, April). Perceived self-efficacy and related social cognitive processes as predictors of student academic performance. Paper presented at the annual meeting of the American Educational Research Association, New Orleans, LA.

Schunk, D. H. (1991). Self-efficacy and academic motivation. Educational Psychologist, 26 (3\& 4), 207-231.

Solmon, M. A., \& Boone, J. (1993). The impact of student goal orientation in physical education classes. Research Quarterly for Exercise and Sport, 64, 418424.

Solmon, M. A., \& Carter, J. A. (1995). Kindergarten and first grade students' perceptions of physical education in one teacher's class. The Elementary School Journal, 95 (4), 356-365.

Solmon, M. A., Lee, A. M. (1996). Entry characteristics, practice variables, and cognition: Student mediation of instruction. Joumal of Teaching in Physical Education, 15, 136-150.

Stipek, D. J. (1984). Young children's performance expectations: Logical analysis or wishful thinking? Advances in Motivation and Achievement, 3, 33-56.

Tannehill, D., \& Zakrajsek, D. (1993). Student attitudes towards physical education: A multicultural study. Joumal of Teaching in Physical Education, 13, 78-84. 
Theeboom M., De Knop, P., \& Weiss, M. R. (1995). Motivational climate, psychological responses, and motor skill development in children's sport: A fieldbased intervention study. Joumal of Sport \& Exercise Psychology 17, $294-311$.

Treasure, D. C., \& Roberts, G. C. (1995). Applications of achievement goal theory to physical education: Implications for enhancing motivation. Quest. 47. 475-489.

Ulrich, B. (1987). Perceptions of physical competence, motor competence, and participation in organized sport: There interrelationships in young children. Research Quarterly for Exercise and Sport, 58, 57-67.

Urban, T. C., \& Maehr, M. L. (1995). Beyond a two-goal theory of motivation and achievement: A case for social goals. Review of Educational Research. 65 (3), 213-243.

Walling, M. D., \& Martinek, T. J. (1995). Learned helplessness: A case study of a middle school student. Journal of Teaching in Physical Education, 14, 454-466.

Weinberg, R. (1992). Goal-setting and motor performance: A review and critique. In G. C. Roberts (Ed.), Motivation in sport and exercise (pp. 177-197). Champaign, IL: Human Kinetics.

Weiner, B., (1985). An attributional theory of achievement motivation and emotion. Psychological Review, 92, 548-573.

Weiss, M. R. (1981). Self-efficacy theory and psychotherapeutic change: A square peg for a round hole. In S. Rachman (Ed.), Advances in behavior research and therapy (Vol. 1, pp. 231-236). Oxford: Pergamon.

Weiss, M. R. (1987). Self-esteem and achievement in children's sport and physical activity. In D. Gould \& M. R. Weiss (Eds.), Advances in pediatric sport sciences (pp.87-119). Champaign, IL: Human Kinetics.

Weiss, M. R. (1993). Children's participation in physical activity: Are we having fun yet? Pediatric Exercise Science, 6, 205-209.

Weiss, M. R., \& Horn, T. S. (1990). The relation between children's accuracy estimates of their physical competence and achievement-related characteristics. Research Ouarterly for Exercise and Sport, 61, 250-258.

Weissinger, N. P. (1994). 'T hit a home run!" The lived meaning of scoring games in physical education. Quest, 46, 425-439.

Wigfield, A., \& Harold, R. (1992). Teacher beliefs and children's achievement self-perceptions: A developmental perspective. In D. H. Strunk \& J. L. Meece (Eds.), Student perceptions in the classoom (pp. 95-121). Hillsdale, NJ: Erlbaum. 
Wigfield, A., Harold, R., Eccles, J. S., Aberback, A., Freedman-Doan, K, \& Yoon, K. S. (1990, April). Children's ability perceptions and values during the elementary school years. Paper presented at the annual meeting of the American Educational Research Association, Boston, MA.

Williams, L., \& Gill, D. L. (1995). The role of perceived competence in the motivation of physical activity. Joumal of Sport \& Exercise Psychology, 17, 363378.

Winne, P. H. (1991). Motivation and teaching. In H. Waxman \& H. Walberg (Eds.), Effective teaching: Current research (pp.295-314). Berkeley, CA: McCutchen Publishing.

Xiang, P. (1995). Determinants of students' achievement-related cognitions and behaviors: A goal perspective theory approach. Unpublished manuscript, Loiuisiana State University at Baton Rouge. 
APPENDIX B

PILOT STUDY 


\section{PILOT STUDY}

Self-perceptions of ability (SPA) are a critical piece in the motivation achievement puzzle. While the relationship is not completely understood, these perceptions appear irrevocably tied to students' overall self-esteem (Duda, 1987; Ebbeck \& Stuart, 1993). Ability perceptions influence motivation to initiate and to sustain activity (Weiss, 1993) and are precursors to the adoption of adaptive or maladaptive behaviors patterns. These self-perceptions are also related to positive affect (Fox, 1990) and have been identified as strong determinants of performance (Feltz, 1992). In the physical education field there is valid concern about students' lack of participation in physical activities both in educational settings and in lifestyle practices. The pathway to behavioral and attitudinal change might well begin with an understanding of what makes some children willing, interested participants and others reluctant bystanders (Goudas, Biddle, Fox, \& Underwood. 1995). Clearly an understanding of the forces that generate high SPA and the methods for manipulating and sustaining such forces may be significant steps towards developing students with positive SPA and active lifestyles.

A review of the literature reveals that individuals acquire and cognitively appraise information to determine their overall SPA to perform a particular task (Bandura, 1986; Feltz, 1988; Harter, 1978; Schunk, 1991). Verbal and nonverbal feedback and reinforcement from significant others such as parents, teachers, coaches and peers provide one important source of information that can influence ability perceptions. While influence may be tempered by the believability, skill, prestige and reliability of the significant other (Feltz, 1988), reinforcement and positive body language of mastery efforts can influence perceptions of ability and control and motivational orientation (Harter, 1978; Weiss, 1987). Historically teacher augmented feedback has been directed towards the acquisition of skill. While numerous studies have determined the viable role of feedback in the learning 
process, the idea of augmented feedback as a tool for the enhancement of student SPA has yet to be adequately explored (Magill, 1993). Perhaps such feedback would facilitate even greater skill acquisition over time. The integration of feedback for skill acquisition with feedback for enhanced SPA might provide the most productive learning.

It also appears that a students' SPA is related to the value or importance attached to the activity in question (Eccles et al, 1983; Feltz, 1988; Weiss, 1987). Students who do not care about their success in a particular activity are rarely concerned with their ability to perform such an activity. This initial valuing of an activity which may reflect any number of influences remains a key to further achievement strivings. An accurate assessment of SPA must first establish participant interest, value or importance for the activity in question.

Performance accomplishments involve previous experience in an activity and appears to be a key mediator of SPA (Ames, 1987; Feltz, 1988). If experiences are perceived as successful, then ability perceptions are enhanced. Conversely perceived failures serve to lower ability perceptions (Feltz, 1992). The extent to which general SPA influence expectancies for success on a specific novel task has received little attention.

While there is agreement that SPA is a vital force in motivation, behavior and performance, the majority of research has involved efforts to pinpoint its determinants and effects (Treasure \& Roberts, 1995). There is presently a need to move beyond identification and into the discovery of how students weight and utilize available information about SPA (Chase \& Feltz, 1995), and to move beyond the evaluation of disposition and situational goal orientations as separate entities and into integrated analyses (Treasure \& Roberts). The study of ability perceptions has been conducted predominantly in academic settings and in relation to athletics and youth sports. Results from these areas are certainly important, but do not 
necessarily have direct application for physical education classrocms and efforts to increase children's activity habits. The limited research specific to the physical education setting, has consisted primarily of pen and pencil surveys (Blumenfeld, 1992). Observation of what children actually do rather than acceptance of what they say they would do in certain situations appears warranted.

This study is designed to further SPA research in the physical education discipline and to extend the understanding of some of the powerful mediators of this construct. Research efforts designed to move from surveys and questionnaires to practical field-based information appear to be driven by the premise that SPA can best be developed and sustained through task induced situations. Remediation of a student's dispositional goal perspective has been viewed as plausible but not practical in educational settings. It is argued that such efforts would prove too costly, time consuming and unpredictable, and that research for the development of task oriented climates would be more productive (Ames, 1992b; Papaioannou, 1995; Treasure \& Roberts, 1995). While this premise makes sense it fails to address students intuitive interest in competition and social comparison. As Weissinger reported in her 1994 study, fourth grade students in games where scoring was downplayed or ignored found their greatest satisfaction in their ability to score. Her suggestions to modify rules to promote greater SPA appear salient until the student ultimately encounters the inevitable real game and real competition. The search for ways to modify games and to design task focused motivational climates are valid and need to be continued, but it also appears meritous to simultaneously search for ways to facilitate positive SPA in the face of inevitable social comparisons.

The purpose of this current study was twofold. First, the feasibility of using the skill of cupstacking as a novel task was examined to see if both males and females were interested in learning this skill, if they would remain attentive throughout the session, and to see if planned feedback progressions were effective. It was predicted 
that students would enjoy working on this novel skill, that it would appeal to both genders, and that informational feedback would help students learn more efficiently. Second, the relationship between augmented ability feedback and the development or maintenance of positive SPA was explored. It was predicted that the majority of subjects would initially project moderate to high ability expectations for the activity, and that experimentally induced augmented feedback could change students' initial SPA. An initial high SPA could be lowered if no positive feedback was provided about progress on a novel task just as initial low SPA could be raised with positive ability feedback.

\section{Method}

\section{Participants}

The subjects for the pilot study were 6 male and 6 females from ages 9 to 11 from a small southem town. Signed parental permission was obtained for each student.

\section{Procedures}

Students were randomly assigned to feedback groups before they arrived. They worked individually with the experimenter for 30 to 40 minutes. Each participant watched a video on the skill of cupstacking and then participated in a brief discussion about the values of cupstacking. All were told that they had the capacity to acquire this new skill with practice. Responses to survey questions were recorded by the experimenter throughout the practice session.

Following a demonstration students were given feedback as they practiced stacking cups in two pyramids of 3 , one pyramid of 6 . or one pyramid of 10 . One third of the students ( 2 girls and 2 boys) were praised for their efforts and told that they showed great promise in terms of their ability, one third ( 2 girls and 2 boys) were simply given technical feedback about how to best perform the skills, and one third ( 2 boys and 2 girls) were given no feedback. Before each skill was introduced, 
students were asked how well they thought they could perform the skill (bad, OK. good, very good, excellent) and why. The student was given 3 minutes to practice while feedback was given, and then two minutes alone to practice while the experimenter did some paperwork. Three time trials were taken and the best time was recorded. The process was repeated for the next two skills, and the student was asked concluding questions about the his or her overall ability and interest in continuing to learn this skill. At the end of the practice time, students were debriefed about the types of feedback that they had received. and they were all praised for their time and help.

$\underline{\text { Results }}$

None of the students had seen or ever heard of the skill of cupstacking before. All indicated an interest in learning and continuing to practice this skill. All remained attentive during the session. All were able to improve their performance scores and reduce the number of mistakes that they made per time trial. Feedback progressions proved helpful except students have to work hard to master some of them (e.g., picking up all the cups but one). All but two rated themselves as good or excellent at the end of the session. One boy and one girl who received no feedback gave themselves a bad and an OK rating respectively.

\section{Conclusion}

Cupstacking was found to be a novel task which could interest and challenge both genders. It was a simple enough task to generate feelings of success and yet difficult enough to demand some understanding of how best to perform. Students remained attentive throughout the session which suggests that students in a physical education class might also be attentive to feedback. Progressions proved logical in that students seemed to understand them and be able to incorporate them. Plastic stadium cups worked for this study, but probably need to be replaced with the recommended cups (small plastic cups with a hole in the bottom). 
Sample Survey Sheet

Subject \#__ Male 0 Female 0 Age ___ Grade

I. A. Have you ever seen or practiced this skill before? $\bar{Y}$ es _ No

B. Do you think practicing eye-hand coordination with this activity will help you in other activities? Yes

C. How might it help you? No

D. Are you interested in learning this activity? Yes

E. Why? No

F. Are you usually BAD OK GOOD VERY GOOD EXCELLENT in physical education activities?

G. Why?

H. How well do you think you can do the $3 \times 3$ cup upstacking and downstacking? BAD OK GOOD VERY GOOD EXCELLENT

I. Why do you think you will do BAD/OK/GOOD/VERY GOOD/EXCELLENT on this activity?

J. $3 \times 3$ upstack/downstack: Practice -3 minutes Performance Outcome Fumbles Time

II. A. How well do you think you can do on the 6 cup upstack and downstack?
BAD
OK
VERY GOOD
EXCELLENT

B. 6 upstack/downstack

FB Practice - 3 minutes

Performance Outcome Fumbles _Time

C. At this point, how would you rate your cupstacking ability?
$\mathrm{BAD} O K$
GOOD VERY GOOD
EXCELLENT

III. A. How well do you think you can do on the $1 \times 10 \times 1$ cup upstack and downstack?
BAD
OK GOOD VERY GOOD
EXCELLENT

B. 10 upstack/downstack

FB Practice - 3 minutes

Performance Outcome

_Fumbles _. Time

C. At this point, how would you rate your cupstacking ability?
BAD OK GOOD VERY GOOD
EXCELLENT

IV.A Do you think this would be a good activity to work on in physical education classes?

B. Why?

C. Would you rather just work on learning this skill or do you think you would prefer racing? 
APPENDIX C

SCRIPTS

90

Reproduced with permission of the copyright owner. Further reproduction prohibited without permission. 


\section{INSTRUCTOR SCRIPT \\ Condition A - No Feedback}

Check the students' nametags to be sure they are in the correct place. Have them introduce themselves to the camera. Introduce yourself and then explain that today, "We are going to learn the $3 \times 6 \times 3$ cupstacking skill". Remind them that the purpose of the lesson is to learn how to do this skill quickly with no wasted motion and with no fumbles. Do not mention time. Remind them also that you want them to learn this skill well enough so that they can teach it to their family and friends.

Demonstrate this skill slowly. Begin with 3 cups stacked together on the left, 6 in the middle and 3 more on the right. Build a 3 cup pyramid on the left, a 6 cup in the middle and a 3 cup pyramid on the right (upstacking). Then collapse (downstacking) the cups again from left to right. Demonstrate 2 times.

At ten minutes after or whenever I signal, all teachers will begin teaching using their condition. If possible let each child have a set of cups. If two students must share a set of cups discuss how they can share most effectively.

In the no feedback condition, you will simply explain to the children what they are to do. You may indicate that there is a best way to do this skill, but you want them to figure it out. Give no praise or criticism. Do not comment on their effort or ability. Only show them - one hand at a time - how to stack the cups. Interact with each child to make sure they understand what they are suppose to do and encourage them to practice so they can learn this skill well.

When the final signal is given, give the students their cards. Be sure they are on side 2. Let them write how well they think they can perform this skill now that they have practiced. Encourage them to explain in as much detail as possible why they selected the number they did. While students are being tested continue to provide your designated feedback. Be prepared to time if necessary, but make sure I verify some of your times.

ON THURSDAY WHEN YOU TEACH THE 1X10X1 SKILL, YOU WILL BEGIN WITH ALL 12 CUPS IN ONE STACK. FIRST THE TOP TWO CUPS ARE PLACED ON EACH SIDE AND THEN THE 10 REMAINING CUPS ARE PLACED IN ONE LARGE PYRAMID. WE WILL FOLLOW EXACTLY THE SAME FORMAT AS USUAL. 


\section{INSTRUCTOR SCRIPT \\ Condition B - Motivational Feedback}

Check the students' nametags to be sure they are in the correct place. Have them introduce themselves to the camera. Introduce yourself and then explain that today, "We are going to learn the $3 \times 6 \times 3$ cupstacking skill". Remind them that the purpose of the lesson is to learn how to do this skill quickly with no wasted motion and with no fumbles. Do not mention time. Remind them also that you want them to learn this skill well enough so that they can teach it to their family and friends.

Demonstrate this skill slowly. Begin with 3 cups stacked together on the left, 6 in the middle and 3 more on the right. Build a 3 cup pyramid on the left, ta 6 cup in the middle and a 3 cup pyramid on the right (upstacking). Then collapse (downstacking) the cups again from left to right. Demonstrate 2 times.

At ten minutes after or whenever I signal, all teachers will begin teaching using their condition. If possible let each child have a set of cups. If two students must share a set of cups discuss how they can share most efficiently. Be sure you give 5 to 10 feedback comments to the class in general, and then move about and give appropriate feedback statements to each student as often as possible.

In the motivational feedback condition, you will simply explain to the children what they are to do. You may indicate that there is a best way to do this skill, but you want them to figure it out. Give praise for effort or general eye-hand ability. quickness, cleverness, etc. whenever possible. Any demonstration will only involve one hand at a time. Interact with each child to make sure they understand what they are suppose to do and encourage them to practice, to try hard, and to concentrate so they can learn this skill well. The following comments are suggested:

You are really trying hard. You sure work hard. You are a worker.

I can see that you are going to be good at this.

Gosh, you have quick hands.

You are a fast learner. You're smart. You're doing a great job.

You are really improving. You concentrate so well.

You sure have good eye-hand coordination.

When the final signal is given, give the students their cards. Be sure they are on side 2. Let them write how well they think they can perform this skill now that they have practiced. Encourage them to explain in as much detail as possible why they selected the number that they did. When the final signal is given, give the students their cards. Be sure they are on side 2 . Let them write how well they think they can perform this skill now that they have practiced. Encourage them to explain in as much detail as possible why they selected the number they did. While students are being tested continue to provide your designated feedback. Be prepared to time if necessary, but make sure I verify some of your times.

ON THURSDAY WHEN YOU TEACH THE $1 \times 10 \times 1$ SKILL, YOU WILL BEGIN WTTH ALL 12 CUPS IN ONE STACK. FIRST THE TOP TWO CUPS ARE PLACED ON EACH SIDE AND THEN THE 10 REMAINING CUPS ARE PLACED IN ONE LARGE PYRAMID. 


\section{INSTRUCTOR SCRIPT \\ Condition C - Task Knowledge Feedback}

Check the students' nametags to be sure they are in the correct place. Have them introduce themselves to the camera. Introduce yourself and then explain that today, "We are going to learn the $3 \times 6 \times 3$ cupstacking skill". Remind them that the purpose of the lesson is to leam how to do this skill quickly with no wasted motion and with no fumbles. Do not mention time. Remind them also that you want them to learn this skill well enough so that they can teach it to their family and friends.

Demonstrate this skill slowly. Begin with 3 cups stacked together on the left, 6 in the middle and 3 more on the right. Build a 3 cup pyramid on the left, ta 6 cup in the middle and a 3 cup pyramid on the right (upstacking). Then collapse (downstacking) the cups again from left to right. Demonstrate 2 times.

At ten minutes after or whenever I signal, all teachers will begin teaching using their condition. If possible let each child have a set of cups. If two students must share a set of cups discuss how they can share most efficiently. Be sure you give 5 to 10 feedback comments to the class in general, and then move about and give appropriate feedback statements to each student as often as possible.

In the task knowledge feedback condition, you will simply explain to the children what they are to do. Your job is help the students understand the best way to to this skill. Give no praise for effort or general eye-hand ability. Demonstration should involve the best possible techniques (using 2 hands at once), but you do not have to move quickly. Explain what you are doing as you demonstrate. Interact with each child to make sure they understand what they are suppose to do. You should encourage students to concentrate on learning how to do the skill correctly so that they move efficiently without wasted motion. The following progressions are suggested:

1. watch the cups as you work

2. always place the cups close together. "Squash them close together"

3. pick up two cups at a time and use both hands to place them.

4. in the 6 cup pyramid, use both hands to pick up all the cups except the bottom one, place cups side by side with the center one and then move up.

5. On Thursday when you teach the $1 \times 10 \times 1$ skill, you will need to add this cue. Always begin the second row in the center and work out.

Give students feedback according to where they are. If they already place the cups close together, then you might say, "you do a good job of placing the cups close together. You can do even better if you try picking up two cups at a time."

When the final signal is given, give the students their cards. Be sure they are on side 2. Let them write how well they think they can perform this skill now that they have practiced. Encourage them to explain in as much detail as possible why they selected the number that they did. While students are being tested continue to provide your designated feedback. Be prepared to time if necessary, but make sure I verify some of your times.

ON THURSDAY WHEN YOU TEACH THE $1 \times 10 \times 1$ SKILL, YOU WILL BEGIN WTHH ALL 12 CUPS IN ONE STACK. FIRST THE TOP TWO CUPS ARE PLACED ON EACH SIDE AND THEN THE 10 REMAINING CUPS ARE PLACED IN ONE LARGE PYRAMID. 


\section{INSTRUCTOR SCRIPT \\ Condition D - Motivational \& Task Knowledge Feedback}

Check the students' nametags to be sure they are in the correct place. Have them introduce themselves to the camera. Introduce yourself and then explain that today, "We are going to learn the $3 \times 6 \times 3$ cupstacking skill". Remind them that the purpose of the lesson is to learn how to do this skill quickly with no wasted motion and with no fumbles. Do not mention time. Remind them also that you want them to learn this skill well enough so that they can teach it to their family and friends.

Demonstrate this skill slowly. Begin with 3 cups stacked together on the left, 6 in the middle and 3 more on the right. Build a 3 cup pyramid on the left, ta 6 cup in the middle and a 3 cup pyramid on the right (upstacking). Then collapse (downstacking) the cups again from left to right. Demonstrate 2 times.

At ten minutes after or whenever I signal, all teachers will begin teaching using their condition. If possible let each child have a set of cups. If two students must share a set of cups discuss how they can share most efficiently. Be sure you give 5 to 10 feedback comments to the class in general, and then move about and give appropriate feedback statements to each student as often as possible.

For this feedback condition, you will teach students the best way to to this skill, and you will give praise for effort or general eye-hand ability. Demonstration should involve the best possible techniques (using 2 hands at once), but you do not have to move quickly. Explain what you are doing as you demonstrate. Interact with each child to make sure they understand what they are suppose to do. You should encourage students to concentrate on learning how to do the skill correctly so that they move efficiently without wasted motion. Use the progressions suggested for condition $C$ such as: 1 . watch the cups as you work; 2 . always place the cups close together, 3. pick up two cups at a time and use both hands to place them: 4 . in the 6 cup pyramid, use both hands to pick up all the cups except the bottom one, then place cups side by side with the center one and then move up. On Thursday when you teach the $1 \times 10 \times 1$ skill, remind them to always begin the second row in the center and work out.

As you teach the students the best way to do this skill, you will also compliment their effort and ability with comments such as those suggested in condition B: (a) You are really trying hard, (b) I can see that you are going to be good at this, (c) You have quick hands, etc. The goal is to try to teach the task and motivate students at the same time. For example, you might say, "Not only do you have quick hands, but you are smart to use them both at the same time."

When the final signal is given, give the students their cards. Be sure they are on side 2. Let them write how well they think they can perform this skill now that they have practiced. Encourage them to explain in as much detail as possible why they selected the number that they did. While students are being tested continue to provide your designated feedback. Be prepared to time if necessary, but make sure I verify some of your times.

ON THURSDAY WHEN YOU TEACH THE $1 \times 10 \times 1$ SKILL, YOU WILL BEGIN WITH ALL 12 CUPS IN ONE STACK. FIRST THE TOP TWO CUPS ARE PLACED ON EACH SIDE AND THEN THE 10 REMAINING CUPS ARE PLACED IN ONE LARGE PYRAMID. 
APPENDIX D

STUDENT SURVEYS

95

Reproduced with permission of the copyright owner. Further reproduction prohibited without permission. 
NAME

BOY / GIRL

1. Have you ever seen or practiced this skill before? Yes No

If you put "Yes" explain where you saw this skill or how much you practiced it:

2. Do you think learning this skill will help you in other activities?

Yes No

If you put yes, explain how you think it might help you?

3. How interested are you in learning this skill?

1 I $\quad$ I'm not at all interested.

2. __ I'm sort of interested

3. I'm interested

4. I_ I'm very interested

5. I I $\quad$ I'm extremely interested

What number did you check? __ Why did you choose that answer?

4. With practice how well do you think you can learn the skill of cupstacking?

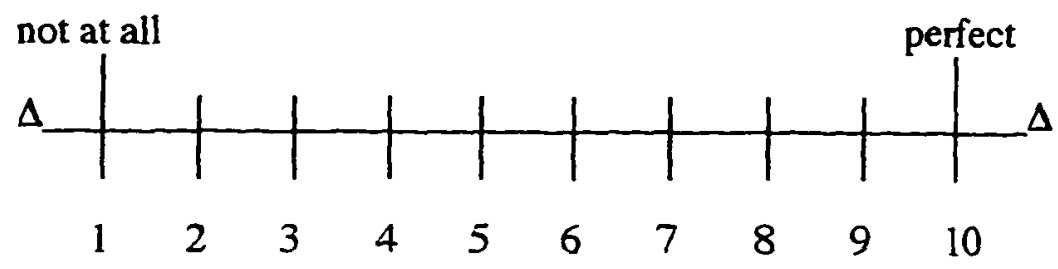

What number did you circle? Why did you choose that number? 
NAME

BOY / GIRL

1. With more time to practice how well do you think you can learn these and other cupstacking skills?

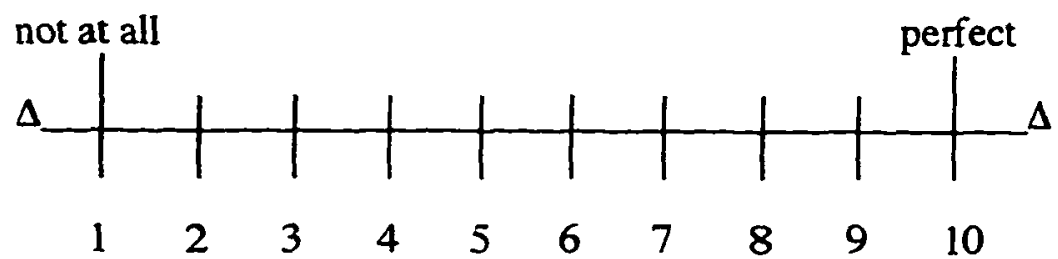

What number did you circle? Why did you choose that number?

2. What was the overall goal of this cupstacking unit?

3. If your teacher had to teach another group of students about cupstacking, how do you think might she improve her teaching?

4. Do you think this would be a good activity to work on in physical education class?

Why or why not?

5. How do you like to learn best? Is it better to work on learning this skill by yourself while you try to improve your own scores learn this skill by competing against other students in your class or is it better to Why?

6. Comments, suggestions or jokes? 


\section{APPENDIX E}

INDEX CARDS 
SAMPLE SPAP INDEX CARD FOR THE $3 \times 6 \times 3$

NAME

\#

$3 \times 6 \times 3 \cdot$ Side 1

1. With practice how well do you think you can perform the $3 \times 6 \times 3$ cupstacking skill?

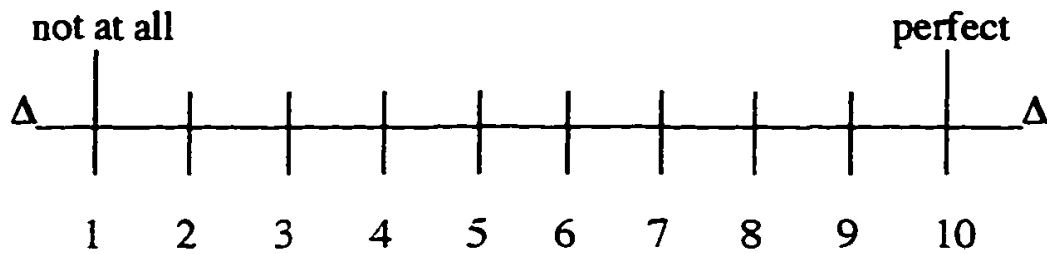

2. What number did you circle? that number?

Why did you choose

NAME

$\#$

$3 \times 6 \times 3 \cdot$ Side 2

1. After practicing how well do you think you can perform the $3 \times 6 \times 3$ cupstacking skill?

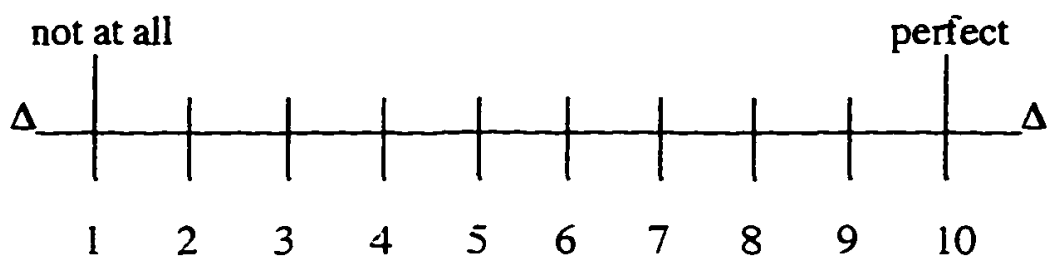

2. What number did you circle? that number?

Why did you choose 
SAMPLE SPAP INDEX CARD FOR THE $1 \mathrm{X} 10 \mathrm{X} 1$

NAME

$\#$

$1 \times 10 \times 1 \cdot$ Side 1

1. With practice how well do you think you can perform the $1 \times 10 \times 1$ cupstacking skill?

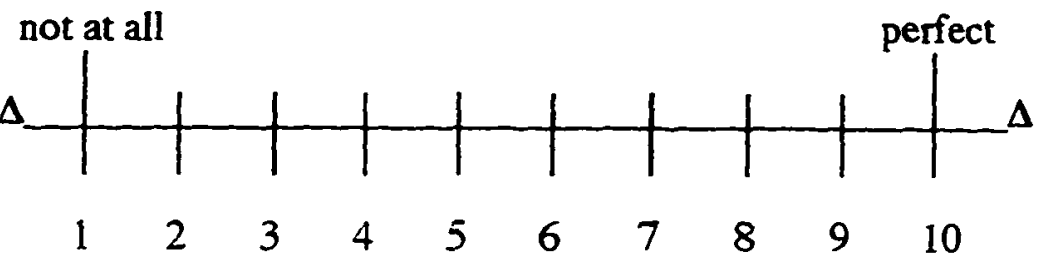

2. What number did you circle? that number? Why did you choose

NAME

$1 \times 10 \times 1 \cdot$ Side 2

1. After practicing how well do you think you can perform the $1 \times 10 \times 1$ cupstacking skill?

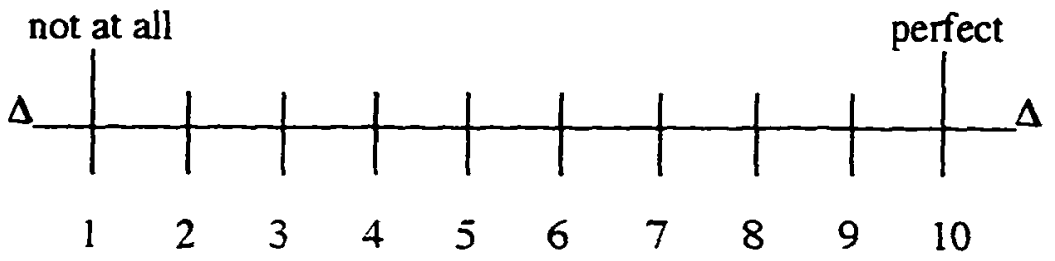

2. What number did you circle? that number?

Why did you choose 


\section{APPENDIX F}

RAW DATA 
OBS CHILD IN CLASS TRT SPAL1 SPAL2 ST1 ST2 CT1 CT2 SP1 SP2 CP1 CP2 OFF1 OFF2

\begin{tabular}{|c|c|c|c|c|c|c|c|c|c|c|c|c|c|c|c|c|}
\hline 1 & 1 & 11 & $\mathrm{Cl}$ & a & 5 & 7 & 20.78 & 16.70 & 19.22 & 15.49 & 5 & 8 & 6 & 7 & 9.83 & 9.28 \\
\hline 2 & 2 & I1 & $\mathrm{Cl}$ & a & 8 & 8 & 17.66 & 16.79 & 18.81 & 18.09 & 7 & 8 & 8 & 9 & 9.67 & 7.98 \\
\hline 3 & 3 & II & $\mathrm{Cl}$ & a & 10 & 7 & 24.09 & 24.76 & 22.48 & 18.66 & 10 & 9 & 6 & 6 & 9.50 & 9.67 \\
\hline 4 & 4 & II & C1 & a & 7 & 8 & 28.36 & 19.69 & 20.48 & 19.39 & 6 & 6 & 5 & 5 & 9.83 & 8.68 \\
\hline 5 & 5 & I1 & $\mathrm{C} 2$ & b & 1 & 8 & 23.18 & 17.55 & 17.23 & 18.02 & 8 & 10 & 9 & 10 & 8.92 & 7.08 \\
\hline 6 & 6 & 11 & $\mathrm{C} 2$ & b & 9 & 9 & 18.19 & 14.31 & 17.24 & 16.95 & 7 & 8 & 7 & 7 & 9.67 & 8.48 \\
\hline 7 & 7 & I1 & C2 & b & 2 & 10 & 12.04 & 8.17 & 10.38 & 8.23 & 5 & 10 & 9 & 10 & 9.11 & 8.40 \\
\hline 8 & 8 & I1 & C2 & b & 1 & 7 & 17.00 & 15.91 & 20.06 & 16.62 & 6 & 7 & 5 & 6 & - & . \\
\hline 9 & 9 & I1 & C3 & d & 4 & 9 & 15.45 & 12.84 & 21.54 & 18.06 & 4 & 5 & 3 & 4 & 9.26 & 8.68 \\
\hline 10 & 10 & I1 & C3 & d & 4 & 6 & 16.70 & 14.96 & 22.99 & 18.18 & 3 & 3 & 5 & 8 & 9.15 & 8.68 \\
\hline 11 & 11 & I1 & c3. & d & 5 & 8 & 13.05 & 12.56 & 19.20 & 13.32 & 6 & 8 & 7 & 9 & 9.15 & 9.25 \\
\hline 12 & 12 & I1 & $\mathrm{C3}$ & d & 6 & 8 & 14.82 & 11.18 & 14.40 & 11.53 & 3 & 8 & 4 & 7 & 9.15 & 9.25 \\
\hline 13 & 13 & II & $\mathrm{C3}$ & d & 7 & 7 & 21.66 & 17.14 & 20.40 & 14.27 & 7 & 8 & 5 & 8 & 10.00 & 9.58 \\
\hline 14 & 14 & 11 & C3 & d & 8 & 10 & 21.70 & 21.45 & 22.90 & 21.70 & 6 & 6 & 9 & 10 & 10.00 & 9.58 \\
\hline 15 & 15 & I1 & $\mathrm{C} 3$ & d & 3 & 9 & 16.58 & 12.87 & 16.10 & 13.07 & 5 & 7 & 1 & 8 & 10.00 & 9.83 \\
\hline 16 & 16 & I1 & C4 & c & 3 & 7 & 17.90 & 12.08 & 24.90 & 11.35 & 5 & 7 & 8 & 6 & 10.00 & 9.83 \\
\hline 17 & 17 & I1 & C4 & c & 6 & 8 & 22.45 & 15.90 & 20.29 & 10.41 & 6 & 8 & 7 & 9 & 10.00 & 9.58 \\
\hline 18 & 18 & I1 & $\mathrm{C4}$ & $c$ & 5 & 8 & 18.01 & 17.77 & 16.99 & 13.70 & 7 & 5 & 6 & 7 & 10.00 & 9.83 \\
\hline 19 & 19 & I1 & $\mathrm{C} 4$ & c & 5 & 8 & 17.79 & 10.44 & 13.84 & 11.11 & 4 & 7 & 5 & 7 & 9.18 & 9.67 \\
\hline 20 & 20 & I1 & $\mathrm{C} 4$ & c & 1 & 8 & 20.01 & 16.04 & 26.20 & 17.38 & 5 & 8 & 9 & 8 & 9.83 & 9.83 \\
\hline 21 & 21 & I1 & $\mathrm{CA}$ & c & 6 & 6 & 12.88 & 10.89 & 20.60 & 9.79 & 8 & 6 & 7 & 8 & 9.33 & 9.58 \\
\hline 22 & 22 & I1 & C4 & C & 5 & 8 & 23.01 & 14.34 & 12.13 & 11.88 & 5 & 6 & 3 & 6 & 9.33 & 9.00 \\
\hline 23 & 23 & I2 & C1 & b & 10 & 10 & 23.40 & 24.79 & 21.79 & 17.97 & 10 & 10 & 10 & 10 & 8.50 & 6.05 \\
\hline 24 & 24 & I2 & $\mathrm{C1}$ & b & 5 & 8 & 16.00 & 10.02 & 14.90 & 12.69 & 5 & 7 & 4 & 9 & 8.67 & 6.86 \\
\hline 25 & 25 & I2 & C1 & b & 5 & 7 & 26.52 & 22.85 & 24.10 & 20.33 & 10 & 5 & 10 & 5 & 6.90 & 7.04 \\
\hline
\end{tabular}




\begin{tabular}{|c|c|c|c|c|c|c|c|c|c|c|c|c|c|c|c|c|}
\hline & & & & 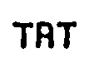 & .1 & PAL2 & ST1 & ST2 & CT1 & СТ2 & SP1 & SP2 & CP1 & CP2 & OFF & FF2 \\
\hline & 26 & 12 & & b & 5 & 8 & 21.70 & 14.29 & 17.40 & 14.78 & 7 & 5 & 8 & 8 & 9.75 & 8.75 \\
\hline 7 & 27 & I2 & c1 & b & 6 & 7 & 16.69 & 12.79 & 22.05 & 21.18 & 6 & 4 & 6 & 7 & 9.17 & 7.83 \\
\hline 28 & 28 & I2 & C2 & c & 10 & 10 & 18.00 & 15.24 & 23.04 & 19.70 & 9 & 10 & 10 & 10 & 9.05 & 9.50 \\
\hline 9 & 29 & I2 & C2 & C & 6 & 6 & 14.06 & 11.92 & 17.39 & 13.94 & 7 & 10 & 6 & 4 & 9.33 & 9.06 \\
\hline 30 & 30 & I2 & $\mathrm{C} 2$ & C & 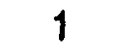 & 1 & 22.94 & 15.80 & 20.39 & 12.50 & 5 & 1 & 2 & 1 & 8.21 & 8.75 \\
\hline 31 & 31 & I2 & C2 & c & 6 & 9 & 15.29 & 11.41 & $14.50^{\circ}$ & 13.04 & 8 & 8 & 6 & 6 & 8.58 & 9.05 \\
\hline 32 & 32 & 12 & C2 & C & 5 & 7 & 20.56 & 15.29 & 18.58 & 14.00 & 6 & 7 & 7 & $B$ & 9.67 & 9.33 \\
\hline 33 & 33 & I2 & C2 & c & 5 & 8 & 16.80 & 15.30 & 16.81 & 15.47 & 6 & 5 & 5 & 7 & 10.00 & 9.75 \\
\hline 4 & 34 & I2 & C3 & a & 9 & 9 & 21.59 & 14.32 & 22.90 & 18.72 & 8 & 9 & 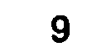 & 8 & 9.83 & 9.67 \\
\hline 5 & 35 & I2 & C3 & $\mathbf{a}$ & 9 & 10 & 16.84 & 14.80 & 14.91 & 16.31 & 8 & 9 & 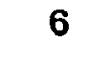 & 9 & 6.38 & 4.29 \\
\hline 6 & 36 & I2 & c3 & a & 5 & 9 & 19.49 & 13.95 & 15.10 & 13.09 & 5 & 9 & 8 & 8 & 7.38 & 6.05 \\
\hline 17 & 37 & I2 & C3 & a & 6 & 10 & 13.90 & 14.28 & 18.00 & 14.90 & 6 & 9 & 9 & 9 & 7.45 & 7.38 \\
\hline 38 & 38 & I2 & C3 & a & 2 & 8 & 14.88 & 14.38 & 18.50 & 14.38 & 5 & 7 & 7 & 8 & 9.83 & 9.67 \\
\hline 39 & 39 & I2 & C3 & a & 9 & 8 & 14.24 & 15.15 & 16.38 & 14.81 & 8 & 5 & 5 & 8 & 7.97 & 3.48 \\
\hline 40 & 40 & I2 & C3 & a & 5 & 8 & 13.34 & 14.01 & 18.70 & 16.06 & 7 & 8 & 7 & 8 & 7.97 & 3.48 \\
\hline 1 & 41 & I2 & C4 & d & 10 & 10 & 17.24 & 15.71 & 20.70 & 13.97 & 10 & 10 & 9 & 8 & 9.50 & 9.50 \\
\hline 2 & 42 & I2 & C4 & d & 7 & 8 & 26.45 & 14.97 & 19.29 & 16.59 & 9 & 10 & 6 & 8 & 10.00 & 9.67 \\
\hline 43 & 43 & I2 & C4 & d & 3 & 5 & 19.88 & 13.13 & 16.94 & 15.05 & 3 & 7 & 2 & 6 & - & $\bullet$ \\
\hline 14 & 44 & I2 & C4 & d & 2 & 6 & 14.66 & 13.56 & 18.50 & 15.06 & 7 & 5 & 4 & 6 & 9.00 & 9.50 \\
\hline 45 & 45 & I2 & C4 & d & 6 & 10 & 14.20 & 14.00 & 16.81 & 11.28 & 3 & 10 & 8 & 10 & 9.68 & 10.00 \\
\hline 46 & 46 & 12 & C4 & d & 6 & 10 & 23.70 & 20.96 & 19.23 & 14.39 & 7 & 10 & 9 & 9 & & \\
\hline 47 & 47 & I2 & C4 & d & 5 & 10 & 14.34 & 16.31 & 15.21 & 15.43 & 6 & 7 & 5 & 7 & 9.00 & 9.50 \\
\hline 48 & 48 & I2 & C4 & d & 5 & 9 & 14.92 & 13.30 & 25.79 & 20.16 & 5 & 5 & 3 & 7 & 10.00 & 9.50 \\
\hline 9 & 49 & I3 & C1 & $c$ & 8 & 9 & 14.47 & 12.74 & 12.81 & 9.28 & 9 & 10 & 7 & 10 & • & . \\
\hline 0 & 50 & 13 & C1 & c & 5 & 8 & 17.01 & 15.05 & 20.50 & 14.71 & 9 & 10 & 9 & 10 & 9.83 & 9.50 \\
\hline
\end{tabular}


OBS CHILD IN CLASS TAT SPAL1 SPAL2 ST1 ST2 CT1 CT2 SP1 SP2 CP1 CP2 OFF1 OFF2

\begin{tabular}{|c|c|c|c|c|c|c|c|c|c|c|c|c|c|c|c|c|}
\hline 51 & 51 & I3 & $\mathrm{C1}$ & c & 5 & 8 & 18.19 & 19.03 & 23.42 & 12.48 & 5 & 6 & 6 & 7 & 9.67 & 9.75 \\
\hline 52 & 52 & I3 & $c 1$ & c & 6 & 7 & 18.93 & 13.00 & 16.90 & 13.30 & 6 & 8 & 5 & 8 & 9.83 & 9.50 \\
\hline 53 & 53 & I3 & $C 1$ & c & 9 & 9 & 20.65 & 17.25 & 21.72 & 13.40 & 8 & 9 & 7 & 9 & 9.83 & 9.50 \\
\hline 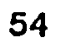 & 54 & I3 & $c 1$ & & 6 & 8 & 22.90 & 19.50 & 22.18 & 9.87 & 9 & 10 & 6 & 10 & 10.00 & 9.17 \\
\hline 5 & 55 & 13 & $\mathrm{C} 2$ & $d$ & 10 & 10 & 25.46 & 15.46 & 18.97 & 14.84 & 7 & 9 & 10 & 10 & 9.83 & 8.20 \\
\hline 56 & 6 & 13 & $\mathrm{C} 2$ & & 5 & 10 & 23.25 & 18.49 & 20.11 & 16.21 & 4 & 10 & 4 & 8 & 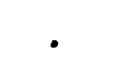 & \\
\hline 57 & 7 & I3 & $\mathrm{C} 2$ & d & 10 & 10 & 22.35 & 17.57 & 16.53 & 13.49 & 4 & 8 & 4 & 10 & 8.87 & 9.17 \\
\hline 58 & 58 & 13 & $\mathrm{C2}$ & d & 8 & 9 & 15.87 & 16.00 & 15.71 & 10.00 & 8 & 10 & 7 & 10 & . & . \\
\hline$y$ & 59 & I3 & $\mathrm{C} 2$ & d & 7 & 10 & 15.96 & 13.56 & 15.52 & 13.42 & 6 & 10 & 5 & 6 & 9.50 & 9.83 \\
\hline 60 & 60 & I3 & C3 & b & 5 & 10 & 13.94 & 14.79 & 14.32 & 13.95 & 5 & 8 & 7 & 10 & . & \\
\hline 61 & 61 & I3 & $\mathrm{C3}$ & b & 5 & 10 & 18.40 & 12.46 & 16.42 & 14.49 & 9 & 10 & 8 & 10 & 8.05 & 7.83 \\
\hline 62 & 62 & I3 & $\mathrm{C} 3$ & b & 5 & 10 & 12.90 & 10.22 & 14.48 & 10.30 & 0 & 10 & 7 & 10 & 9.08 & 8.05 \\
\hline 63 & 63 & I3 & C3 & b & 10 & 7 & 18.31 & 17.38 & 17.90 & 14.37 & 4 & 7 & 7 & 8 & 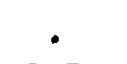 & . \\
\hline 64 & 64 & I3 & $\mathrm{c3}$ & b & 1 & 10 & 20.70 & 17.36 & 20.38 & 18.44 & 8 & 10 & 9 & 10 & .75 & 5.92 \\
\hline 65 & 65 & I3 & C3 & b & 8 & 9 & 13.56 & 16.98 & 16.08 & 12.29 & 5 & 7 & 5 & 5 & ${ }^{\circ}$ & \\
\hline 66 & 66 & 13 & C3 & b & 2 & 4 & 13.32 & 14.95 & 13.86 & 11.88 & 5 & 7 & 4 & 8 & ${ }^{\circ}$ & 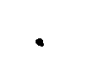 \\
\hline 67 & 67 & I3 & $\mathrm{C3}$ & b & 9 & 9 & 20.06 & 21.85 & 17.39 & 15.13 & 7 & 9 & 5 & 9 & . & . \\
\hline 68 & 68 & I3 & $\mathrm{C3}$ & b & 1 & 8 & 15.90 & 17.01 & 17.76 & 14.49 & 7 & 9 & 5 & 7 & 9.50 & 8.68 \\
\hline 69 & 69 & I3 & $\mathrm{C} 4$ & a & 7 & 9 & 19.66 & 16.88 & 18.82 & 14.16 & 7 & 9 & 7 & 9 & 8.75 & 9.33 \\
\hline 70 & 70 & 13 & $C 4$ & a & 8 & 10 & 16.25 & 12.13 & 16.03 & 11.89 & 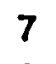 & 9 & 6 & 8 & 8.75 & 9.33 \\
\hline 71 & 71 & I3 & $\mathrm{C} 4$ & a & 5 & 8 & 15.31 & 16.00 & 16.39 & 16.14 & 8 & 8 & 8 & 10 & 9.58 & 4.78 \\
\hline 72 & 72 & I3 & $\mathrm{C4}$ & $\mathbf{a}$ & 5 & 10 & 17.00 & 15.25 & 18.98 & 17.45 & 8 & 9 & 9 & 10 & 9.67 & 5.00 \\
\hline 73 & 73 & I3 & $\mathrm{C} 4$ & $\mathbf{a}$ & 5 & 9 & 19.88 & 15.10 & 16.37 & 12.84 & 6 & 8 & 8 & 9 & 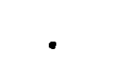 & . \\
\hline 74 & 74 & I3 & C4 & a & 10 & 10 & 16.13 & 14.19 & 19.06 & 15.67 & 5 & 10 & 10 & 10 & 9.50 & 9.50 \\
\hline 75 & 75 & I3 & $\mathrm{C} 4$ & a & 5 & 7 & 17.63 & 16.72 & 18.90 & 15.53 & 6 & 7 & 5 & 7 & 9.33 & 8.75 \\
\hline
\end{tabular}




\begin{tabular}{|c|c|c|c|c|c|c|c|c|c|c|c|c|c|c|c|c|}
\hline BS & CHIL & IN & CLASS & TRT & SPAL 1 & SPAL2 & ST1 & ST2 & CT1 & ст2 & SP1 & PP2 & CP1 & $\mathrm{CP} 2$ & OFF1 C & OFF2 \\
\hline 76 & 76 & I3 & C4 & $a$ & 3 & 4 & 17.59 & 13.78 & 19.17 & 18.17 & 2 & 4 & 4 & 6 & 9.67 & 7.17 \\
\hline 7 & 77 & I4 & C1 & d & 8 & 9 & 16.65 & 16.10 & 19.49 & 11.71 & 7 & 9 & 6 & 8 & 10.00 & 10.00 \\
\hline 8 & 78 & I4 & c1 & d & 5 & 8 & 19.85 & 12.66 & 15.66 & 13.25 & 10 & 10 & 9 & 10 & 10.00 & 9.83 \\
\hline 9 & 79 & I4 & C1 & $d$ & 8 & 9 & 18.66 & 17.95 & 17.92 & 15.12 & 5 & 7 & 5 & 7 & 9.67 & 9.50 \\
\hline 30 & 80 & I4 & C1 & d & 7 & 9 & 19.54 & 14.53 & 16.27 & 15.16 & 6 & 10 & 0 & 9 & 10.00 & 10.00 \\
\hline 31 & 81 & I4 & $\mathrm{Cl}$ & d & 7 & 9 & 22.93 & 18.00 & 24.52 & 15.59 & 6 & 7 & 7 & 8 & 9.83 & 10.00 \\
\hline 32 & 82 & I4 & C1 & d & 7 & 10 & 12.90 & 11.10 & 14.18 & 10.18 & 6 & 10 & 8 & 9 & 10.00 & 10.00 \\
\hline 33 & 83 & I4 & C2 & a & 6 & 6 & 17.53 & 15.22 & 13.60 & 16.81 & 6 & 9 & - & 6 & 8.82 & 6.90 \\
\hline 34 & 84 & I4 & C2 & a & 10 & 10 & 26.16 & 22.28 & 19.30 & 14.84 & 10 & 5 & -7 & 10 & 9.50 & 4.38 \\
\hline 35 & 85 & I4 & C2 & a & 10 & 10 & 18.95 & 15.03 & 14.39 & 10.75 & 8 & 10 & 9 & 10 & 9.67 & 5.83 \\
\hline 86 & 86 & I4 & C2 & a & 0 & 9 & 27.28 & 21.03 & 19.40 & 18.66 & 5 & 9 & 9 & 10 & 9.50 & 6.58 \\
\hline 87 & 87 & I4 & C2 & a & $=$ & 6 & 21.69 & 17 & 19 & 17 & 8 & 10 & 4 & 8 & 9.83 & 6.18 \\
\hline 88 & 88 & I4 & C3 & c & 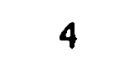 & 8 & 18 & 10 & 14.34 & & 6 & 8 & 7 & 8 & 9.83 & 9.67 \\
\hline 89 & 89 & I4 & C3 & $c$ & 7 & 8 & 15.65 & 11.96 & 13.90 & 11.87 & 6 & 8 & & 8 & 9.83 & 9.67 \\
\hline 90 & 90 & 14 & C3 & c & 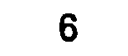 & 7 & 13.00 & 9.53 & 11.90 & 7.59 & 9 & 10 & 8 & 8 & 10.00 & 9.50 \\
\hline 91 & 91 & 14 & C3 & c & 4 & 8 & 15.59 & 12.97 & 14.30 & 10.47 & 4 & 9 & 5 & 8 & 10.00 & 10.00 \\
\hline 92 & 92 & 14 & C3 & c & 6 & 6 & 17.20 & 16.41 & 21.54 & 17.60 & 6 & 8 & & 6 & 9.58 & 9.75 \\
\hline 93 & 93 & I4 & C3 & c & 7 & 8 & 11.28 & 13.27 & 15.70 & 9.89 & 7 & 9 & & 8 & • & \\
\hline 94 & 94 & 14 & C3 & $c$ & 10 & 9 & 18.13 & 11.22 & 19.92 & 12.75 & 8 & 10 & & 9 & 10.00 & 10.00 \\
\hline 95 & 95 & 14 & C3 & c & 5 & 9 & 14.40 & 9.59 & 12.30 & 8.38 & 7 & 9 & 8 & 9 & 9.58 & 310.00 \\
\hline 96 & 96 & I4 & C4 & b & 7 & 8 & 15.00 & 16.68 & 16.15 & 12.16 & 7 & 8 & 8 & 7 & $\cdot$ & . \\
\hline 97 & 97 & 14 & C4 & b & 7 & 8 & 17.53 & 12.70 & 16.00 & 12.10 & 7 & 9 & 8 & 8 & • & • \\
\hline 98 & 98 & I4 & C4 & b & 6 & 6 & 20.03 & 14.50 & 18.53 & 18.00 & 6 & 10 & 6 & 9 & 8.50 & 8.05 \\
\hline 99 & 99 & 14 & C4 & b & 4 & 8 & 16.46 & 14.09 & 18.00 & 16.84 & 4 & 8 & 6 & 9 & 8.50 & 8.25 \\
\hline 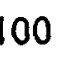 & 100 & I4 & $\mathrm{C}_{4}$ & b & 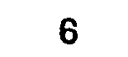 & 7 & 18.07 & 13.29 & 17.20 & 12.75 & 8 & 9 & 7 & . & & \\
\hline
\end{tabular}




$$
\begin{aligned}
& \text { 岕 } \\
& \text { 岌 } \stackrel{0}{0} \text {. } \\
& \text { 品 } \infty \omega \infty \\
& \text { 品 } \infty \text { n } \\
& \text { 整 } \infty \infty \\
& \text { क } 0 \text { un } \\
& \text { 논 } \\
& \text { ₹ } \\
& \text { N } \forall 0 \\
& \text { क } \\
& \text { E } \quad \begin{array}{l}
0 \\
\text { क }
\end{array} \\
& \text { 苋 } \\
& \text { 齐 } 0 \text { क } \\
& \text { م مص م }
\end{aligned}
$$

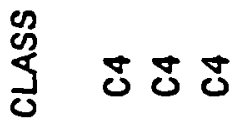

$$
\begin{aligned}
& \Xi \pm \pm \\
& \text { 온 둥ํㅇ응 } \\
& \text { 용 으유융 }
\end{aligned}
$$




\section{VITA}

Karen Anne Buckner, the second of five children, was born to the Reverend Mr. and Mrs. James Clinton Buckner on September 23, 1947, in Longview, Texas. After attending schools in Arkansas and Louisiana, she graduated from Clear Creek High School in League City, Texas, in May of 1965. In May of 1969, she graduated from Southwest Texas State University in San Marcos with a Bachelor of Science in physical education (all-level) and English.

In July of 1969, Karen married Pete Fredenburg. They have three children: Kori Celeste (1/27/74), Denver Wayne (3/26/76), and James Cody (1/28/81).

Karen began her graduate studies at Southwest Texas State University in August of 1969, and completed a Master of Arts in physical education and counseling in August of 1970. She began a coaching and teaching career at Bulverde Elementary and Junior High in the Comal Independent School District. In 1971, she accepted a job at Canyon High School, and in 1974, she transferred to New Braunfels High School.

In the fall of 1976, Karen was named the Women's Athletic Coordinator at Southwest Texas State University. She taught classes and coached the women's volleyball and track teams. In the fall of 1978 , the Fredenburgs moved to Giddings, Texas, where Karen taught elementary physical education. The following year she taught and coached basketball, volleyball and track at Giddings High School.

In the fall of 1980 , the family moved to Waco, Texas, where Karen coached and taught at Midway High School. In 1981, she began a 14 year teaching position at Baylor University.

In 1994, husband, Pete, accepted a football coaching job at Louisiana State University, and Karen began her doctoral program there. She completed the Doctor of Philosophy degree in May, 1997, and began looking for a job. 


\section{DOCTORAL EXAMINATION AND DISSERTATION REPORT}

Candidate: Karen Anne Buckner Fredenburg

Hajor Fleld: Kinesiology

Iitle of Disbertation: The Effects of Augmented Feedback on Students' Perceptions and Performance
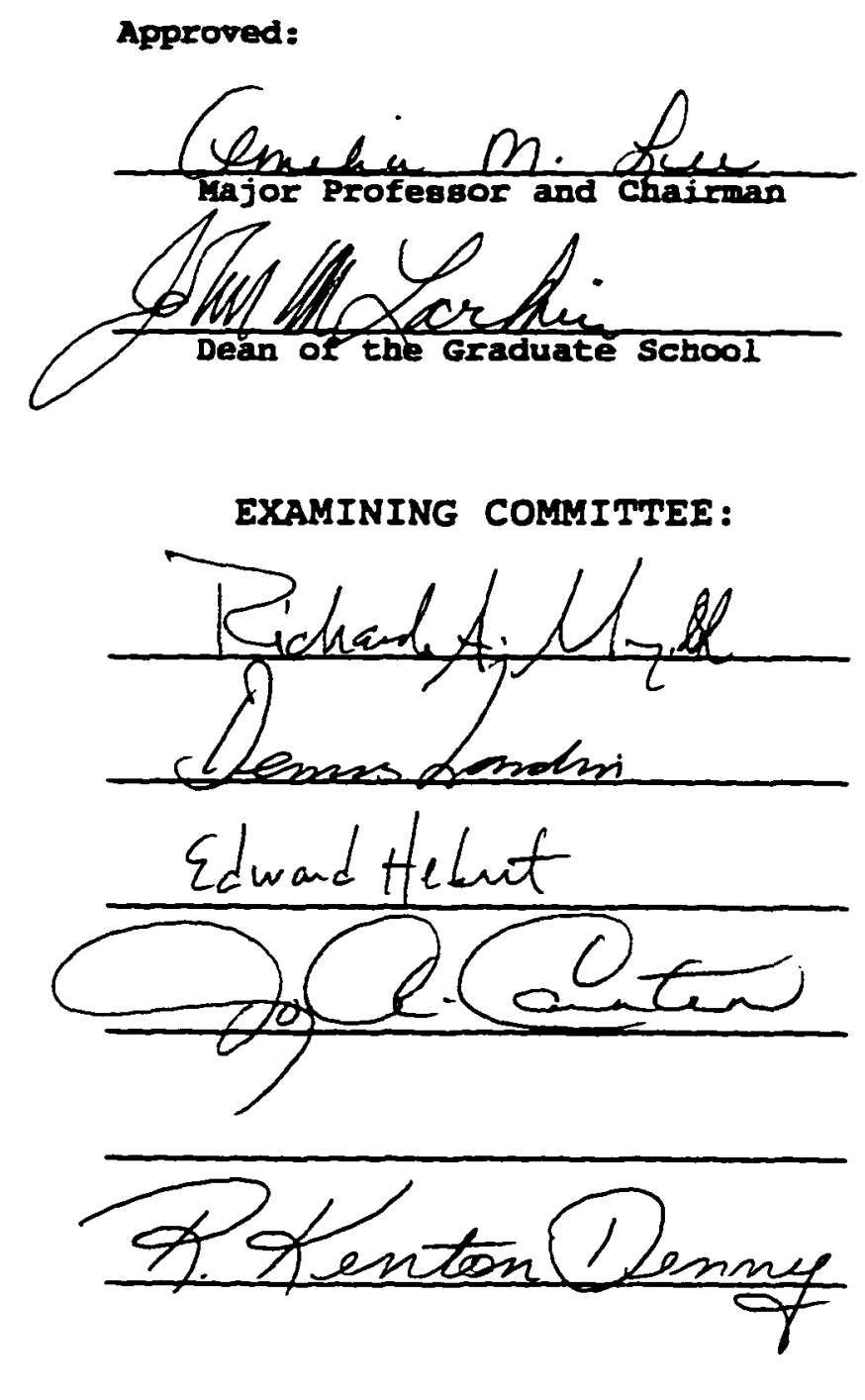

Date of Bxamination:

Apri1 4, 1997 